\title{
Advancing the Spatial Turn in History through Deep Mapping: Ghost Maps, Neogeography, and Frederick Jackson Turner
}

Jessica L. Mathai

West Virginia University, jbrewer1@mix.wvu.edu

Follow this and additional works at: https://researchrepository.wvu.edu/etd

Part of the Geographic Information Sciences Commons, Human Geography Commons, Spatial Science Commons, and the United States History Commons

\section{Recommended Citation}

Mathai, Jessica L., "Advancing the Spatial Turn in History through Deep Mapping: Ghost Maps, Neogeography, and Frederick Jackson Turner" (2021). Graduate Theses, Dissertations, and Problem Reports. 8289.

https://researchrepository.wvu.edu/etd/8289

This Dissertation is protected by copyright and/or related rights. It has been brought to you by the The Research Repository @ WVU with permission from the rights-holder(s). You are free to use this Dissertation in any way that is permitted by the copyright and related rights legislation that applies to your use. For other uses you must obtain permission from the rights-holder(s) directly, unless additional rights are indicated by a Creative Commons license in the record and/ or on the work itself. This Dissertation has been accepted for inclusion in WVU Graduate Theses, Dissertations, and Problem Reports collection by an authorized administrator of The Research Repository @ WVU.

For more information, please contact researchrepository@mail.wvu.edu. 


\title{
Advancing the Spatial Turn in History through Deep Mapping: Ghost maps, Neogeography, and Frederick Jackson Turner
}

\author{
Jessica L. Mathai \\ Dissertation submitted to the \\ Eberly College of Arts and Sciences \\ at West Virginia University \\ in partial fulfillment of the requirements \\ for the degree of \\ Doctor of Philosophy \\ in \\ Geography \\ Trevor M. Harris, PhD., Co-Chair \\ Melissa R. Bingmann, PhD, Co-Chair \\ Gregory A. Elmes, PhD \\ Kenneth A. Fones-Wolf, $\mathrm{PhD}$ \\ Kenneth C. Martis, PhD \\ Timothy A. Warner, PhD \\ Department of Geography and Geology \\ West Virginia University 2021
}

Keywords:

GIS - Historical GIS - Neogeography_-Historical Geography_-Deep Map — Ghost Map — Frontier-Frederick Jackson Turner-Spatial Story - Spatial Humanities-Digital History

Copyright 2021 (Jessica L. Mathai) 


\begin{abstract}
Advancing the Spatial Turn in History through Deep Mapping: Ghost maps, Neogeography, and Frederick Jackson Turner
\end{abstract}

\author{
Jessica L. Mathai
}

The permeation of the spatial turn into the humanities, and in particular history, has both imbued scholarship and opened up new areas for research. This dissertation examines the conceptual and theoretical implications of advancing the spatial turn in history and evaluating existing approaches such as Historical GIS and ghost mapping as a foundation for deep mapping. The resulting deep map developed in this study utilizes Neogeography and web technology in the form of JavaScript Application Programming Interfaces (APIs) to develop a prototype that overcomes many of the limitations that occur when simultaneously integrating multiple sources of data and software functionality, as well as qualitative and quantitative data. These are issues central to humanities scholars as they navigate multi-disciplinary narratological research. The deep map platform is a web application designed to enable a user to explore both spatial and temporal data through function calls made to multiple APIs. The result of these function calls are displayed in the web application dashboard as maps, text, images, photographs and documents. By selecting an event or time frame portrayed on a series of timeline bars, the user initiates the multiple API calls and is enabled to develop a series of spatial stories.

The application is tested using a case study based on American western historiography and the work of Frederick Jackson Turner and the New Western history. In particular, the deep map centers on the westward frontier movement in early western Pennsylvania and (then) north western Virginia and discerns a north to south frontier movement that augmented the more commonly accepted meta narrative of an east to west settlement movement. Furthermore, the deep map examines the Martin family who were early settlers in Morgantown, (then Virginia). Through the deep map an examination is made of the Martin family and their slave Littleton who was granted his freedom in approximately 1812. Notably for the times, Littleton's residency in Monongalia County was the subject of a series of petitions by both Littleton and prominent citizens of Morgantown for him to remain in the county and this at a time in American history when slavery divided the nation. The deep map advances the spatial turn in history by enabling historical events to be explored in the context of their spatial relationships using a methodology situated in applying APIs to the emerging field of deep mapping. 


\section{DEDICATION}

This dissertation is dedicated to the two people that listened to me talk about Deep Maps for a decade, that were shoulders to cry many tears on, but were more than anything my rocks, what kept me going when I thought this would never end. They never doubted me and at the end of the day, told me to just keep flipping going and do it. George, the love of my life, my confidant, my best friend, my life partner, you will finally know what it is like to have a wife without a $\mathrm{PhD}$ to finish and Kennedy, your momma finally did it.

In addition, this dissertation is dedicated to all those out there who persevere and live everyday with anxiety, depression and bipolar disorder. It is possible to make your way out of the fog no matter how long it takes. Just keep going.

Nevertheless, She Persisted 


\section{ACKNOWLEDGMENTS}

\section{Trevor Harris}

Trevor has not only been my "advisor" for more years than he ever thought he would be, but he has become my mentor and a friend. There were many times I know he thought I gave up, but he was one of the reasons I kept going. I could not have done this without his wisdom, guidance and unwavering support, even into retirement. I appreciate him more than he will ever know.

\section{My Dissertation Committee}

First, thank you Melissa for stepping in and making this possible. Had I met you earlier in the process, you would have been a part of it from the beginning. Ken Fones-Wolf, you have mentored me longer than anyone. Your support and guidance throughout my MA and PhD have shaped who I am as a writer (no passive voice!) and as a scholar. Greg, you may have taught me the fundamentals of GIS, but more importantly, you enabled me to critically think about GIS and without that, this dissertation would not have been possible. Ken Martis, you didn't have to take

this seemingly never-ending project on to begin with. You were retired when I started, but I remain truly grateful for your expertise and that you saw enough in me to join my journey. Tim, I don't think you realized what you were getting into when you signed on 10 long years ago, but I am so glad that you did. Your support has been invaluable.

Barb, my cohort, my friend, the Thelma to my Louise: We did this together, we trudged through the trenches, sometimes you carried me, sometimes I carried you, but we did it. We kept going, even when there seemed to be no light at the end of the tunnel, we kept going, kept swimming...I owe you so much. Your blood, sweat and tears are a part of this too.

Frank, your encouragement and support did not go unnoticed. You were always there with answers to my questions and to remind me that I could do it. Thank you.

To Pragya, who spent time in the trenches with me too and helped me to laugh when I wanted to cry and remember there was an end, thank you for everything.

To Steph and Tom, who were babysitters, cheerleaders and sources of never-ending support. To my Lily, who probably withstood most of my emotional breakdowns and was always there to hug... and has a tail wag and floppy-eared look that could bring immense joy to anyone.

To Chrissy, who gave me the ability to believe in myself by being one of my biggest cheerleaders. Our sessions have transformed how I engage with the world. You reminded me when I needed it most that I could do it. And I will always remember the importance of separating the red socks.

To my new friend Zoa who was always there with cheerful encouragement and an intoxicating laugh, I will forever cherish our Friday morning meetings.

And to my Mom and Dad: I finally did it, I finally finished my "paper". I am so blessed that through this process you have endured five cancers and a Parkinson's diagnosis, yet are here to see me do it. Your constant love and support have carried my through. I don't know what I would do without you. I can finally say I am done.

I am incredibly grateful for my time within the WVU Department of Geography and Geology, where I have had some of the most amazing professors and have learned to see the world from a new perspective.

Finally, I owe many thanks to the WV GIS Technical Center. You provided me with knowledge, resources and most of all, an incredible group of colleagues who created one of the best work environments I have ever experienced. 


\section{Table of Contents}

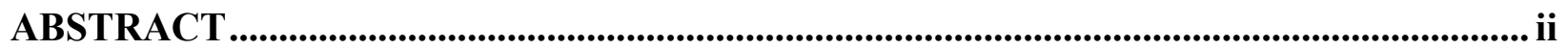

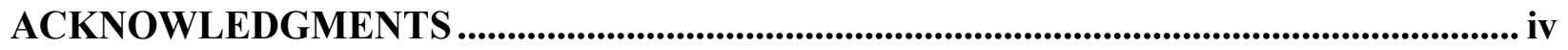

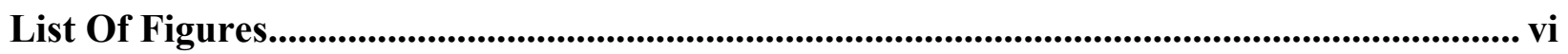

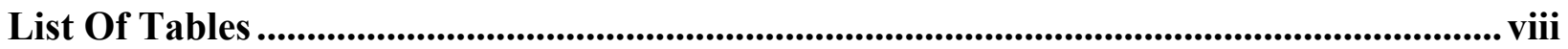

Chapter 1 | Advancing The Spatial Turn In History: An Overview ..................................... 1

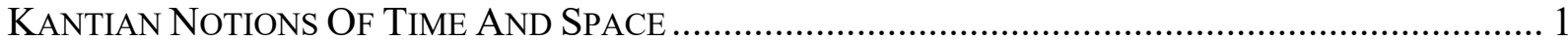

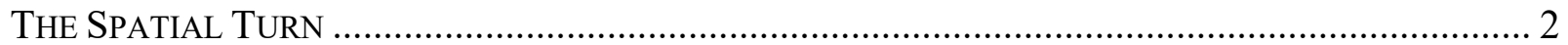

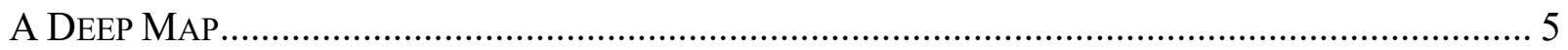

RESEARCH GOAL AND RESEARCH QUESTIONS............................................................... 9

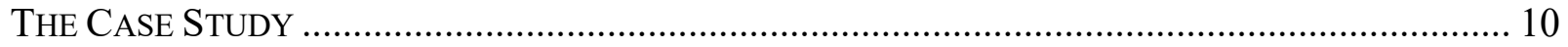

Chapter 2 | Bridging The Geography And History Divide ................................................... 14

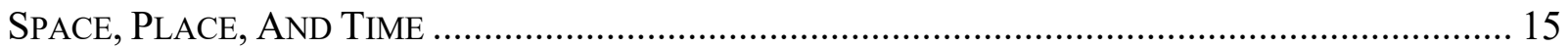

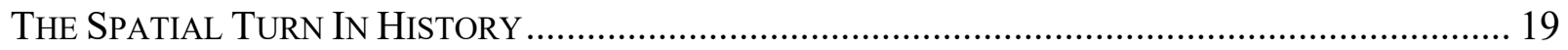

Advancing The Spatial TuRn: CRITICAL GIS ............................................................ 20

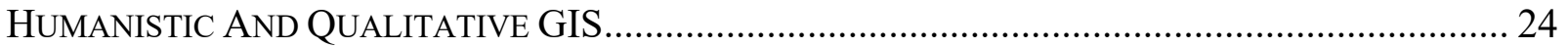

Chapter 3 | The Spatial Humanities And Deep Mapping ..................................................... 28

SPATIAl History, HistoricAl GIS, AND THE SPATIAL HUMANiTIES .................................... 29

The Spatial Humanities, Spatial Storytelling And DeEP Mapping.............................. 32

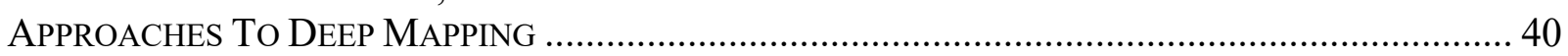

Chapter 4 | Frederick Jackson Turner's Frontier Thesis, Its Historiography And Defining

The Case Study Area ..................................................................................................................... 44

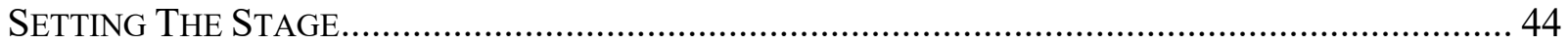

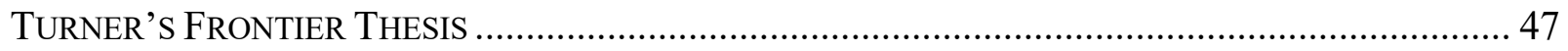

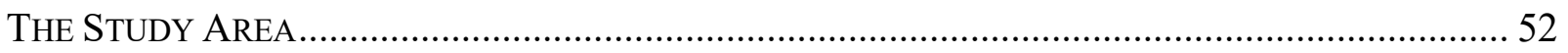

Chapter 5 | Prelude To Deep Mapping ...................................................................................... 59

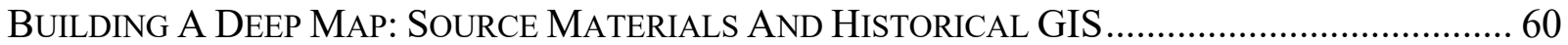

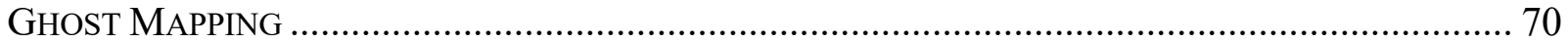

Chapter 6 | A Deep Map Prototype Of Turner's Frontier Thesis ........................................ 73

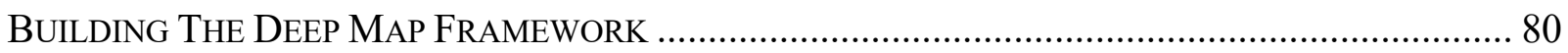

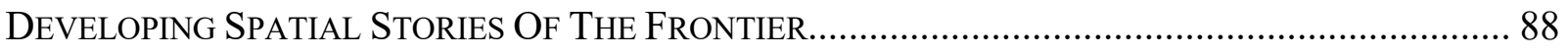

Chapter | 7 Conclusion ............................................................................................................... 92 


\title{
List of Figures
}

\author{
Figure 3.1: Ghost Metropolis by Ethington (2014). \\ Figure 3.2: Clifford McLucas’ Map on a Wall, 1994 \\ Figure 3.3: Deep map framework by Trevor Harris \\ Figure 4.1: Map of the British and French Settlements of North America (1755) (Lodge) from \\ the Library of Congress Map Collection (https://www.loc.gov/item/74693889/). A red overlay \\ has been added to identify French territory which is generally bounded by the Appalachian \\ Mountains. \\ Figure 4.2: Map from the Statistical Atlas of the United States based on the Results of the \\ Eleventh Census (1898) that illustrates the "center of population" at each decade. Note that \\ Monongalia County is located in same area as the 1840 center of population \\ designation. This map echoes the sentiment of the greater narrative that states that there was a \\ westward movement rather than uneven or north to south \\ development. https://lccn.loc.gov/07019233) \\ Figure 4.3: Maps from the Statistical Atlas of the United States based on the Results of the \\ Eleventh Census (1898) that illustrates population densities in 1790 and 1800 \\ (https://lccn.loc.gov/07019233). \\ Figure 4.4: Cantonment of His Majesty's forces in N. America according to the disposition \\ now made $\&$ to be compleated as soon as practicable taken from the general distribution dated \\ at New York 29th. March 1766. (Paterson, 1767). Accessed from Library of Congress Map \\ Collection (https://lccn.loc.gov/gm72002042)
}

Figure 4.5: Map of the Proclamation line in 1763 (pink) and the boundary line created by the Treaty of Fort Stanwix in 1768 (red).

Figure 4.6: The study area for the Deep Map study

Figure 4.7: Map of Monongalia County in 1776

Figure 4.8: Map of main openings to the interior and Monongalia County. Forbes path is in yellow, purple is a water access path from Lake Erie down to the Ohio River and then to the Monongahela, green is Nemocolins Path, orange is the Ohio River and red is a section of the Catawba Path that went north to south though Pennsylvania, Virginia, Tennessee, North Carolina and South Carolina

Figure 4.9: [Braddock's route, 1755, Fort Cumberland to Fort Pitt. (1760). Sketch from the Library of Congress map collection showing major land formations along Braddock's Road. (https://lccn.loc.gov/gm71002325) 
Figure 4.10: Legislative Petitions of the General Assembly, 1776-1865, Accession Number 36121, Box 335, Folder 19 (1825). Map from a petition to build a road to Smithfield, PA which was proposed to provide access to the National Road.

(http://digitool1.lva.lib.va.us:1801/view/action/singleViewer.do?dvs=1626649190757 890\&lo cale $=$ en_US\&show_metadata $=$ true\&VIEWER_URL=/view/action/singleViewer.do?\&DELIV 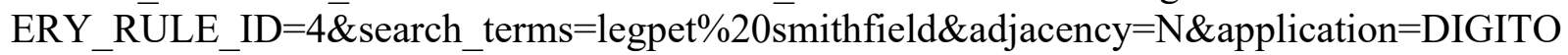 OL-3\&frameId $=1 \&$ usePid1 $=$ true \&usePid2=true)

Figure 5.1: Forts constructed within the study area. The earliest local fort was Fort Pierpont in 1769. Source: Core (1974)

Figure 5.2: Settlements in the study area

Figure 5.3: Example of Mind Map (Brandner, 2015).

(https://www.mindmeister.com/blog/why-mind-mapping/)

Figure 5.4: Mind Map sketch of the slave Littleton

Figure 5.5: Mind Map sketch of the major openings to the interior of North America.

Figure 5.6: The first step in creating a ghost map was to access and review the materials through layering.

Figure 5.7: Ghost map design developed through arranging transparent images on workspace

Figure 6.1: APIs utilized in deep map web application

Figure 6.2: Chart of potential APIs to be utilized in deep map web application

Figure 6.3: An early iteration of the deep map concept where the user and a GUI is at the center of the deep map.

Figure 6.4: Code snippet of selectHandler function

Figure 6.5: The user selects a timeframe on the timeline to populate a spatial story

Figure 6.6: Code snippet of the switch statement used to call different APIs

Figure 6.7: Ghost Map created from archival materials, maps and images

Figure 6.8: Deep Map web application dashboard before it is populated with the API responses

Figure 6.9: Chart illustrating the framework in which the code was structured 
Figure 6.10: Timeline where five themes function as timelines, decreasing in scale from top to bottom. Each bar can be selected which then calls APIs respective to that time period and event.

Figure 6.11: This example shows dynamic "spatial story" text at the top of the results that supports the images populated from the API call.

Figure 6.12: Spatial Story that results from selecting an event from the timeline related to westward development

\section{List of Tables}

Table 5.1: Boundary files created for the Historical GIS

Table 6.1: APIs utilized in deep map web application

Table 6.2: Details of APIs used for the deep map web application 


\section{Chapter 1 | Advancing the spatial turn in History: An Overview}

It would be difficult to find a modern humanities scholar who would argue that space, place and time are not intrinsically linked. However, there has been a push recently to delve deeper into these conceptual and methodological relationships and particularly so in history. This paradigm shift is often referred to as the spatial turn and emphasizes the importance of geographical social theory, space, and place in humanities scholarship.

Even though the spatial turn in history is considered a recent development, the incorporation of geography, albeit peripherally, in historical studies has a longer antecedence. Historians such as Frederick Jackson Turner and his Frontier Thesis (1893) examined the connection between historical events and geography in the US population westward movement and the "conquering" of space. While arguments have arisen surrounding his theories of the "frontier" and the “democratic process", Turner's connections between population movement in the US and historical time has been significant and highly influential to historians over the ensuing century and more.

\section{Kantian notions of Time and Space}

Despite scholars acknowledging the importance of space and time it can be argued that the spatial and temporal are largely detached concepts. Historical geographers and historians, for example, while examining the conjunction of space and time nonetheless use methods that often emphasize one over the other (see Domosh et. al., 2020; Baker, 2003; Bodenhamer et. al. 2010; Warf and Arias, 2009; Soja, 2011). Historians have been accused of overshadowing if not precluding the role of space in favor of a dominant chronology, in which historical events occur in a spatial vacuum. However, making the connection between the temporal and spatial is key to understanding the complex fabric of history. The relationship and intrinsic link between space 
and time is the foundation for this dissertation and while generations of historians, geographers and philosophers have debated the conceptualization of space and time (see Locke, 1689; Newton, 1687, 1713; Leibnez, 1646-1716; DesCartes, 1644; Hume, 1888), Kant's philosophy of Transcendental Idealism in which he insists that we experience space and time with 'intuition' has been particularly inciteful in writing this dissertation. Kant (1781) in his rejection of absolutism and empirically conceptualized space as well as relativism, where space exists within the relationship between things, insisted that we intuitively encounter space and time. Thus, if space and time are experienced as an intrinsic part of our being, then it could be argued that the relationship between the two is inherent and therefore should be treated equally. This dissertation stresses that time and space are indeed symbiotic partners and advancing the spatial turn in history further bridges the divide.

\section{The spatial turn}

Soja (2009) suggests that the spatial turn "has the potential to be one of the most significant intellectual and political developments of the twenty-first century." The spatial turn has a threepronged foundation: space, time, and social theory. The injection of critical social theory seeks to reveal the underlying systems that drive the manner in which humans react to, and behave within, their environment. As the spatial turn becomes more prominent in scholarship, it has the potential to deeply impact the humanities including sociology, law, economics, and in particular, history (Warf and Arias 2009). The concept of the spatial turn emerged with the writings of Michel Foucault (1972) and Henri Lefebvre (1974) in the 1960's and 70's, who introduced the ideas of socially constructed spaces and social theory as fundamental components of in everyday life. Spatiality was thus reevaluated, and the injection of social theory has become increasingly critical to many areas of geographical research. 
The influence of Foucault and Lefebvre has been vital to developing a foundation for the spatial turn yet an epistemological shift in the humanities has been slow to develop not least because of other epistemological changes such as GIS in geography. In geography, historical geographers and landscape historians such as Cosgrove (1992), Mitchell (2002), Conzen (2010) and Massey (2005) furthered the research into underlying social structures. Historians were likewise being challenged to look beyond upper class and Euro-centric history to examine the social aspects of all classes, races, and cultures.

The work of early historical geographers was primarily empirical. A paradigm shift occurred in the 1980's, well after the initial scholarship of Foucault and Lefebvre, where scholars began integrating social theory into their work. Historical Geography played an important role in developing a platform for integrating space and time. Edward Soja, writing on the emergence of the spatial turn, insists that the work of Lefebvre and Foucault built upon "existing spatial modes of thought" (Soja 2009: 19). Foucault and Lefebvre furthered early concepts of space, place, and time in Historical Geography and developed a foundation on which the spatial turn emerged. The shift that occurred in Historical Geography ran parallel to another transition in geography where criticisms were levelled surrounding Geographic Information Systems (GIS) for its positivist undertones and lack of potential for qualitative studies (See Pickles 1995, Openshaw 1991, Sheppard 1993, Taylor \& Overton, 1991). As the spatial turn emerged by the mid-1990s, Critical GIS and GIS and Society debates, having among its arguments whether GIS is a "tool" or "science" (Pickles, 1997), were developing the foundation for the field of GIScience. In the years since, GIS has progressively become a part of dialogue both within and outside of Geography, including the history where spatial concepts have been incorporated into scholarship, 
further supporting the notion that the humanities have been experiencing the surfacing of the spatial turn.

During the latter part of the $20^{\text {th }}$ century, as Historical Geography and GIS in Geography evolved, setting the stage for the emergence of the spatial turn in the humanities, History too experienced epistemological change as historians began to acknowledge the social structures that underpinned events. Scholarship began to increasingly acknowledge influences like class, gender, and ethnicity. Many of these social historians, and in particular Western Historians (See Montoya, 2012; Limerick, et. al. 1991; White, et. al. 1994;) rebuked earlier scholarship for being racist and neglecting to include all of society. However, as this more "inclusive history" evolved, it was attacked for going too far, throwing the baby out with the bathwater, so to speak (See Allen 1994). As a response, historians have recently strived to balance the paradigm shift to "social history" with the scholarship of early- $20^{\text {th }}$ century historians, asserting that both have their merits, and a more balanced assessment is necessary. In this pursuit of a more balanced history, a faction of modern scholars are also trying to overcome the accusation that space is often an afterthought, peripheralized, as Edward Soja (1993: 140) put it. Ultimately the paradigm shift experienced in History has allowed the discipline to acknowledge the concept of the spatial turn, readying itself for scholarship that emphasizes achieving a distinctive balance between time, space and social theory. Historical research that acknowledges the spatial turn rests on the foundational work of both geographers and historians. The work of H.C. Darby, W. G. Hoskins, Paul Vidal La Blache, Carl Sauer and J. B. Jackson, and others, emphasized time and space, and in particular transformed the way historic scholarship treated space. Emphasizing space and place as integral parts of how humans perceive, participate in, and react to events, an increasing number of historians have evolved the manner in which they approach research (see 
Ethington, 2007). As a result, not only has space become an important consideration in scholarship, but idea of place and its implications on human behavior over time has become equally as important. Historian Philip Ethington (2007), for example, who insists that all human action takes and makes place, states that the past is the set of places made by human action and that history is a map of those places. Rather than time being the ultimate gauge of history, as is traditionally thought, Ethington proposes that history takes place and therefore place is critical to historical scholarship. Ethington is suggesting that chronology alone, or as the primary analytical component, cannot entirely get to the essence of history. Considering space and place as mutual counterparts to time forces scholars to reevaluate the manner in which they research and write about historical events.

Phillip Ethington is heavily influenced by geographer Yi-Fu Tuan $(1977$; 198), whose writings have revolutionized the way that geographers think about place. Tuan suggests that place is a pause in the movement of time. Therefore, if history takes place, which is a pause in the movement of time, then place is intrinsic to the complex movement of time and should not be overlooked. Tuan states that as humans move through space, characteristic sets of pauses or places are developed. Inevitably, as humans move through space, time transpires, history is made. Quite simply, one cannot exist nor outweigh the other.

\section{A Deep Map}

A deep map, according to Harris (2014: 188) is “...heavily narrative-based and interlaced autobiography, art, folklore, stories, and memory with the physical form of a place to 'record and represent the grain and patina of place through juxtapositions and interpenetrations of the historical and the contemporary, the political and the poetic, the discursive and the sensual..." A deep map attempts to get to the core of a place, seeking to convey its essence, to investigate a 
particular place at a micro-level, and to recursively drill down into its history and uncover the unseen subtleties that broader analysis often overlooks. Ultimately, a deep map expresses the details at a micro-level, but then also within context of a macro-level. The goal of a deep map within this dissertation is to make the connection between the minute and the large, innately tying together seemingly disparate levels of society that include culture, class, gender, and race with broader historical events.

The earliest form of a deep map is a book by William Least Heat-Moon entitled PrairyErth (1991). PrairyErth is a dense text that delves into the minute details of life in a small county in Kansas. Using PrairyErth as a foundation, Michael Shanks and Mike Pearson (1994) developed a concept that they referred to as "Deep Maps.” Then, based on Shanks and Pearson's concept, artist Clifford McLucas developed his idea of a deep map. McLucas' Map on a Wall is a largescale artistic work, 8 feet high by 42 feet long, which combines photographs, surveys, maps and text to represent the San Andreas Fault in California.

A deep map is complex, developed beyond Euclidean space, and contains many layers. The deep map laid out in this dissertation will use a thin map as part of its foundation. A thin map works to define the spatial limitations within the deep map. However, a deep map goes beyond Euclidean space, which requires additional layers and analysis. A thin map will be developed in a GIS system and will contain many layers to convey events of the case study. My research pursues a conceptual approach to deep mapping in three phases. The first phase is the creation of a Thin Map through Historical GIS, which will serve as a foundation for an experiment in deep mapping. Given that GIS is limited by the types of data that can be included, a second phase is necessary to convey the details required when creating a Deep Map. The Historical GIS serves as the foundation for a ghost map. A ghost map will add details and 
nuances that cannot be expressed in a Historical GIS. The goal of a ghost map is to tie together the details with the broader history.

A ghost map is based on the Philip Ethington's Ethingtographies that use image, map, and text layers of varying transparency to illustrate the history of particular place. Ethington's Ghost Metropolis, Los Angeles utilizes juxtaposed layers to convey history that emphasizes space and place. Ghost Maps are graphic works. One of the key components of Ethington's work is its ability to be examined both broadly and in detail, making connections with each other to reveal a larger story.

In addition, it is the position of this dissertation that to be a deep map, to get to the essence of a place and analyze interaction between the micro and macro as history unfolds, both Historical GIS and Ghost Maps must provide the foundation for the last phase. Additionally, in a deep map the dissertation will utilize the concept of deep contingency to investigate reciprocal associations that are revealed as the effects of everyday life occurrences reverberate outward within the context of national historical events. Deep contingency explores the idea that all events, large and small, are contingent on each other and that there is an interconnectedness that is inherently present because all facets of life interact with each other.

Ed Ayers, historian and noted for his use of deep contingency, has created an online application called The Valley of the Shadow in which he examines two counties, one in the North and one in the South, just before and during the Civil War. Ayers' purpose is to analyze the broader events of the Civil War during this time, but through the eyes of the individual by examining details from personal letters, diaries, local newspapers and other imagery. Ayers can then provide a unique view of how the effects of a macro-scale event like the Civil War penetrated the everyday 
lives of those who lived through it and how their decisions and actions permeated outward becoming a part of greater American history.

Even though the phases and components for a deep map have been utilized separately by scholars, it still remains that they have little collaborative precedent. Creating a conceptual approach is challenging and experimental. In order to develop a deep map that utilizes the aforementioned phases and pushes the boundaries of geohistorical research, the GeoSpatial Semantic Web will be utilized as a platform. The Semantic Web and NeoGeographic techniques will be utilized to address some of the limitations of Historical GIS and ghost maps. The use of Neogeography will afford the flexibility to include an array of materials comprised of videos, imagery, text, audio recordings, and newspaper clippings, among other sources. Neogeography has the ability to create a deep map that is open, that can be added to and changed. The storyboard, or the main venue for allowing the user to view the data is a web page. Within that web page, the deep map platform will integrate various Application Programming Interfaces (APIs) using JavaScript programming language. Each application will become a part of the deep map. For example, each application may be text, photos from Flickr, or a cartographic component from ArcGIS Online. Each application is "called" as the viewer wants to access it. In order to build layers within a deep map, access to what are often disparate and diverse sources of data is required. These complex reservoirs of data, while having an inherent connection within a deep map in terms of media types and content, also require a certain organizational schema that links each fragment of information to one another and to the underlying conceptual theme. Without an organizational structure to house the data, the methodology established for developing a deep map becomes obfuscated, impeding the user as they strive to comprehend and reveal an experienced sense of place. 
In addition, given that the concept of a deep map incorporates sources of information in such a way that they work together to go beyond what can be conveyed through a thin map, data cannot be simply alphabetized, themed or characterized into one-dimensional categories. Rather, data might be better organized within a structure that mimics the complex processing undertaken as the human mind comprehends information. This type of "organizational learning”, also known as "mind-mapping", is not necessarily a new concept, but has yet to be explored within the realm of spatiality and geo-historiographical thought. Traditional mind mapping refers to a technique that designers and engineers use to express and generate ideas. A mind map visually organizes information. Commercial software is marketed to guide users through the mind mapping process, but at its core mind mapping is a way to get the ideas in your head down onto paper or in this case from digital stores to a meaningful and organized display of that data. In pursuit of an approach to deep mapping, a case study based on Fredrick Jackson Turner's "Frontier Thesis" and Geographic Sectionalism will specifically detail the facets of north central West Virginia frontier history, demonstrating how deep mapping can contribute to and overcome some of the shortfalls of conventional or thin mapping.

\section{Research goal and research questions}

The goal of this research is to examine the emergence and importance of the spatial turn in the humanities and to advance these concepts through experimentation in deep mapping Turner's American western frontier to reveal the contingent ties between historical events and the historical narratives of space and place.

- What are the concepts and themes that underpin the spatial turn in historical scholarship? 
- What methodological approaches have been pursued to advance the spatial perspective in history?

- What is deep mapping and in what ways have Deep Maps been conceived?

- How might Historical GIS provide a methodological base for deep mapping and Ghost Mapping? What are the constraints associated with using Historical GIS as a base for deep mapping?

- How might Ghost Maps provide a methodological base for deep mapping? What are the constraints associated with using ghost mapping as a base for deep mapping?

- In what ways might NeoGeographical technologies be used to overcome limitations in Historical GIS, Ghost Maps and advance deep mapping concepts?

- Using the critique of Turner's frontier thesis and Geographic Sectionalism, and based on a case study of north-central West Virginia, in the area that is Monongalia County and surrounding areas, to what extent does deep mapping shed light on the subtleties of historical space, place, and process in US westward frontier expansion?

- Does the development of an approach to deep mapping advance the spatial turn in historical scholarship? If so, to what extent does deep mapping advance historical scholarship in the light of the spatial turn?

- To what extent can the development of an approach to deep mapping contribute knowledgeable commentary to current historical scholarship?

\section{The Case Study}

In 1893, Frederick Jackson Turner presented his now famous paper 'The Significance of the Frontier in American History' (Turner, 1893). In defining what he considered to be the "frontier," Turner spurred an ongoing debate in U.S. historiography. Western historiography's treatment of the word "frontier" is, to say the least, wide-ranging and reactions to Turner's frontier thesis ranged from accolades to derision. In particular, Turner failed to recognize the significance of gender and race in the frontier movement, and he treated the "conquering" of the 
American west in a very literal sense. According to Turner, prior to European settlement the frontier region was primitive, wild, and untouched and as white European settlers "conquered" this territory, so the frontier line moved west. As such Turner completely ignored the fact that the west already settled by indigenous people, but white European occupation did not occur in such an orderly fashion.

The work of Fredrick Jackson Turner, a historian by trade, was deeply embedded in the frontier as a space in which not only events transpired, but as a place where processes occurred. As a result, Turner claimed the conquering of space transformed the ways in which Americans conceived their identity. Turner's 'The Significance of the Frontier in American History' (1893) has been the source of much controversy among historians. Regardless as to which side historians take, Turner's frontier thesis was a critical foundation for western and frontier history. Turner instigated a discourse that continues even today, as modern scholars still debate the merits of his frontier thesis and his contributions to understanding the American past. In the study of Western historiography and Turner's frontier thesis, one issue that emerges is the idea of the "frontier." The word "frontier" and its association with westward movement in western history have been called into question by a number of historians (see Juricek, 1966; Billington, 1984; Slotkin, 2000). The historian, Tiya Miles, suggests drawing a dotted, flexible line around the South and the West. In doing so, the regional borders can be manipulated as historical accounts unfold. Avoiding nonmalleable boundaries where different cultural groups, social networks, and economic systems, for example, intersect and overlap enables the researcher to pursue a richer historical understanding (Miles, 2012; 275). Miles' dynamic method to pursuing regional history operates similarly to the deep mapping approach set forth in this dissertation which suggests a platform that is also reflexive and adaptable. 
Turner's thesis led to great debate among historians as to how to accurately convey European contact in the American West and the frontier. Among those who take issue with Turner's work are "New Western Historians." New Western Historians felt that Turner largely ignored race, class, and gender and suggest that rather than being conquered, the American West was transformed. In reaction to the scholarship of New Western Historians, a group of scholars emerged labeled as the "New New Western Historians" or "Next Western Historians". The New New Western Historians claimed that when New Western Historians spurned all things Turner, they went too far. New New Western Historians assert that Turner's ideas do have validity, having had tremendous impact on the way that historians pursue research.

Ultimately, there is still debate within western history as to how to best represent European contact in the American west. Developing a deep mapping approach that utilizes a case study within the context of Turner's frontier thesis and subsequent western historiography has the potential to contribute to ongoing scholarship. In particular, this dissertation research seeks to uncover the economic, cultural, and social connections that developed as the frontier developed and evolved in response to broader American history.

In developing a deep map, a study area has been selected that both represents wider early European settlement in the west and Appalachia and is also distinctive in depicting the unique development and evolution of a particular place. To that end, Monongalia County, West Virginia as it existed in the late $18^{\text {th }}$ and early $19^{\text {th }}$ centuries, centering on present day Morgantown, has been selected as the study area. Utilizing Monongalia County and Morgantown as a case study, with respect to western historiography and frontier theory both uncovers the nuances and distinction of place, as well as ties it to broader America as it underwent monumental change during the pre-industrial revolution period. Many of the earliest 
records for European contact in Monongalia County date to the $18^{\text {th }}$ century. Therefore, the bulk of the deep map will utilize records from the $18^{\text {th }}$ and early $19^{\text {th }}$ century to when Morgantown became a borough (approximately 1838). Where possible, pre-European contact settlements and cultures will be explored, but given a lack of documentation, native historical accounts will be limited. The $18^{\text {th }}$ and early $19^{\text {th }}$ century represent a period of significant growth that provided the foundation for the establishment of major industrial and education facilities, as well as the platform from which social, economic, and cultural change emerged.

Through developing an approach to deep mapping that centers on north-central West Virginia, the objective of this dissertation is to contribute to scholarship that advances the spatial turn in History, as well as add to the greater narrative in early American History. A goal of the deep map is to reveal nuances in the region's history, but more significantly, weave together the temporal and spatial by developing an innovative methodology that furthers research that is founded in space, place, and time. 


\section{Chapter 2 | Bridging the Geography and History divide}

As long ago as 1901, H. B. George in his 'The Relations of Geography and History' emphasized the importance of the dialectical relationship between the disciplines of history and geography, writing that "History is not intelligible without Geography" (George, 1901: 1). Though in general there has been a clear desire to seek a more meaningful integration of space and time, the discourse between, and among, historians and geographers, and especially historical geographers, has not been without contention. While George made his aspirational call over a century ago, some historical geographers still write that a "great divide" continues to exist between the two (Baker, 2003: xi). The linking of space and time has taken many forms since the early historical geography that emphasized cartographic mapping (Domosh, et. al., 2020) and later, Sauer (1925) and the Berkeley School that emphasized the morphology of landscape and the role of human events and place in cultural landscapes. More recently, the humanities, and history in particular, has engaged with the so-called spatial turn with its focus on social theory and concepts of spatiality and place (Foucault, 1972; White, 2010; Warf et al., 2009). Several terms have been used to describe recent aspects of this shift in history toward advancing the spatial turn including spatial history and geohistory (White, 2010). Equally, initiatives in geography have sought to concurrently seek closer links between the humanities and geography and these connections have largely involved GIS and mapping and have been labelled geohumanities and spatial humanities (Dear, 2011; Bodenhamer et al., 2010). Several broad literatures thus guide, inform, and contextualize this dissertation's research focus on deep mapping and the linking of space, place and are discussed in this and the next chapter. These literatures comprise the spatial turn in history, Critical GIS, humanistic and qualitative GIS, the spatial humanities, and deep mapping. 


\section{Space, place, and time}

According to Domosh, et. al. (2020) there are two 'generations' of early practitioners in historical geography, each asking different questions in research and operating at differing ends of the spectrum. Earlier scholars, pre- $20^{\text {th }}$ century, were not trained geographers per se and approached historical geography, if it could be called that at the time, as a political project ad focused on the two aspects of mapping political and administrative boundaries and mapping biblical and classical civilizations. A host of scriptural or biblical guides and study aids emerged during this early phase including Wells (1809) Historical Geography of the New Testament and the three volume Historical Geography of the Old Testament (Wells, 1710; 1711; 1712), and Smith (1894) Historical Geography of the Holy Land. Each study explored the biblical past and although the physical geography of the holy lands was emphasized it was also heavily grounded in theology (Butlin, 1993). The cartographic map reigned supreme whether in mapping wars, political events, the boundaries of nation states, religious and social upheaval, transportation networks, and what became euphemistically known as 'capes and bays geography'. Maps became significant historical records and recorded elements of change over time. Butlin (1993) suggests the transition to a so-called 'modern' Geography was marked by a move away from mapping as the geographers' primary contribution in the examination of change through time and more so to explain how locations changed over time. It was the empirical scholarship of self-declared geographers such as Alexander Humboldt and especially Carl Ritter (See Domosh, et. al., 2020; Humboldt, 1845-1865; Ritter, 1817, 1818, 1822) who espoused the connectedness of nature and human activity within regions and the changing geography of regions through time (Gregory, et. al., 2018; Domosh, et. al., 2020). While Humboldt and Ritter's work teetered on the edge of environmental determinism, they never quite specifically asserted that the 
environment was the determining factor in human behavior (Gregory, et. al., 2018; Domosh, et. al., 2020).

Environmental Determinism, however, did become a common thread in geography and history not least in the work of Frederick Jackson Turner's frontier thesis which is significant for this study. Semple's (1903) American History and its Geographic Conditions and the work of Barrows (1923) were early exponents of environmental determinism, even though these perspectives evolved to include human possibilism in later studies (Butlin, 1993). While many schools of geography embraced environmental determinism, it was De La Blache (1918) and the Annales School who advocated a greater focus on the social, behavioral, material and structural aspects and analysis of history and less an environmentally determined world. As an early important contribution to modern geography, De La Blache emphasized possibilism and the importance of history in the new French geography (Butlin, 1993). It was Darby (1953), the 'father' of modern historical geography, who advanced historical geography to another level in his seminal On the Relations of Geography and History. Darby's work was further reinforced by local landscape historian W.G. Hoskins (1955) in his The Making of the English Landscape as he emphasized the landscape as a record imbued with "a rich body of evidence about the past and a problem to be investigated" according to Baker (2003: 115).

In Germany, observing the landscape or the 'Landschaft' was considered integral to understanding the cultural geographical relationships. Landschaft was influential in the work of Carl Sauer (Baker, 2003; Butlin, 1993; Sauer, 1925) who similarly emphasized the cultural landscape as influenced by human agent. Much of Sauer's work promoted regional geography and chorology along with comparative differentiation (Deneven and Matthewson, 2009). The study of regions was not only integral to modern geography, but to history as well, as around the 
same time, Turner published his The Significance of the Section in American History (1926: 255) based on the "regional settlement of different peoples and types of society on the Atlantic Coast" Methodologically, these empirical, observation-based, historical geographers transformed the discipline, as did a later group of scholars that incorporated ideas of critical social theory into their work. Influenced by Michel Foucault (1972) and Henri Lefebvre (1974) these critical theorists conceptualized space as socially produced subject to transformational critical theories. Foucault and Lefebvre advanced the role of critically informed spaces in geography and history and critical social theory "formed the centerpiece for a critical re-evaluation of space and spatiality in social thought" (Warf and Aria, 2009: 3). Critical social theory recognizes that in addition to physical manifestations, cultural, social, political, economic, religious, and symbolic influences also impact human behavior even though these forces are not necessarily visible. As an iterative inductive approach, critical social theory can be both subjective and situated.

Whereas during the 1950s and 1960s geographical thought was premised largely on empirical and positivist approaches and sought objective outcomes, critical geography posited questions focused not on answers so much as the production of knowledge.

Critical social theory and the examination of the underlying processes and structures that occur within space and place challenged the whole field of human geography during the 1970s and 1980s and had a profound, if divisive, impact on the discipline and on historical geography in particular. Subsequently, Cosgrove (1988), Mitchell (2002), Conzen (1990; 2010) and Massey (2005), explored the symbolic and underlying social processes of human behavior and had a profound impact on an evolving historical geography. Cosgrove (1988) drew on his research into Renaissance painting and art history to decipher the cultural symbolism embedded and manifested over time within landscapes. Cosgrove (1990) and Conzen (2010), similarly sought 
the deeper hidden cultural meanings of landscape and the societal processes that lie beneath the physical features. Mitchell (2002) in particular, argued that the landscape is a manifestation of numerous ongoing power struggles between dominant social, economic, and political groups. Mitchell (2002) and Massey (2005) also emphasize the contested nature of landscapes and the ever-changing processes inherent to those scapes.

While much historical geography over the course of the 20th century was heavily based on positivist approaches, Meinig $(1979,1986)$ suggested that landscape is defined by human vision and interpretation and he stressed the significance of multiple landscape interpretations. In The Beholding Eye (1979), for example, Meinig proposed that landscapes are composed not only of what lies before our eyes but what lies within our heads and that there are numerous ways in which people perceive landscape as nature, habitat, artifact, system, problem, wealth, ideology, history, place, and aesthetic.

More recently, historical geographers such as Naylor (2005; 2008), Mayhew (2009) and Offen (2011) emphasize the role of critical theory in taking so-called 'old geographies' to 'new places'. The works of Braudel (1949) and early map-based historical geography have become the fodder of this new historical geography where critical theory and the production of knowledge are dominant themes. Almost contemporaneous to the rise of this new historical geography and critical social theory has been the rise of digital mapping and GIS. Over the past few decades computer technology and GIS have progressed markedly and have garnered progressively more attention from both proponents and critics alike. Given the ability to analyze and visualize historical data and Big Data in particular, GIS has garnered considerable attention by historians and humanists (See von Lunen, 2012; White, 2010; Knowles, 2016). 


\section{The Spatial Turn in History}

At first glance the spatial turn may be seen as solely the introduction of geographic concepts of space into the humanities, and in particular that of history (Bodenhamer et al., 2010: vii). However, even though history and geography appear central to the spatial turn, it is not solely the insertion of geographical concepts and sophisticated cartographic mapping into historical scholarship that has informed the turn. The spatial turn is considerably more substantive and involves a reworking of the very notion and significance of spatiality to offer a perspective whereby space is every bit as important as time in the unfolding of human affairs. As Warf and Arias (2009: 2) write, “...space is a vehicle for examining what it means to be interdisciplinary or multidisciplinary, to cross the borders and divides that have organized the academic division of labor, to reveal the cultures that pervade different fields of knowledge, and to bring these contrasting lines of thought into a productive engagement with one another". The viewpoint that geography should not be relegated to an afterthought in the examination of human behavior and events and social relations, but is intimately involved in their construction, in central to the spatial turn in history: "Geography matters, not for the simplistic and overly used reason that everything happens in space, but because where things happen is critical to knowing how and why they happen" (Warf and Arias, 2008: 1).

Building on the works of Foucault (1972) and Lefebvre (1974) and their triangulation of space, time and critical social theory, Soja (2009) asserts that the ideas of an ideological, lived and subjective space is central to many areas of interdisciplinary research. Warf and Arias (2009) suggest that four primary reasons underpin the advent of the spatial turn. First, contemporary globalization, whereby the world is now in effect 'smaller' because of the rapid development of 
extensive transportation and information networks that have amplified cultural integration and increased the flow of tourism and interaction, has led to a new revisioning of what space and geography means. Second, cyberspace and the internet enable people to 'jump scale' by transcending the friction of distance. Third, GIS has revolutionized the way in which space is analyzed and is both reflective of the new importance of space and constitutive of it. As Harris (2015) has suggested, GIS and social theory are odd bed fellows in the spatial turn and yet both have become integral to it. Finally, the growing impact of global ecological and environmental issues has created increasing awareness among scholars and citizens of both the local and the global (Warf and Arias 2009). As the spatial turn has evolved, history, historical geography, and geography have undergone transitions that have readied them as critical foundations for contemporary scholarship.

\section{Advancing the Spatial Turn: Critical GIS}

Much as history has reached out to geography for ideas and methods with which to pursue the spatial turn and advance their discipline, so too has geography sought greater outreach into the humanities and history through GIS, the geohumanities, and the spatial humanities. The GIS and Society debates of the 1990s presaged the rise of critical GIS which questioned the validity and growing role of a positive and quantitative GIS on geographical research. In particular, human geographers were highly critical of GIS, asserting that it was based on "data instead of information" (Schuurman, 2006: 2). Claims were laid against GIS that as a positivist technology, it was a return to naïve empiricism and people had been reduced to a categorical variable (Schuurman, 2006: 2). Focus was also placed on its masculinist technological format, its role in marginalizing populations, and the political economy of GIS and the heavy emphasis on its government and corporate foundations (see Sheppard, 2005 and Harvey, 2005). Taylor (1990: 
212) went so far as to call GIS the "quantitative geographer's revenge". Edney (1991) and Pickles (1995) questioned the anti-democratic predilections that they saw in GIS and the "cultures of indifference" as John Pickles labeled GIS. These disputations were almost entirely held within the discipline of geography. Sheppard (1993) called for a research agenda to explore what he saw as the 'undemocratic' nature of GIS.

Initiative 19 of the NCGIS arose out of the Friday Harbor conference and these critical GIS debates and proposed that GIS was indeed set within a series of social practices and institutions embedded in a particular discourse. Pickles (1995: 25) Ground Truth was preeminent in bringing these issues to a broader geographical audience and suggested that GIS was both a "disciplinary practice and socially imbedded technology" and that the critiques of GIS had to be acknowledged and addressed. In response Goodchild (in Pickles, 1995) proposed a change from a discussion of GIS as a system toward an engagement with critical GIS based on a theoretically informed Geographic Information Science. If GIS were seen to be a tool, then, it would merely be a methodological means to an end and theoretical engagement would be stymied. As a science, however, theory and epistemology become central to any engagement, and can inform the ways in which GIS is used and valued in contributing to knowledge production. Even though Sheppard labels GIS as a social process rather than as a science, his assertion that "technologies are not only are rooted in society but have social consequences", still rings true (Sheppard, 1995: 6-7). Critical GIS and the GIS and Society debates were powerful in moving the discipline forward and one early outcome toward addressing the needs of a humanistic GIS was the focus on Participatory GIS (PGIS). Harris and Weiner (1998) and their work in South Africa were indicative of an embryonic GIS that was empathetic to the Critical GIS discussions and to the necessity of bending GIS to 
humanistic needs. Since then, PGIS has developed into both its own sub-discipline and has sought to address many issues at the heart of the critique on GIS including the need for a qualitatively informed GIS. Participatory GIS sought to incorporate multiple forms of knowledge and data, as well as address issues of marginalized groups in the GIS decisionmaking process. PGIS highlighted the inherent power relationships in GIS and gave voice to underrepresented groups, legitimate local information, and to the multiple realities that GIS had to represent. However, the research also acknowledged that in the drive to incorporate marginalized voices and qualitative local knowledge PGIS also ran the risk of legitimizing bad data, and also run foul of the political economy of GIS that required extensive skills, training, along with costly hardware and software and the commodification of data (Abbot et al., 1998). Elwood (2006a, 2006b) noted that PGIS introduced its own contradictions with respect to knowledge access, representation and power and new technological developments such as geovisualization may actually further the digital divide. Elwood called for continuous critical reflection in PGIS while striving to find multiple appropriate ways to represent and communicate spatial knowledge.

Indicative of these advances in GISc is what Goodchild (2007) termed Volunteered GIS (VGIS). VGIS is founded on volunteered information as part of an extensive citizen science. With the innovations in Web 2.0 and social media technology, cloud-based data repositories, and the proliferation of mobile phones and almost universal GPS, individuals are now able to capture, contribute, and share online their personal geographic information via the geotagging of photos, blogging, and mapping. Goodchild (2007) asserted that the great value of VGI is in making the familiarity of place that people inherently achieve through day-to-day activities, and which is arguably vastly more expert, useful, and accessible, available to a broader community of 
potential users. Despite concerns that volunteered information might be used for unintended purposes and is asserted rather than verified, Goodchild suggests that the emerging technology creates new possibilities and conceptions of what can be achieved and what is meaningful to people. Perhaps one of the more challenging ideas to arise out of Critical GIS was the creation of an entirely new form of GIS, a GIS 2.0 and VGI coupled with PGIS may well fall within this vision (see Harris and Weiner, 1998; Sieber, 1996). As will be argued subsequently, however, deep mapping is proposed here as a way to bridge multiple technologies and concepts to create a GIS 2.0. In contrast to the then existing GIS platforms (v1), or an abridged GIS 1.2 based on an adapted GIS 1.0, GIS 2.0 was to be a reworking of GIS itself in a form that more closely mirrored a system built in the light of critical GIS input and a humanistic focus. Sieber (1996: 25 ) set forth a number of requirements that such a system must integrate local knowledge, support cultural and multi-lingual distinctions, and preserve -rather than reduce-friction, disagreement, redundancy, and even error. Sieber (1996) further suggests that GIS must be viewed as material and discursive in order to provide a successful GIS 2.0 and Pickles (1997: 58) required that the platform would "certainly have to be cheaper, more accessible and sufficiently flexible to be of use to a wider range of users....have to develop ways to represent different conceptions of space or Nature, and preserve contradiction, inconsistency and disputes...[and]...be capable of integrating all data components such as WWW, data archives, parallel and counter texts in diverse media, standard maps and datasets, and sketch map and field notes, all from one interface.” To address this seeming wish list of capabilities, Sieber (1996) suggested actually aggressively scrapping the old GIS and starting afresh. Three of Sieber's recommendations, however, continue to build on existing GIS by integrating local and traditional knowledge, 'infiltrating cyborg', and rewriting code to create a qualitative GIS. 


\section{Humanistic and Qualitative GIS}

Historical data poses significant challenges to GIS because they tend to be incomplete and representative of only certain periods of time and groups of people. More problematic is the textual, argument based, and qualitative narrative form of historical studies. Even when substantial historical data are available, such as the Sanborn maps and the US census statistics, gaps and silences remain in the data, particularly when accessing earlier periods. The foundation of GIS on measured space, accuracy, spatial primitives, categorical variables, and Boolean logic is not empathetic to many historical studies that are premised on place, fuzzy space, and conflicting argument. Mapping travel diaries, for example, may include textual observations about places and experiences which are difficult to capture in GIS and necessarily change over time. In addition, locational metrics and levels of spatial accuracy may vary markedly when using terms such as 'near' or 'north of'. Incorporating such information in a system that relies on precise coordinate systems and exact location is problematic. Irrespective of all these challenges, while GIS is rooted in positivist epistemologies and the integration of 'qualitative' appears almost to be 'an oxymoronic endeavor" (Harris, 2015), Qualitative GIS has sought to push even these boundaries (Kwan and Knigge, 2006).

Cope and Elwood (2009: 3) suggest that "qualitative data are not simply those data that are nonnumerical. Rather...that data may be qualitative in part by virtue of the rich contextual detail they provide about social and material situations...[and]...data may also be qualitative if they contain or provide interpretations of the situations or processes that they describe". In this regard, data are qualitative because they situate negotiated knowledge. Qualitative GIS requires new epistemologies and additional analytical techniques and remains an emerging yet untested field for reflexively and iteratively representing multiple forms of knowledge. A number of 
approaches to QGIS have been proposed (see Pavlovskaya, 2009, 2017; Schuurman, 2008; Jung, 2010) but Cope and Elwood's (2009) concept of a hybrid mixed methods approach is widely recognized. The hybrid mixed methods approach "weave together diverse research techniques to fill gaps, add context, envision multiple truths, play different sources of data off each other, and provide a sense of both the general and the particular". Such a QGIS, "may produce complementary explanations of phenomena, while other times (and equally valuably) they may produce contradictory explanations, leaving the task of understanding how and why these multiple versions of 'truth' intersect" (Cope and Elwood, 2009: 4-5). Another widely referenced QGIS approach is Knigge and Cope's (2006) grounded visualization technique. Grounded visualization “...builds upon and integrates the strengths and potentials of .... two exploratory methods, enabling multiple queries of the data through an iterative, recursive process that blends qualitative and quantitative research...from a geographic perspective" (ibid.: 97). The grounded visualization technique is currently one of the most integrated qualitative approaches that has yet been tested using cartographic representations and non-visual forms such as interviews and observations (Knigge and Cope, 2006b). Knigge and Cope (2006), for example, sought to uncover the underlying reasons why certain areas in Buffalo, NY, were vacant which required them to define the term 'vacant' how the term had different interpretations between different groups of people. The authors found multiple perceptions of the term such as abandoned building, a barren lot, or even a beautified lot, and that groups responded differently to their presence in their neighborhoods. Essentially, the reflexive, iterative, and dynamic procedures within QGIS generated further questions to pursue rather than achieve some perceived objective and categorical answer. 
Jung and Elwood (2010) list three ways in which qualitative data can be integrated into GIS, including transformation and hyperlinking strategies and software modifications using an Imagined Grid as a means of geo-referencing qualitative data and storing data in layers, and thereby solving the problem of separation of data from system. While this approach allows qualitative data to be assigned coordinate values and allows conventional GIS operations to be carried out, this approach can only store one item per grid and numerous problems remain to be addressed. Jung further suggests the use of Computer Aided Qualitative GIS (CAQ-GIS) to analyze and interpret data within the GIS. The qualitative data held within the Imagined Grid is analyzed much in the same way that Nvivo, analyzes texts by assigning codes and pulling out themes for the researcher to pursue. This data can be incorporated into research results via a report, tag clouds, or other textual representation.

Kwan and Ding (2008) take an entirely different approach to Qualitative GIS in their study of post 9-11 Muslim women in the Columbus area. Kwan and Ding's geo-narrative approach incorporates time geography, 3D modeling, 3D-VQGIS based on CAQDAS, and narrative analysis. Rather than incorporating separate technologies linked to GIS, their method is based on extending current GIS capabilities. The study creates time-paths of Muslim women in the months following the 9-11 attacks to gain a sense of how their day-to-day activities were altered by perceived or real threats on their person. A key component to the time paths was the ability to integrate narratives of the women to further understand how and why they took the routes they did while avoiding other pathways. Three-dimensional terrain modeling was then used to gain insight into the experiences and behaviors of the Muslim women. Kwan and Ding's work is truly a mixed methods approach for it blends both quantitative and qualitative analysis by building on the capabilities of GIS. 
Schuurman (2009: 54) suggests the use of an ontology-based metadata as a requirement for integrating qualitative data into GIS where the goal is to preserve the context within which the data was collected and analyzed. Schuurman states that the "ultimate goal of ontology-based metadata is to ensure data are used not as the truth about the world, but rather as information that is contextual and contingent." Schuurman (2009) proposes using seven fields: sampling methodologies, definition of variable terms, measurement system, taxonomic system data model, collection rationale, policy constraints, and anecdotes. Finally, Leszczynksi (2009: 362) suggests a 'quantitative-qualitative GIS' whereby “Critical GIS practices certainly employ and constitute qualitative methods, but these are distinctly quantitative qualitative engagements that are ultimately expressed within the universe of computing".

While the term Qualitative GIS can be somewhat misleading, the goal remains to augment a wholly Boolean GIS system with a more multi-faceted and humanistic system that includes multiple hybrid approaches and that includes qualitative as well as quantitative measures. The humanities and history pose a direct challenge as to how GIS might be adapted to pursue the spatial turn, and this is pursued in the following chapter. 


\section{Chapter 3 | The Spatial Humanities and Deep Mapping}

The term spatial humanities has recently been coined in an endeavor to reformulate how the spatial turn might be incorporated within the humanities. Bodenhamer, Corrigan, Harris (2010) sought to revitalize and redefine geo-humanities scholarship by reintroducing spatial concepts to the humanities within the context of ongoing initiatives and intersections between geographic information science and the humanities. In doing so, the spatial humanities grapples with the incorporation of qualitative data within GIS and with concepts of geographic space and spatial thinking. Unlike research areas that seek to integrate space with the humanities primarily through using GIS as a tool, the spatial humanities is both a theoretical and methodological engagement between the humanities and GIScience. Within the spatial humanities Qualitative GIS, Deep Mapping, Deep Contingency, Immersive Technologies and Neogeography have emerged as areas of research against the backdrop of the spatial turn.

While the core focus of this study is based in the spatial humanities because of its advances in both conceptual and methodological contexts, a number of other terms and fields have arisen. Among the oldest is Digital Humanities, though Historical GIS, Spatial History, and Geohumanities have emerged largely based on the disciplinary emphases. The Digital Humanities utilizes computer technology to further scholarship in a range of humanities disciplines, from history and archaeology to music and art (see Berdan, 2013; Gold et al., 2019; Berry et al., 2017; Kirschenbaum, 2012; Clement, 2016). In the Digital Humanities, the primary sources are generally converted from analog to digital form and although the Digital Humanities may include geography, it does not necessarily acknowledge spatial concepts or locational data as a primary focus. The Digital Humanities, in many ways, harness the potential of innovative computer technology and have made great strides in disseminating data and cultivating research 
(Gardiner, 2015; Berry et al., 2017). An increasing amount of historical data is available to researchers and is opening up many new avenues of scholarship. Part of the Digital Humanities, and perhaps the most important part, has been the questioning of its use of computing as a digital environment for humanistic enquiry. Thomas (2004: 66) in referring to the use of digital technologies in history wrote: "The goal for historians working in the new digital medium needs to be to make the computer technology transparent and to allow the reader to focus his or her whole attention on the 'world' that the historian has opened before investigation, interpretation, inquiry, and analysis". The Digital Humanities has garnered significant attention, yet fundamental issues have arisen that question how analysis in a digital environment contributes to, or detracts from, scholarly understanding of the topic in hand (Gold, 2019). While spatiality may be somewhat peripheral in the digital humanities to varying degrees, in spatial history and the spatial humanities, space and place are central to both theory and method.

\section{Spatial History, Historical GIS, and the Spatial Humanities}

According to Gregory et al. (2018: 1), the primary methodology for exploring the spatial component in history is through Historical GIS (HGIS), which he suggests "remains at the core of Spatial History." A central component of the spatial turn in history has been the increasing importance that GIS has taken in historical studies. This has been greatly facilitated through the growing availability of digital historical databases that have spatial attribution. The availability of these databases in conjunction with the increased popularity and accessibility to GIS, has led to its greater use in historical studies (Debats et al., 2011; Knowles, 2008, 2016). The term Historical GIS has been used to describe the use of GIS in historical analysis though in reality the term really refers to nothing unique in Historical GIS than GIS, other than a focus on historical data. Thus, temporal analysis which one would think would be central to a historical 
GIS is no different from GIS as a whole and suffers from the same constraints. Nonetheless, "GIS enables space to be a powerful integrating theme enabling multiple scaled explorations of relationships by virtue of their common location in ways that text cannot" (Harris in Kobayashi, et al., 2015: 1353). Historical GIS facilitates the visualization of spatially distributed historical data, often revealing patterns of spatiality overlooked by traditional historical research. While Historical GIS is limited by the positivist and Boolean connotations outlined in the critical GIS literature it nonetheless has been a valuable tool when applied to tabulated digital historical data. However, the difficulty experienced when including other historical source materials such as text, images, autobiographies, document images, film, music and other types of qualitative information available to humanists remains a constant. Historical GIS has, without doubt, raised awareness as to the importance of spatial analysis in historical scholarship and addresses a number of spatial questions with regard to significant historical events (see chapters in Gregory et al., 2018; Schlichting, 2008; Knowles, 2002, 2008). But historians are cognizant that, "GIS privileges certain types of data, information, representations, logic systems, and ways of knowing over that of others. Incomplete data, silences in the data, and structural knowledge distortion pose significant challenges to the users of GIS in the humanities..." (Harris, 2010: 170). Thus, while GIS provides a formidable tool for data management, mapping, and analysis it is not a panacea for pursuing the spatial turn in historical studies. Integrating the spatial turn in history goes beyond the application of Boolean logic GIS for the theoretical constructs of the spatial turn are seemingly often peripheral to historical GIS and spatial history research. For this reason, the term and broader meaning of the field of spatial humanities is preferred. The focus on GIS in the humanities and history as a method, runs in the face what Goodchild (2010) suggests is central to the spatial humanities which "...must be underpinned by critical spatial 
thinking and an understanding of spatial concepts involving scale, respatialization, accuracy, uncertainty, ontology, representation, and complexity". Tellingly a critic of White's (2010) Shaping the West project, Huelman (2011) suggests, "The project feels more as if it is an archive of visualizations than a persuasive argument leading towards one conclusion. A severe lack of narration and annotation leaves the viewer to make their own conclusion based on the visualizations they decide to open and interact with. Narrative would be helpful in reiterating the evidence in support of a conclusion on the railroad's impact in the West".

White's work is a part of The Spatial History Project (2010) at Stanford University (https://web.stanford.edu/group/spatialhistory/cgi-bin/site/index.php) (Accessed 7/15/2021) which was one of the first robust collections of spatial history studies undertaken by scholars and students. The studies in The Spatial History Project primarily utilize GIS as the vehicle for integrating space with historical events and has given rise to a growing recognition of spatial history as a constituent approach to the study of history. Gregory et al. (2018) brings together 50 scholars undertaking research in historical population and demography studies, economic history, urban history, rural and environmental history, and political history, and this points to the tremendous growth that spatial history has experienced. Distinguishing between spatial history and historical GIS however is no easy task and is more one of nuance and preference than one of substance.

Bodenhamer's (in Gregory, et al., 2018) study on Bakhtin's 'ghost' traces the evolution of spatial history into the spatial humanities and ultimately to deep mapping. Bodenhamer states that “...we must chase—and corral—Bakhtin's ghost”. Bakhtin, an early $20^{\text {th }}$ century Russian philosopher developed the idea of the chronotype, which has particular relevance to the spatial humanities and deep mapping in that it literally translates to 'space time'. The intrinsic 
connectedness of space and time are both the foundation for Bakhtin's writings as well as the critical components, together with social theory, that underpin the spatial humanities.

Bodenhamer, Harris and Corrigan (2010) propose that the spatial humanities is a more suitable field than the aforementioned, with which to pursue research that emphasizes the spatial turn in history. Bodenhamer (2018: 539-540), stresses that supporting historical research with maps or GIS should not "model or replicate the past but complicate it" and that 'simply' displaying historical data in a GIS does not shift our way of knowing. Bodenhamer goes so far as labeling GIS as "a weak reed on which to base this shift". Bodenhamer details both the importance of injecting social theory into history as a response to the spatial turn, as well as emphasizing the broadening of the field to include all of the humanities. Within geography this has been termed GeoHumanities.

The GeoHumanities has gained a strong following among geographers, historians, planners and artists and is closely linked to the release of a journal of the same name (Dear et al., 2011). The GeoHumanities integrates "urbanism, literature, the visual arts, and science" (ibid: 3 ). The GeoHumanities is not grounded in GIS or critical social theory but rather focuses on "...part of a broader realization that space and place, long held constructs of geography, play a critical and central role in people's lives and human behavior" (Harris, 2015: 182) Thus the digital humanities, spatial history, and the GeoHumanities all bring particular approaches to the spatial turn yet for a number of reasons the spatial humanities is preferred as a bedrock foundation to this dissertation study.

\section{The spatial humanities, spatial storytelling and deep mapping}

The spatial humanities, according to Bodenheimer, et al. (2010), reintroduces geographical concepts of space into the humanities. While space has not been historically precluded from the 
humanities, it has often been overshadowed outside of geography. Unlike other areas of study, spatial history and historical GIS for example, which also acknowledge space as fundamental components, the spatial humanities encompass a broader spectrum and stresses the integration of space in all humanities disciplines to better understand the human experience. The spatial humanities examine the symbiotic relationship that exists between humans and space, critiquing it, exploring the theoretical concepts and themes that influence it and investigating the use of potential technology that could have the ability to further analyze it (see Bodenheimer, et al., 2010).

For the purpose of this study three themes in the spatial humanities are particularly relevant to this study. These comprise spatial storytelling, ghost mapping, and deep mapping. One important element in historical studies involves the elucidation of spatial stories, which according to Harris (2015: 40), “...weave pathways through deep maps to track, organize, and record people's experiences and relationships with places." Spatial storytelling connects the local, the experiences, the intimate, and the mundane through personal trajectories that are linked to broader spatio-historical events. Spatial stories are intricately linked to space and to place. Not to be confused with spatial narratives which similarly detail spatial events, the spatial story is distinct and goes further to intrinsically connect the storyteller, the reader and listener to the experiences of the storyteller. Spatial stories immerse the reader in the experiences of the account and are meaningful and expressive. A spatial story need not be a visualization, although it can be a component of a visual experience by connecting it with spatial elements such as a deep map or ghost map. 
Ghost mapping was developed by Ethington and represents an intriguing approach to the blending of place, space, and history. Historians, he suggests, often confuse time with chronology (Ethington, 2007). Rather than seeing history and place as separate dimensions, Ethington proposes that history is comprised of a changing geography that takes place over time (Ethington, 2007). Ghost maps according to Ethington (Presner, 2014: 69) map the footprints of these past geographies by creating a visual collage of moments: "As a rich and complex graphical composition drawn directly from the profound complexity of past social life itself, the content of a ghost map...exceeds the capacity of any textual narrative to explain it (Ethington, 2014: 71). Ethington's Ghost Maps or 'Ethingtographies' are large format artistic pieces that detail significant historical, one could argue geographical, occurrences in a specific place. His seminal work, Ghost Metropolis (see Figure 3.1), utilizes color, iconography, images, and text to overlay 3000 years of Los Angeles' history on a historic street map. The artistic piece is multilayered and intricately detailed, creating multi-media spatial stories that might take on the form of a map or a "cartography of time", as Ethington describes it. Ethington's work contains

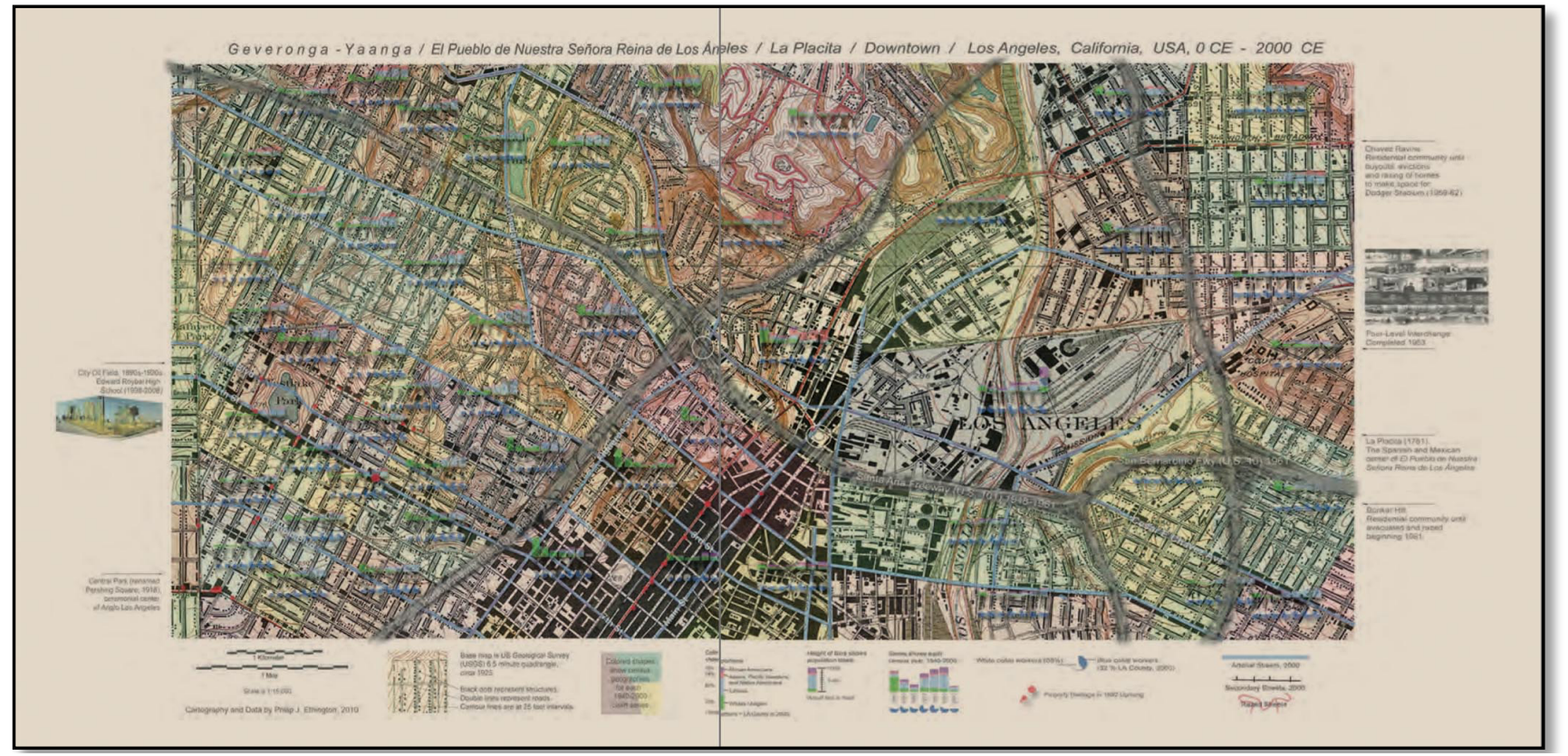

Figure 3.1: Ghost Metropolis by Ethington (2014). 
typographic narratives, photographic narratives, and cartographic narratives, sound and video, which work together to create a layered work that "visualizes the past". The foundation of the Ghost Map is the juxtaposition of media and map layers, which reveal intricate nuances and connections associated with places. In some regard, a detailed inspection of a ghost map is not dissimilar to the way that historical geographer Hoskins (1955) insisted that landscapes needed to be studied at the local level to best interpret the cultural impacts of a landscape. As visual representations of space and place, ghost maps not only challenge the idea of what constitutes a map but provide an alternative visual map/media representation of source materials for investigation. Hypercities is a website dedicated to spatial history and in similar form to Ghost Maps is a collection of projects that utilize google earth, historic maps, text, sound, video, and images to show change in a particular place over time.

The third component to this study is that of deep mapping which has arisen out of the spatial humanities literature (Bodenhamer et al., 2015). A deep map is “...heavily narrative-based and interlaced autobiography, art, folklore, stories, and memory with the physical form of a place to 'record and represent the grain and patina of place through juxtapositions and interpenetrations of the historical and the contemporary, the political and the poetic, the discursive and the sensual..." (Harris, 2014: 188). Harris describes traditional cartographic maps as thin maps rather 'shallow' maps, the antonym to deep maps, so as not to suggest 'shallowness'. Thin maps are invariably a cartographic representation, nowadays the product of GIS, that are conceived, designed, created, and maintained by experts to meet specific governmental, corporate, or community needs, but which is heavily focused on the material and physical characteristics of landscape. Thin maps and their content have been the backbone of spatial databases and have proven invaluable in many innumerable areas of society (Harris, 2012). However, these 
traditional maps lack the thick text and fine grain evident in deep maps, which strive to understand space and place and deep contingency. A deep map is a conversation and a dialogue, that communicates information through its use of detailed layers which can be text, video, images, maps, photographs or sketch maps. Unlike a GIS, these layers combine to reveal the deeper context of a space and a sense of place. Whereas a GIS documents a particular location with layers of spatial data, it struggles to incorporate or evoke placial stories. In contrast, a deep map conveys a story or narrative of a place by weaving together components into a highly visual and sensual experience that strives to understand a place at a deeper level. Harris (2012) proposes that a deep map has its foundations in deep contingency. Given that all facets of social life interact, and all parts of life are contingent on one another (Ayers, 2003: xviii), deep contingency examines the core of what is place. Ayers, one of the most notable historians working in deep contingency studies, insists that traditional examination of the past results in generalized experiences that often blur categories. Alternatively, Ayers emphasizes place distinctiveness which requires the study of the everyday, the individual, and the local. As a companion to his Valley of the Shadow project, Ayers has published In the Presence of Mine Enemies (2003) which utilizes deep contingency to convey a history of the Civil War from the viewpoints of everyday people who were afforded only glimpses of the drama surrounding them, and who made decisions based on what was happening locally, through each other and through impressions they gathered from local newspaper. Most histories of the American Civil War present a history that supersedes that of everyday lives. Ayers challenges traditional historical thinking by placing the event in everyday lives. The everyday reverberates outward, forming a dialectic relationship with a greater history that ultimately unfolds. Harris in Bodenhamer et. al. (2010: 174) describes deep contingency as focusing “...less on the factors of causation than on 
interpreting the consequences and the resonances of events.....as evidenced through the intersection of documented nodes of place, time, and action---where geocoded singular events and larger patterns intersect across time and space, a collage of moments." In deep contingency and deep mapping, the scholar peels back the layers to uncover the overlooked, the oversimplified, and the oft discounted, and exploring the interrelationships that exists within and between each of the layers. In the process, spatial narratives and stories surface about a particular place and a set of events.

Ultimately a deep map allows users to comprehend the nuances that contribute to an inherent sense of place and provides what Ayers $(2000,2003)$ describes as an "unmatched, ground-level view" to historical events. Deep maps are open ended and depart from positivist thinking by emphasizing "...the flux of emotion and belief, the intertwining of reason and feeling, the constant revision of history as people lived within history" (2004: xvii).

A deep map inherently tells a spatial story or may be composed of many small stories, or spatial vignettes that convey a broader narrative. Based on the rich text of William Least Heat-Moon's PrairyErth (1991), the most comprehensive definition of a deep map comes from Shanks and Pearson in 1994:

"Reflecting eighteenth century antiquarian approaches to place, which included history, folklore, natural history and hearsay, the deep map attempts to record and represent the grain and patina of place through juxtapositions and interpenetrations of the historical and the contemporary, the political and the poetic, the discursive and the sensual; the conflation of oral testimony, anthology, memoir, biography, natural history and everything you might ever want to say about a place ..." (http://documents.stanford.edu/MichaelShanks/51). 
Theorist and artistic director Clifford McLucas (1994) proposed that there were ten significant elements of deep maps:

- Deep maps will be big - the issue of resolution and detail is addressed by size.

- Deep maps will be slow - they will naturally move at a speed of landform or weather.

- Deep maps will be sumptuous - they will embrace a range of different media or registers in a sophisticated and multilayered orchestration.

- Deep maps will only be achieved by the articulation of a variety of media they will be genuinely multimedia, not as an aesthetic gesture or affectation, but as a practical necessity.

- Deep maps will have at least three basic elements - a graphic work (large, horizontal or vertical), a time-based media component (film, video, performance), and a database or archival system that remains open and unfinished.

- Deep maps will require the engagement of both the insider and outsider.

- Deep maps will bring together the amateur and the professional, the artist and the scientist, the official and the unofficial, the national and the local.

- Deep maps might only be possible and perhaps imaginable now - the digital processes at the heart of most modern media practices allow for the first time, the easy combination of different orders of material - a new creative space.

- Deep maps will not seek the authority and objectivity of conventional cartography. They will be politicized, passionate, and partisan. They will involve negotiation and contestation over who and what is represented and how. They will give rise to debate about the documentation and portrayal of people and places.

- Deep maps will be unstable, fragile and temporary. They will be a conversation and not a statement. 
McLucas' "Map on a Wall” (see Figure 3.2) is a series of 8 feet tall panels of multi-medic layers “... that seeks to visually represent places, peoples and events - techniques that are more complex and (dis)located than those associated with landscape painting, the photograph, or the

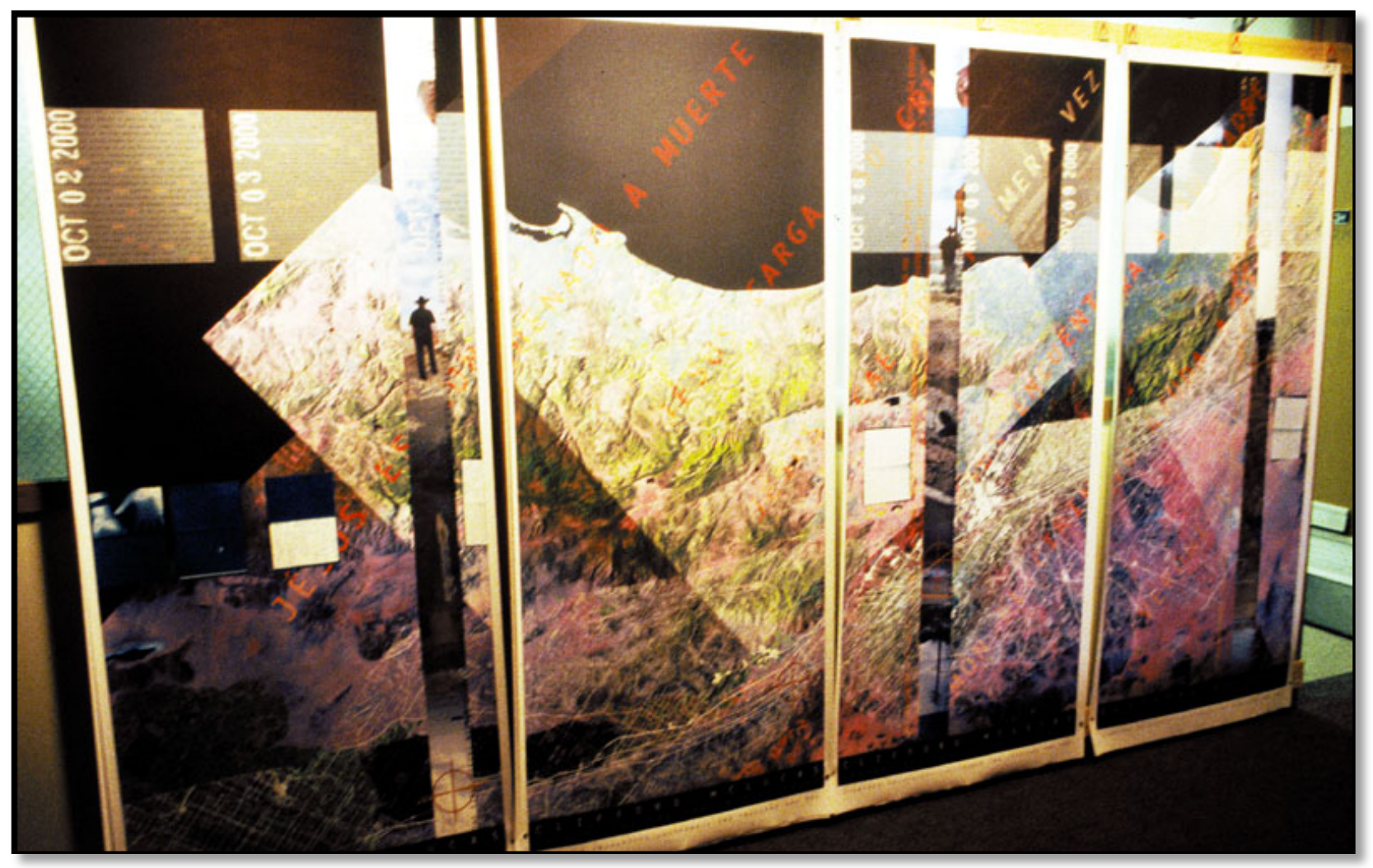

Figure 3.2: Clifford McLucas' Map on a Wall, 1994

conventional map (http://web.stanford.edu/ mshanks/MichaelShanks/51.html) (Accessed 7/15/2021). By McLucas' own admission, his ideas are the foundation for what a deep map could be, not necessarily the finite product. Alternatively, more recent research by MurrietaFlores et al. (forthcoming), suggest that a form of deep maps have existed for centuries. The authors examine Meso-American codices and $16^{\text {th }}$ century colonial maps as potential examples. Murrieta-Flores et al., (forthcoming: 4) state that “....spatial Indigenous representations may be better thought of as mnemonic spatial technologies (similar to 'deep maps') that could include 
diverse elements that were recognizable to the Western eye". The codices are often accompanied by oral histories and can evolve through time with each generation. The works “...reveal, just as deep maps do, the topological, relational, and narrative ties among the human agents and space." (Murrieta-Flores et al., forthcoming: 8). The important contribution of this work is that deep maps can take on other forms and do not have to be computer generated. For indigenous societies, these codices were a type of deep map that were in use for hundreds of

years. Deep maps provide an exploratory environment that enables underlying concepts such as deep contingency, multi-media, openness, and ability to relay a spatial story. Significantly, Murrieta-Flores et al. (forthcoming: 30) do not “...deny the role of the Western tradition in the production of these paintings, but.....that in its syncretic process, [deep maps] ....go far beyond 'simple' cartographic maps.

\section{Approaches to Deep Mapping}

The methodologies for making deep maps are largely experimental, untried, and untested (Bodenhamer et al., 2015) but a few approaches have been proposed (see Harris' framework in Figure 3.3): hence the innovative nature of this study. Among the approaches taken to date are geovisualization and immersive technologies, the geospatial web, and Neogeography (Bodenheimer, et. al, 2015; Forthcoming). By way of one exploratory approach, Harris used virtual reality and immersive geography to create deep maps (Harris, 2012; 2015). The recent 
rapid technological advances in

high-end processors, graphics

cards, computer graphics, and

sound systems have enabled

advanced virtual reality and

immersive systems to be widely

available. The Cave Automatic

Virtual Environments (CAVE)

date from 1992 and are expensive

high end fixed systems but low

cost, mobile, virtual reality

headsets are now widely

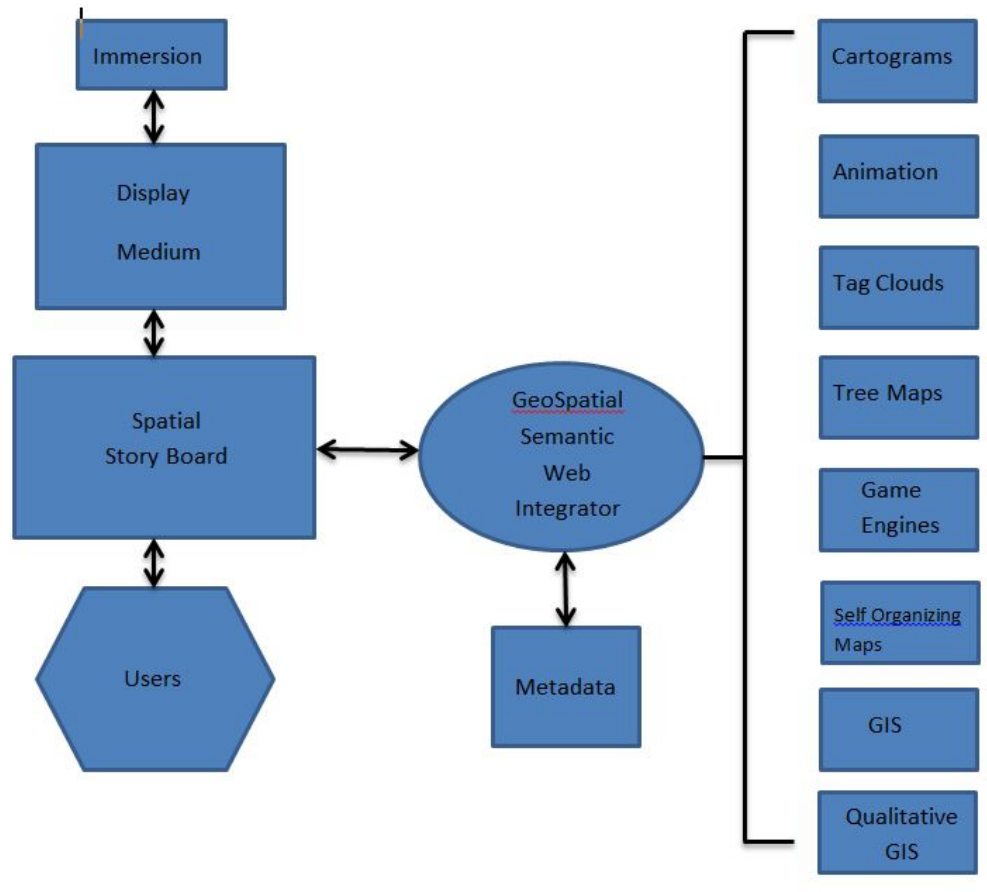

available. A CAVE is "a room-

sized, advanced visualization solution that combines high-resolution, stereoscopic projection and

3D computer graphics to create a complete sense of presence in a virtual environment."

(Mechdyne, 2021). First developed at the University of Illinois at Chicago in the 1980s the

CAVE A CAVEs are an immersive reality environment where content is projected onto multiple walls of a cube enabling the user, who stands within the cube, to experience, full immersion as in the projected scene (Cruz-Neira at al., 1992). Such experiences might entail walking through a digitally constructed historic town or flying over a landscape or historic landscape. The CAVE may include not only sound but binaural spatial sound from multiple speakers, imagery, smell, and other sensory and tactile elements that contribute to the sense of 'being there' and experiencing a sense of immersion Mobile virtual reality headsets are now available which 
create a similar immersive environment. For example, the Oculus Rift S, primarily used in entertainment gaming, is composed of a headset that fully encloses a user's eyes and enables the user to visualize the environment. The system also has a computer-user interface by way of a wand or handheld devices that enable user interaction with the virtual scene (https://www.oculus.com/rift-s/) (Accessed 7/15/2021).

An immersive environment is one where the user experiences the spatial story rather than reading text or maps or viewing static $2 \mathrm{D}$ images. In an immersive environment the user can interact with the system to experience events as they unfold and determine the nature of the interaction and participation with the scene. In this respect the user has agency rather than being a recipient of some predetermined image. An immersive environment presents information dynamically. Knowles (2008: 235) presents a famous example of General Lee's actions and 'what Lee could see' at Gettysburg and using GIS she modeled how geography influenced events at the battle. Her research illustrates the powerful role of 2D geography and line of sight analysis whereas in a virtual immersive environment one could actually experience the scene as if in realtime 3D, and how it can be better understood visually.

The GeoSpatial Web has also been proposed as a platform for deep mapping (Bodenhamer, et al., 2010). Web browsers such as Google Earth coupled with Internet 2.0 provide the opportunity to merge social media platforms, technology, and data to create versatile environments for deep mapping. Whereas, traditionally, the map was thought to be the creation only of experts, the Geospatial Web provides a platform for use by non-expert and expert. According to Harris in Bodenhamer et al. (2010: 140), “Accessibility, ease of use, base mapping, 3-D scenes, point, line, polygon integration, and the power provided by API capability, along with semantic interpretation, promise significant rewards.” 
While the GeoSpatial Web does not necessarily require NeoGeographic technologies, it often uses them to close the gap between data producers and data consumers in the humanities (Bodenhamer et al., 2010). Neogeography in literal terms means 'new geography' and stresses the importance of not only utilizing innovative technologies but strives to level the playing field between expert and amateur by utilizing online technologies that allow non-professionals to participate in map making and publication on the web. Neogeography is changing conceptions of traditional geographic mapping and sharing practices. Significantly for this study, Neogeography utilizes the GeoSpatial Web and Application Programming Interfaces (APIs) that connect data, and software systems. APIs were revolutionized in 2006 when Google released their API which enabled other users to hook into their platform. Since then, many other software systems have released their APIs which enable users to make JavaScript calls for data or functions. In the Flickr API, for example, a user can request images by gallery, title, or keyword and the specific image is returned. Neogeography utilizes the GeoSpatial Web to collect, collate, house, and display numerous types of geographical data generated from 'nontraditional' methods and challenges more traditional, academically-based geographic methods in favor of techniques available to the non-expert user.

Scholars in GeoHumanities and Spatial Humanities have acknowledged the considerable impact and potential of Neogeography research (Bodenhamer, et al., 2010; Johnson, 2011; Goodchild, 2009; Hudson-Smith, 2009). Neogeography is dynamic, flexible, reflexive, and as will be demonstrated in this study has the potential for innovative scholarship in deep mapping. 


\section{Chapter 4 | Frederick Jackson Turner's frontier thesis, its historiography}

\section{and defining the case study area}

In 'The Significance of History', Frederick Jackson Turner (1891: 10) stressed that with each generation of historians, the narrative can, and will, change based on a combination of the interpretation of events, researcher perspective, and current trends in academia and society: "Each age writes the history of the past anew with reference to the condition uppermost in its own time. Each age tries to form its own conception of the past." Fittingly, two years later, Turner (1893) produced his seminal 'The Significance of the Frontier in American History', which has been one of the most provoking historical references for generations of scholars who have sought to understand the history of U.S. western movement. Turner's Frontier Thesis has been written about, revered, or balked at for over a century, with each generation imparting a new perspective and contributing additional data and viewpoints to the research. In the process of developing an 'alternative' approach through deep mapping of part of the U.S. westward expansion, this dissertation will add to this historiography.

\section{Setting the stage}

Research into the frontier movement in present day southwest Pennsylvania and northwest West Virginia provides an excellent window into the broader narrative of U.S. westward expansion. The study draws heavily on eighteenth century accounts of the region east of the Mississippi River, including travel diaries and maps generated by the French and English (Fry and Jefferson, 1755; Batts and Fallom, 1671; Gist, 1750-51; Washington, 1754; Gibson, 1763; Mitch, 1755). Travelers and surveyors recorded their findings in diaries, survey books, guidebooks, drawings, and maps that detailed the ongoing westward movement of European settlers and the oftenhostile relationships with indigenous peoples. Detailed traveler descriptions of the landscape and 
topography such as those by Christopher Gist, Jefferson and Fry, and Batts and Fallom, focused on the Appalachian Mountains and the Ohio Valley and were written to provide private trading companies, military officials, and prospectors information about how to exploit and utilize the resources of the region: "It was a pleasing tho' dreadful sight to see the mountains and Hills as if piled one upon another" (Batts and Fallom, 1761: 188).

Travel diaries are key sources that describe and provide the topography of North America some 200-300 years ago. These invaluable diaries include Travels in America performed in $1806:$ for the purpose of exploring the rivers Alleghany, Monongahela, Ohio, and Mississippi, and ascertaining the produce and condition of their banks and vicinity (Ashe, 1806), Christopher Gist's Journal (Gist, 1750, 1751), The Journal Major George Washington (Washington, 1754; 1865), and A Journey from Virginia to beyond the Appalachian mountains (Batts and Fallom, 1761). The topography to the west of the eastern seaboard greatly impacted the early explorations and excursions of European settlers into the region as they made their way westward. Although waterways provided the primary means of access in the early years of settler expansion, indigenous trails were also used in the opening up of the interior. The French, seeking trade routes, made their way through the Great Lakes region into the Ohio River Valley and ultimately to the Mississippi River and the Gulf of Mexico. The English, seeking to primarily establish new settlement areas, took a more direct route westward from the east coast over the Appalachian Mountains. Despite utilizing waterways, such as the Potomac River which originated in the Allegheny Mountains, the predominantly English settlers were forced to traverse more difficult routes through rugged terrain (Figure 4.1). In addition to utilizing indigenous paths, revolutionary war military trails in the Allegheny Mountains and Ohio River Valley were used and recorded on military maps, greatly influenced the location of early 
settlement. Reaching the Ohio River was a primary objective (Hine, et. al, 2017). Unfortunately for the English, the French had early claimed the territory along the Ohio, limiting the English westward movement and this ultimately led to the French and Indian War for control over the region (https://www.loc.gov/rr/program/bib/frenchindian/) (Accessed 7/15/2021). The French and Indian War led to the French surrender of land that extend west of the Allegheny Mountains to the Ohio River, which enabled the British to extend their influence further west. This westward expansion, however, was not uniform.

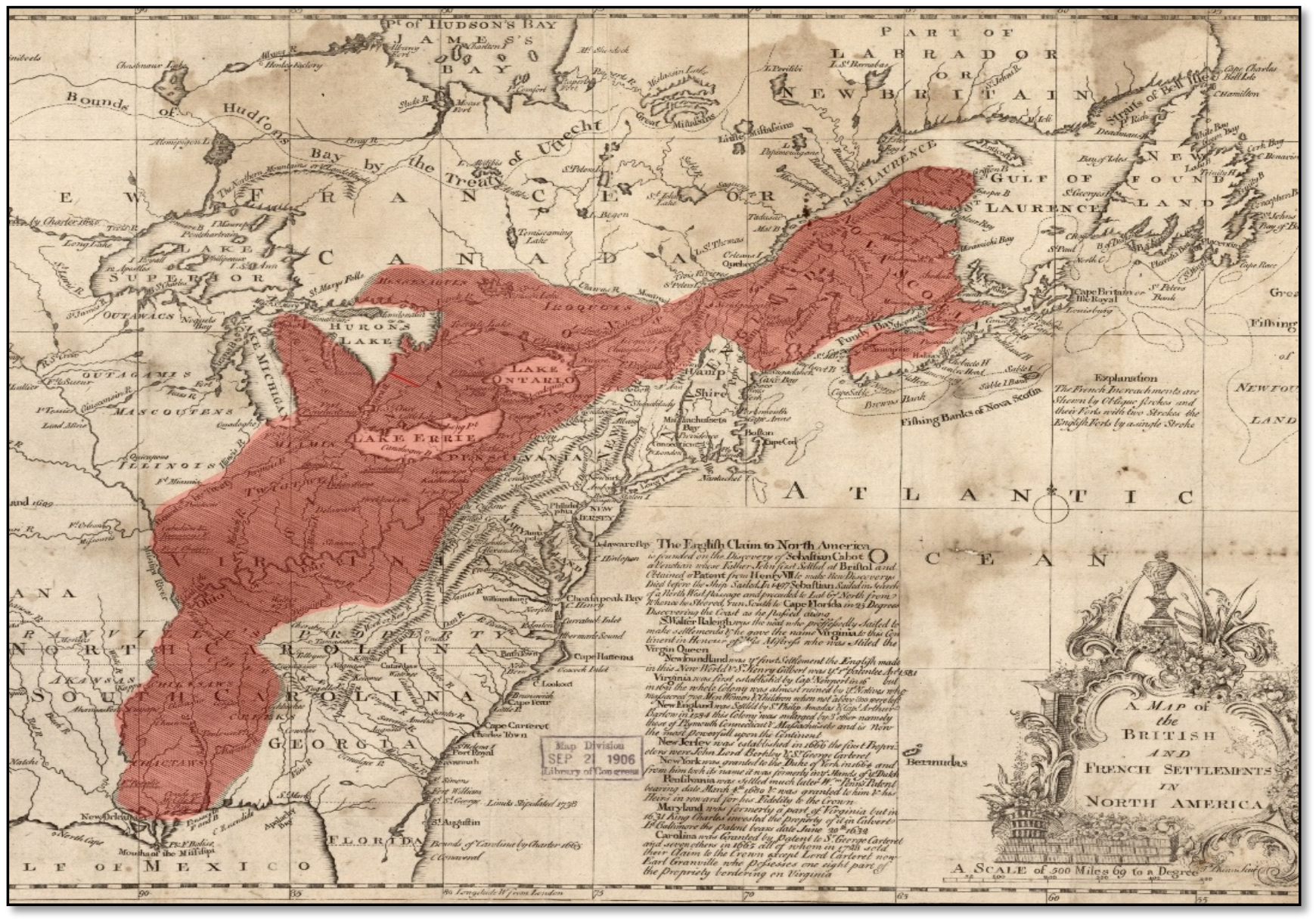

Figure 4.1: Map of the British and French Settlements of North America (1755) (Lodge) from the Library of Congress Map Collection (https://www.loc.gov/item/74693889/). A red overlay has been added to identify French territory which is generally bounded by the Appalachian Mountains. 


\section{Turner's frontier thesis}

The historiography of this early westward expansion comprises two primary schools of thought.

According to Turner (1893) the frontier movement was a continual process of conquering the

land as European settlers pushed further and further toward the west. In general, Turner and

later historians have depicted this westward movement as a boundary extending from north to

south that progressively moved from the eastern seaboard of the U.S. to the Appalachians to the

Ohio River Valley to the Mississippi and beyond. Turner believed that as settlers 'conquered'

the landscape and advanced the frontier westward, a sense of organization, civilization, and

democracy was instilled which became the foundation for a manifest destiny for the American

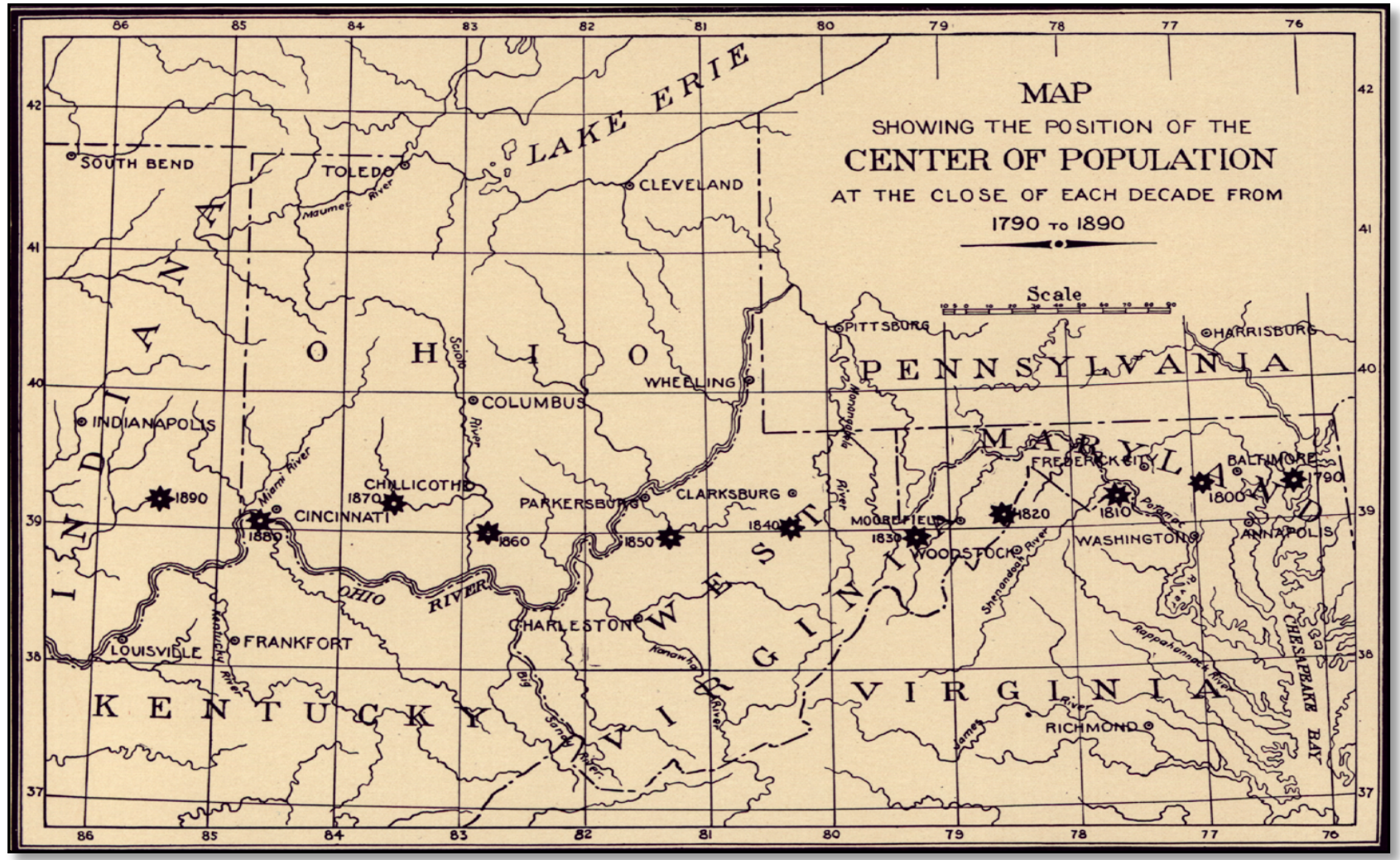

Figure 4.2: Map from the Statistical Atlas of the United States based on the Results of the Eleventh Census (1898) that illustrates the "center of population" at each decade. Note that Monongalia County is located in same area as the 1840 center of population designation. This map echoes the sentiment of the greater narrative that states that there was a westward movement rather than uneven or north to south development. (https://lccn.loc.gov/07019233) 
peoples. In his 1893 thesis, Turner announced that the frontier was closed and issued a warning that the United States could not continue its unfettered growth which had shaped the nation's identity to that point. Turner believed that the frontier was a "safety valve" whereby as long as it remained "open", then the American people had the means to relieve pressure in the eastern United States where population surges were greatly impacting economic growth and job availability. Turner asserted that the west was a “....region for hopeful restoration," and a place where economic stability could be restored.

A second school of what has become known as 'new' western historians have argued that the frontier was not simply a defined boundary but one that encompassed social constructions which defined the 'boundaries' at specific locations (Cronan, et. al., 1992; Limerick, et. al., 1991). In
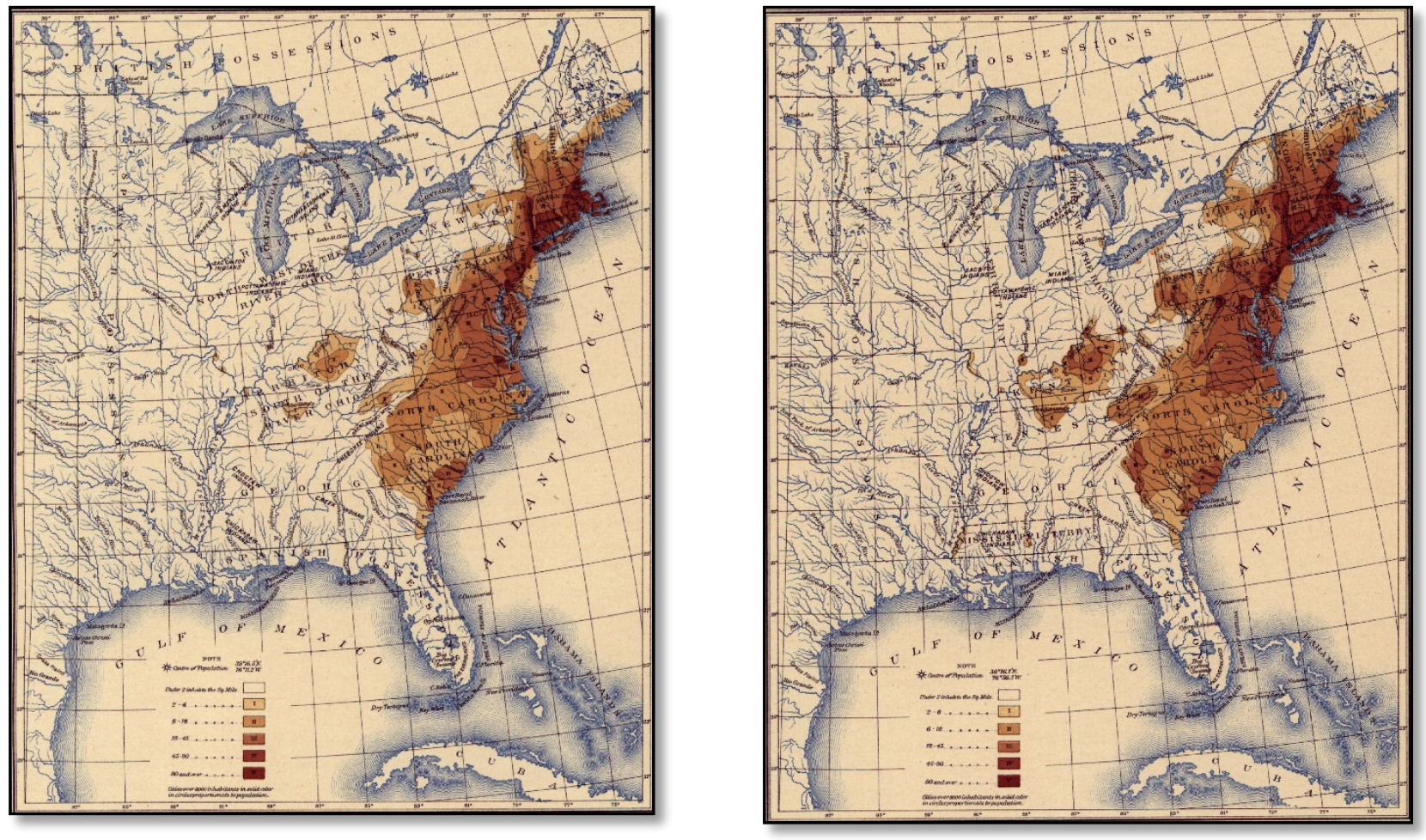

Figure 4.3: Maps from the Statistical Atlas of the United States based on the Results of the Eleventh Census (1898) that illustrates population densities in 1790 and 1800 (https://lccn.loc.gov/07019233)). 
proposing these social constructs of space, scholars interpret the frontier as a metaphorical place where several themes intersect.

The heavy emphasis on Turner's frontier movement is reflected in early writings of the $18^{\text {th }}$ and $19^{\text {th }}$ centuries and especially in available census maps which may have been contributary to the formation of Turner's thoughts on frontier formation. As geographers would suggest, the map fixes the gaze (Harris, 2015). This moving boundary can be seen on the 1890 census map displayed as a star on the map which purportedly showed the center of population in each

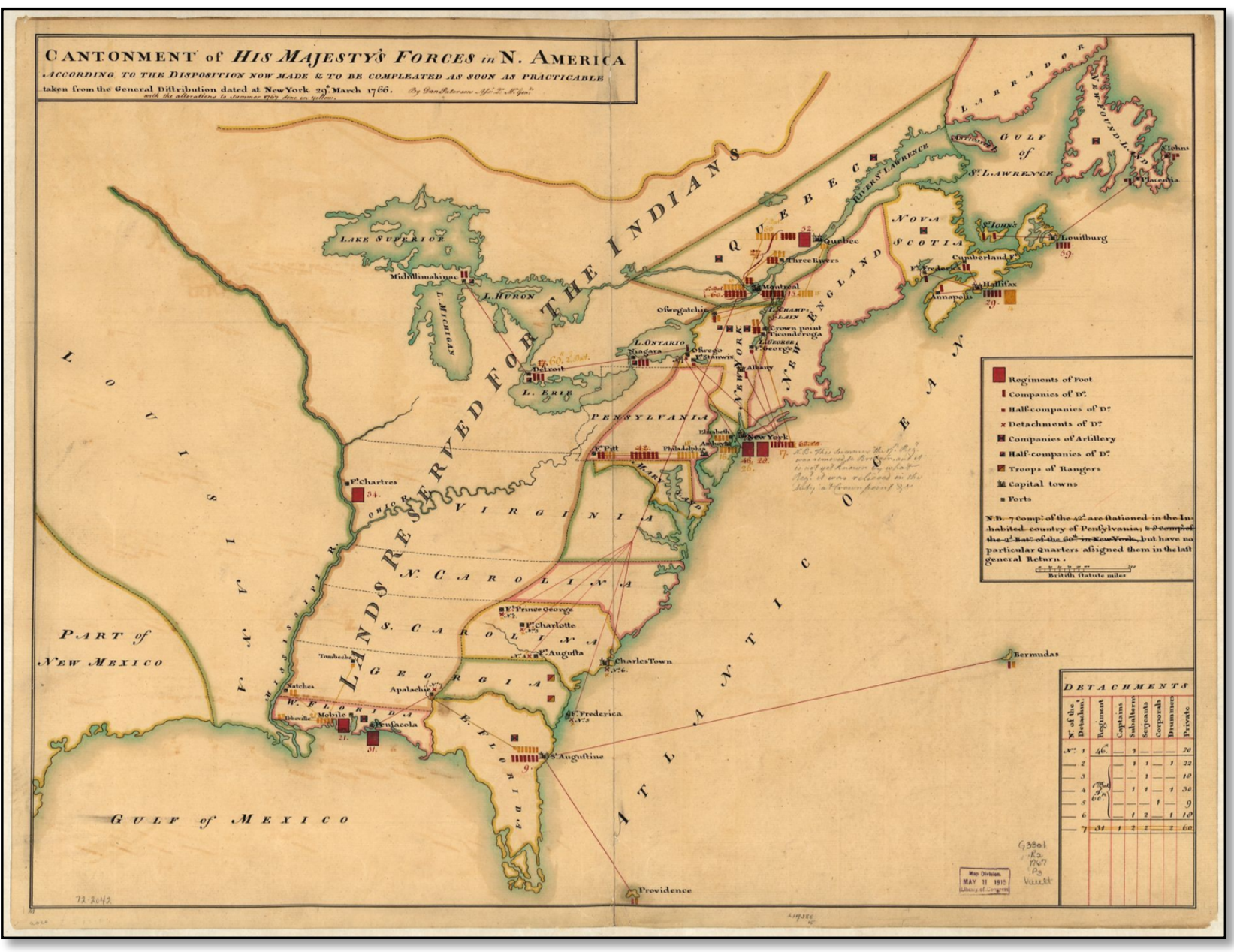

Figure 4.4: Cantonment of His Majesty's forces in N. America according to the disposition now made \& to be compleated as soon as practicable taken from the general distribution dated at New York 29th. March 1766. (Paterson, 1767). Accessed from Library of Congress Map Collection (https://lccn.loc.gov/gm72002042) 
decennial census from 1790 to 1890 (Figure 4.2). Maps published by the US census showing population densities display similar representations (Figures 4.3). Noteworthy, however, is the uneven pattern of population that appears to contradict Turner's implied progression of a uniform westward movement.

Even prior to the census, the British/American government made proclamations that declared the existence of a number of frontier boundaries based on both physical features (usually barriers to further westward movement) and political arrangements that essentially divided the continental America into 'east' and 'west'. Thus, a 1766 map issued by the British and entitled Cantonment of His Majesty's forces in N. America according to the disposition now made \& to be compleated as soon as practicable taken from the general distribution dated at New York 29th. March 1766, was created to quell conflicts with hostile indigenous populations that were

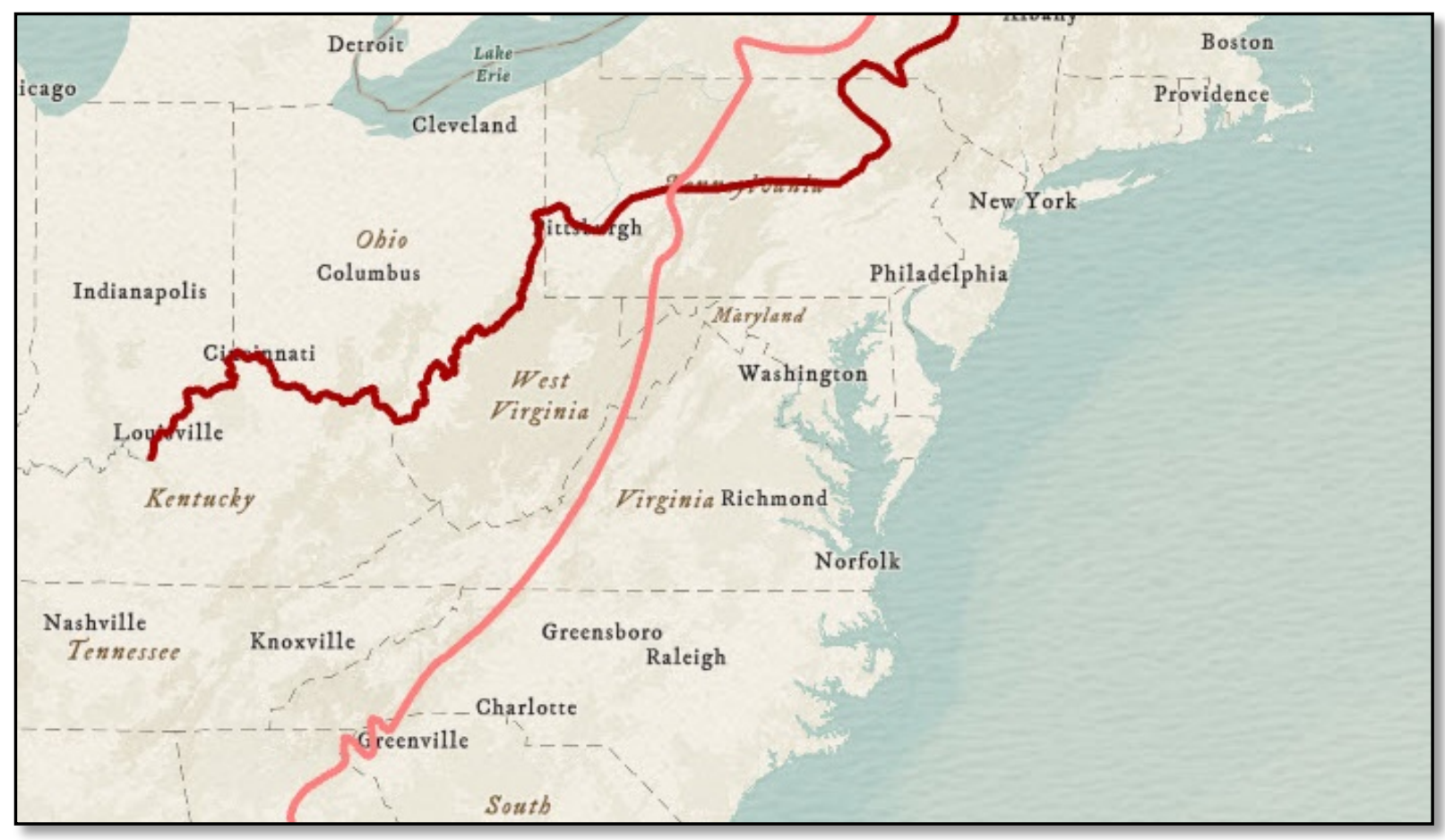

Figure 4.5: Map of the Proclamation line in 1763 (pink) and the boundary line created by the Treaty of Fort Stanwix in 1768 (red). 
becoming increasingly violent in reaction to the continual encroachment on their homelands (Figure 4.4).

The 1766 map was derived from the Proclamation of 1763 and depicts the frontier as passing through then northcentral Virginia and southwestern Pennsylvania. It was this map that set a precedent as an official designation of the north-south frontier and what was 'east' and what was 'west'. The map shaped how the government would relate to the frontier for another century. It was the census frontier maps, however, that were a key component underlying Turner's frontier thesis. These boundaries appeared to lack any uncertainty to indicate a fuzzy boundary line. One outcome of this dissertation and the deep mapping exercise is to provide evidence that appears to contradict this traditional Turnerian narrative.

In 1768, the Treaty of Fort Stanwix pushed the proclamation frontier line even further west to the Ohio River, thereby including southwestern Pennsylvania and then northwestern Virginia as undergoing European settlement (Figure 4.5). A growing number of violent confrontations between settlers and indigenous people required the British Government to continually redefine the western boundary of the colonies in order to keep a modicum of control in the region. 


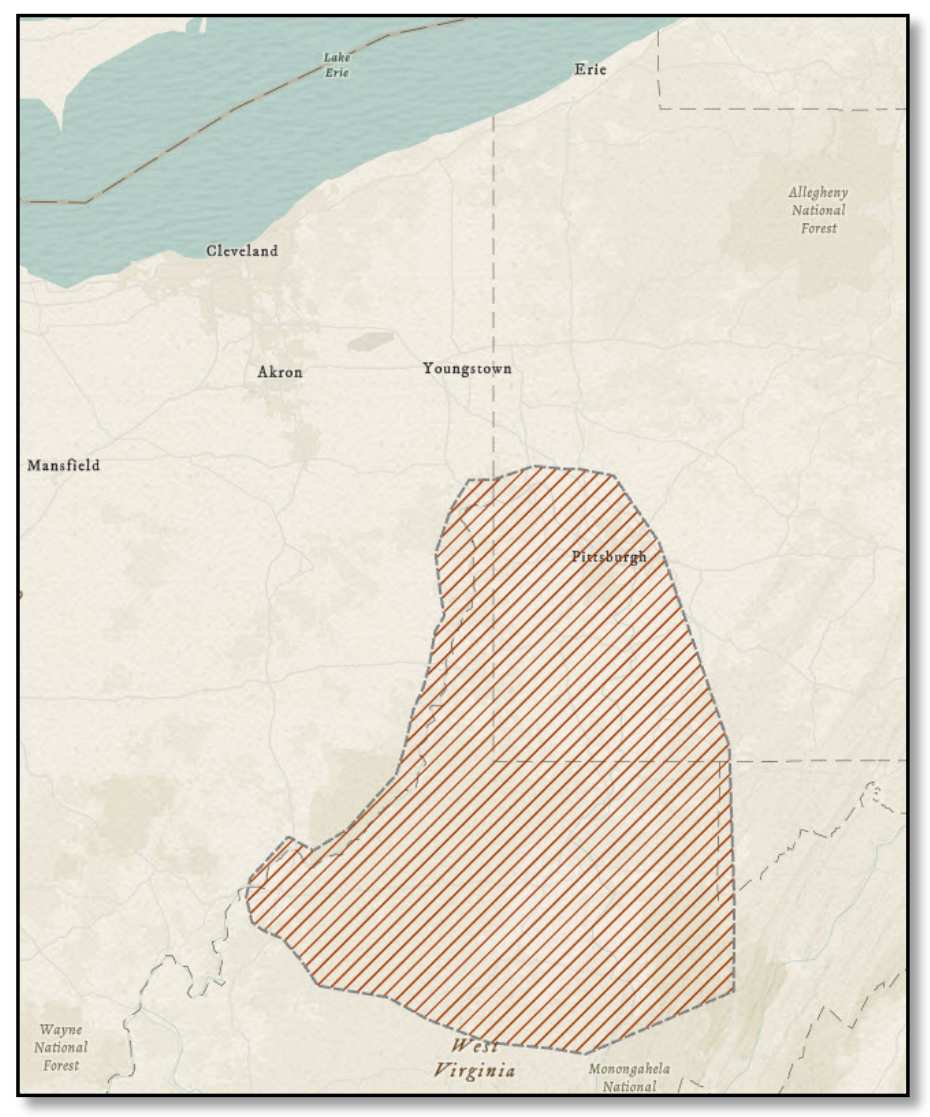

Figure 4.6: The study area for the Deep Map study

\section{The study area}

Generally, the study area lies in the present day north central West Virginia (then Virginia), southwestern Pennsylvania, and the eastern part of the Ohio Valley Region (Figure 4.6). Specifically, the study area is centered on the then Monongalia County, Virginia and its immediately surrounding areas (Figure 4.7). The study area was selected based on a number of factors, including its centrality to the frontier movement and access to archival resources. The Appalachian Mountains, in part, form the eastern boundary of the study area which, according to the British in 1763, were a major geographical barrier that prohibited passage to "Lands Reserved for the Indians" (Figure 4.4). The easternmost Appalachian Mountains essentially formed the first official 'frontier line' and the barrier through which settlers had to pass to gain access to lands to the west and the Appalachians serve as a fitting eastern boundary for the study area. 


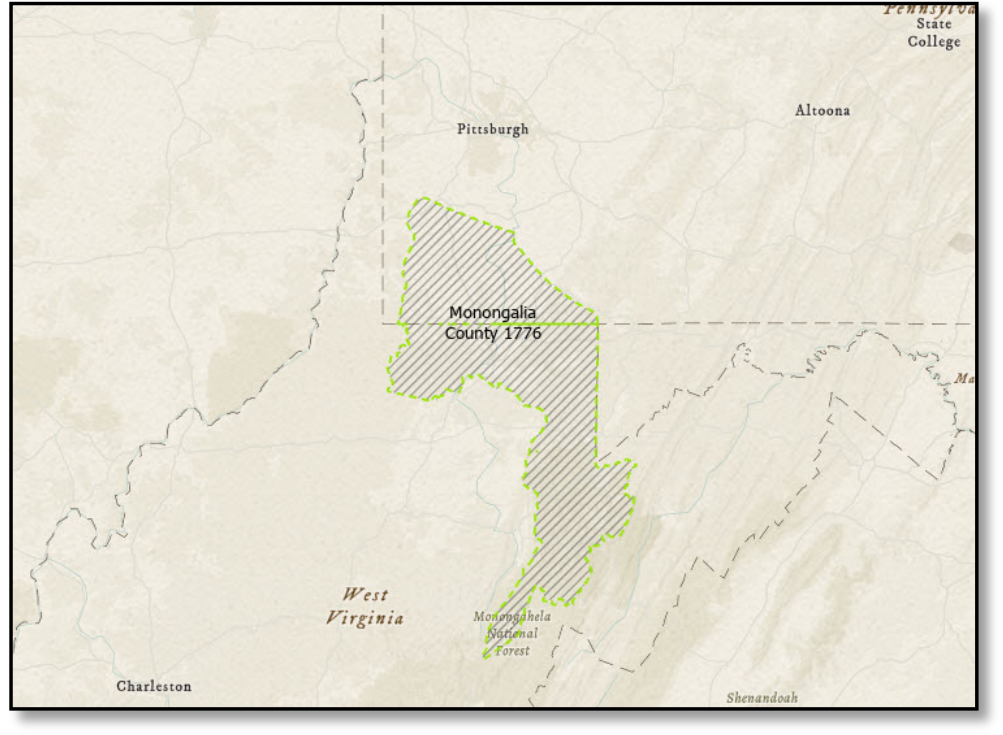

Figure 4.7: Map of Monongalia County in 1776
The northern and western boundaries of the study area were determined based on the major transportation routes of the eighteenth century that provided access through the study area to the interior of North America. Primary access into and through the study area was initially by waterways or indigenous trails that ultimately

gave access to the waterways (see figure 4.8). Early in the $18^{\text {th }}$ century, the French accessed the area via Lake Erie from the north down to as far as Fort Duquesne and the Ohio River. The Ohio River was a primary artery for Europeans in that it gave access ultimately to the Mississippi and to the Gulf of Mexico. There were two major access points to the Ohio River for the British. The northern waterway passage consisted of navigating the Potomac as far as Cumberland (Fort Cumberland) and thereafter connecting to the Monongahela River and to Fort Duquesne (Fort Pitt) where it meets the Ohio. The southern route, partially discovered by Batts and Fallom (1671), crossed the Appalachian Mountains and then followed the New River. Although Batts and Fallom did not traverse the whole distance to the Ohio River, later travelers gained access through a similar route and then followed the Little Kanawha River to the Ohio River. The Ohio River would eventually form another 'frontier' as both a literal and symbolic gateway to the west. The Ohio River thus serves as the western boundary for the study area.

The northern boundary of the study area was heavily influenced by the strategic location of Fort Duquesne at the mouths of the Ohio, Monongahela, and Allegheny rivers. Fort Duquesne, built 
in 1754, later to become known as Fort Pitt, became an early point of military control in the

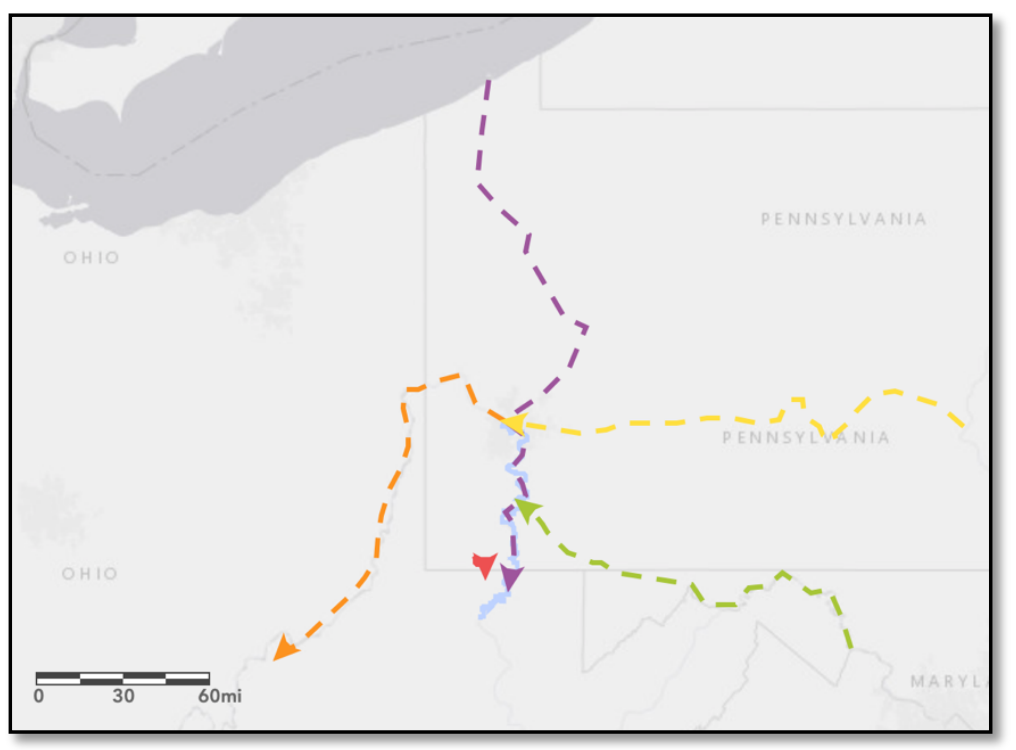

Figure 4.8: Map of main openings to the interior and Monongalia County. Forbes path is in yellow, purple is a water access path from Lake Erie down to the Ohio River and then to the Monongahela, green is Nemocolins Path, orange is the Ohio River and red is a section of the Catawba Path that went north to south though Pennsylvania, Virginia, Tennessee, North Carolina and South Carolina region and was hotly contested between the British and the French . Not only did it provide access to the three rivers but was also the terminus of Braddock's Road, which ran east to west through Pennsylvania. Braddock’s Road (Figure 4.9) followed the already established indigenous paths, the Wilderness Road and Nemocolin's Trail. The Wilderness Road followed parts of Nemocolin's Trail and connected Fort Cumberland with Brownsville, Pennsylvania, which sits alongside the Monongahela River. In 1749-50, the Ohio Company and Christopher Gist along with George Washington, improved and widened a wagon road along Nemocolin's Trail, to create aa overland passageway from the Potomac River to the Monongahela River. While a portion of the military road followed Chief Nemocolin's Trail, at a point around present day Uniontown, the road veered north to Fort Duquesne and the Ohio River, with the sole purpose of gaining control of the French fort for the British. In addition to Braddock's Road, Forbes Road, built in 1758 and named after General Forbes who captured Fort Duquesne, ran further north and provided access to Fort Pitt from Carlisle, 


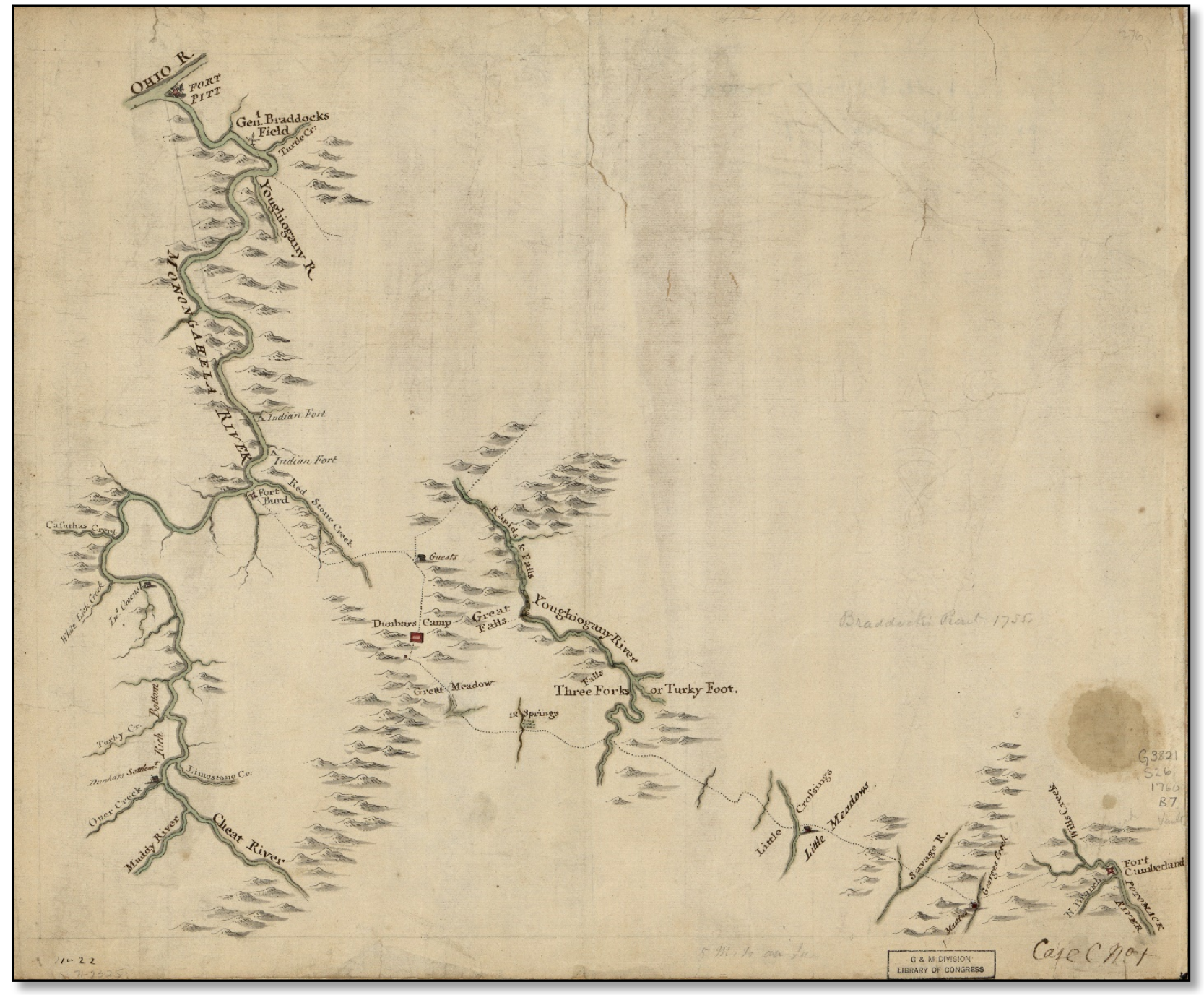

Figure 4.9: [Braddock's route, 1755, Fort Cumberland to Fort Pitt. (1760). Sketch from the Library of Congress map collection showing major land formations along Braddock's Road. (https://lccn.loc.gov/gm71002325)

Pennsylvania. The two routes were the main thruways for the British to traverse the Allegheny Mountains and Appalachian territory to reach the Ohio River.

In addition to the Wilderness Road and Nemocolin's Trail, there were a number of other indigenous trails that were used by European settlers and became the basis of the transportation network that emerged in the study area. One of the more significant trails nearest to Morgantown was the Catawba Trail or Seneca War Path. The Catawba Trail, "...which, like a 
modern grand railroad, [was] served by branches and turn-outs. After receiving the Warrior Branch junction, it kept on through land late of Charles Griffin, by Long's Mill, Ashcraft's Fort, Philip Rogers' (now Alfred Stewart's), the Diamond Spring, (now William James') ; thence nearly on the route of the present Morgantown road, until it came to the Misses Hadden's ; then across Hellen's fields, passing near the Rev. William Brownfield's mansion...” (Veech, 1858: 25) The trail was not used as a primary access to the Ohio River Valley, although it went through Morgantown where it accessed the Monongahela River which flowed north to join the Allegheny and form the Ohio River. The Catawba Trail followed a north-south axis and made its way from New York through northcentral Virginia and thence south to the Carolinas.

The southern boundary of the study area approximately follows the path of what would be the Northwestern Turnpike from Winchester to Parkersburg, completed around 1820. Fittingly, Winchester fixes the easternmost access point here to the Appalachian Mountain, while Parkersburg fixes the then frontier as it reached the Ohio River. The Northwestern Turnpike was a critical artery in the transportation network during the early to mid- $19^{\text {th }}$ century and frames the southern part of the study area.

As sparse settlements developed into towns in the early $19^{\text {th }}$ century, the road networks were densified to bypass waterway obstacles further opened up the region with the Smithfield Road to Fishing Creek, the road to Clarksburg, and significantly the National Road. The Smithfield 
Road, also known as Morgantown Road

(Figure 4.10) provided access from

Morgantown to Pennsylvania and thence to

the National Road. "We represent to the

Legislature that there is no road, leading

from any part of this county [Morgantown]

to intersect the National road or to any

market town that a carriage can pass with

safety over or can carry three fourths of a

load and such must be the case for a great

many years.... we are ajijed (sic) by the

Legislature....In a country uneven, broken

and rugged and thinly populated it cannot

be affected, that any road can be made

barely pasable (sic) under our present made

laws" (Legislative Petitions of the General

Assembly, 1776-1865, Accession Number

36121, Box 335, Folder 19). The National

Road was laid out primarily along

Braddock's Road (as far as Uniontown) and

Chief Nemacolin's Trail, though the

topography, the desire to connect

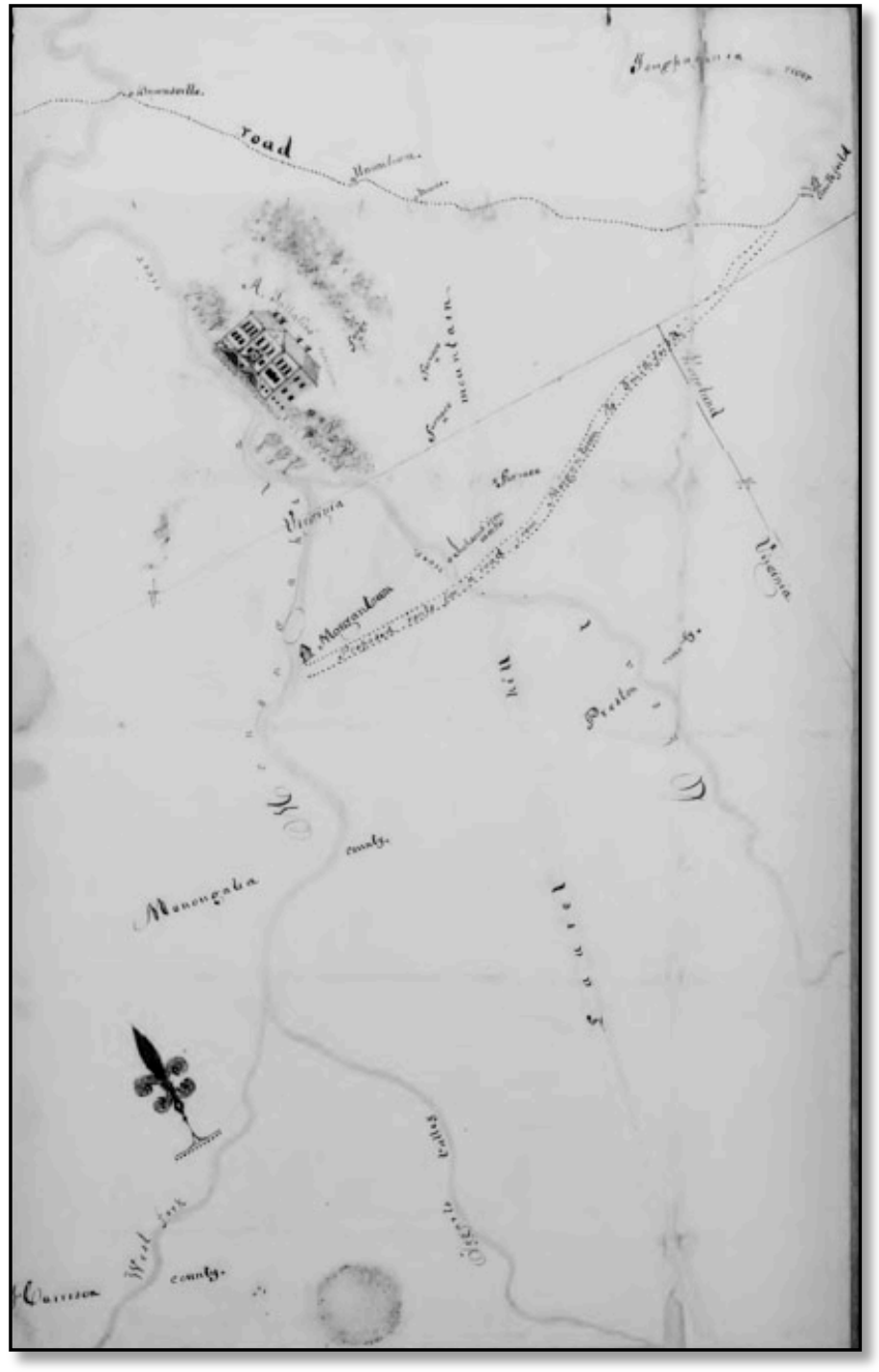

Figure 4.10: Legislative Petitions of the General Assembly, 1776-1865, Accession Number 36121, Box 335, Folder 19 (1825). Map from a petition to build a road to Smithfield, PA which was proposed to provide access to the National Road. (http://digitool1.lva.lib.va.us:1801/view/action/singl eViewer.do?dvs $=1626649190757 \sim 890 \&$ \&locale $=$ en_U S\&show_metadata $=$ true\&VIEWER_URL $=/$ view/ac tion/singleViewer.do?\&DELIVERY_RULE_ID $=4$ \& 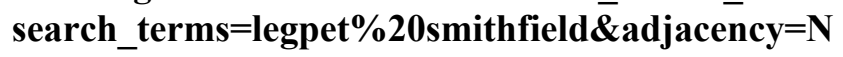 \&application=DIGITOOL$3 \&$ frameId=1\&usePid1=true\&usePid2=true) 
settlements en route, and political maneuvering influenced local deviations.

Gaining access to the National Road, and a few years later, the Northwestern Turnpike, provided considerable impetus for population and settlement growth in the region and the development of new political, economic and social networks. Political and social relationships were important factors in the routing of both thoroughfares, bypassing Morgantown in favor of Wheeling and Parkersburg. Wheeling became the gateway to the west and an industrial powerhouse during the mid to late nineteenth century. The failure of Morgantown to obtain the rights for either route exemplifies just how significant were the political and social networks in the economic development of the area.

This region thus provides a case study to examine the frontier movement through the application of a deep mapping exercise. In the process the deep map will emphasis not solely the macro factors outlined here but the micro histories that expose the inherent contingency existing between macro and micro scale historical events and $18^{\text {th }}$ century settlement patterns. 


\section{Chapter 5 | Prelude to deep mapping}

This dissertation seeks to advance both the concepts and methodology of deep mapping and this is undertaken using Turner's frontier thesis as a case study. Much as the events and history of the battle of the Alamo in 1836 as written by nineteenth century U.S. historians has become folklore and yet has now largely been disproved as egregiously erroneous (Burrough and Stanford, 2021), so too has Turner's frontier thesis been accepted as the primary explanation of U.S. westward for over a century and yet is now being progressively dismantled amongst a fierce post-colonial reexamination of the frontier movement(Limerick, 1987; White, 1991; Milner et al., 1997). Turner's study is used here as a vehicle with which to explore a deep mapping approach to a historical theme and in the process develop a methodology that enables both quantitative spatial data and qualitative placial information to be combined in an innovative and dynamic platform with the intent to examine what additional insight, if any, might be added to the frontier thesis. The ultimate goal is to develop a prototype deep map that pushes the boundaries of both history and geography by examining the interdependent relationship between space and time during a critical period in American history. The study 'drills down' through multiple levels to examine events, each deeply contingent on each other, and in the process seeks to reveal any subtle gradations in the story that reveal more than the universal claims of the frontier story. In particular, the study windows in on the story of the Martin family who lived in Monongalia County around 1800 and their slave, Littleton. The Martin family was one of the first to settle in the area and their micro history supplements and augments the accepted macro narrative of Turner. 


\section{Building a deep map: source materials and historical GIS}

The study builds on primary historical sources obtained from local, regional, and national archives, including maps, travel guides and surveys, as well as secondary sources and historical accounts of present day north-central West Virginia and southwestern Pennsylvania. Initially, comprehensive and exhaustive historical accounts such as Core's (1977) five volume Monongalia Story and Wiley's (1883) History of Monongalia County, West Virginia, from its first settlements to the present time were consulted to develop elements of the historical narrative and identify primary sources. In utilizing these secondary sources, relevant travel diaries, period maps, personal accounts, military documents and land records were consulted. These primary sources were integral to piecing together the historical and geographical narrative of the $18^{\text {th }}$ century and early $19^{\text {th }}$ centuries. Building on the primary sources and secondary accounts a comprehensive historiography was created. Where possible, locational information was identified and assigned to the information garnered from written texts, traveler's diaries, surveys, military accounts, court records and land grants. Extensive searches were made for maps created during this time period and which almost all corresponded with early European contact in the study area with very little referencing native American peoples. Maps created by prominent travelers, the military, surveyors, and land companies archived in the Library of Congress (https://www.loc.gov/collections/?fa=original-format:map) (Accessed 7/15/2021), the West Virginia Regional History Collection, and the Virginia State Archives were examined along with online map collections such as the David Rumsey Collection (https://www.davidrumsey.com/) (Accessed 7/15/2021). Additional spatial information was garnered from place names, the construction of forts, landscape descriptions and topographical elements such as rivers, bluffs, 
valleys and passageways, and these were geographically linked to period maps and other relevant sources.

Based on these source materials a tentative chronology and geography were established and a database was constructed. While a historical GIS, or even a cartographic map, is arguably not a necessity for a deep map, in this study GIS was utilized early on to manage the spatial data layers ready for subsequent inclusion within the deep map. Despite the concern about traditional cartographic maps as being thin maps, nonetheless space contextualizes place and is an essential component to this deep mapping exercise. Accordingly, what might be called an historical GIS (to distinguish it from the deep map) was created based on the data collected from the primary and secondary sources. In reality as a GIS practitioner this was a GIS that was established which in this case happens to contain historical data. Indeed, one ironic challenge to establishing an historical GIS was how to include the temporal dimension. Spatial data was ingested into the GIS and topologically encoded.

Initially a schema and geodatabase with feature classes was established that included roadways and trail routes, administrative boundaries, waterways, forts, and settlements. Attribute information containing names, dates, people, armed conflicts, and other pertinent information was included. The Historical GIS was an important first step to capture spatial data and visualize maps and their spatial relationships. Travel networks such as trails and rivers, forts, towns and cities, as well as various boundaries were represented as layers with associated attribute data, such as dates, feature names, and people. At the present time this is the extent to which GIS has been incorporated within most historical studies.

Maps from the Library of Congress, the Virginia State Archives, the West Virginia Regional and Local History Collection and the West Virginia State Archives, as well as survey and travel 
materials were digitally formatted and integrated within the GIS multiple layers categorized by year were created. Administrative boundaries were digitally captured through the georeferencing and digitizing of period maps and an examination of the historical records of travelers, surveyors and government officials (Table 5.1). State boundary layers obtained through the National Historical GIS website (https://www.nhgis.org/ (Accessed 7/15/2021) and as laid out by the official governing bodies at the time were also included. These boundary layers give context to how the administrative boundaries changed over time and their relationship to each other. The boundaries of Turner's hypothetical western movement were also captured and included and the link to 'official' administrative maps can be seen following significant events on the frontier. Thus, as increasing unrest transpired between indigenous peoples and European settlers, so the western boundary was pushed further west by the Proclamation of 1763, for example, although squatters were already infiltrating and settling many of these frontier lands in advance of official acknowledgement and sanction.

\begin{tabular}{|l|l|l|}
\hline Historical GIS Geodatabase & & \\
\hline Layer & Year & Source \\
\hline WestBoundsAppalachianMtns_1730 & 1730 & Digitized from USGS Topo Map \\
\hline WestBoundsProc_1763 & 1763 & Digitized from period maps \\
\hline WestBoundsStanwix_1768 & 1768 & Digitized from period maps \\
\hline StateBoundCensus_1790 & 1790 & Data from NHGIS \\
\hline StateBoundsCensus_1800 & 1800 & Data from NHGIS \\
\hline StateBoundsCensus_1810 & 1810 & Data from NHGIS \\
\hline StateBoundsCensus_1820 & 1820 & Data from NHGIS \\
\hline CountyBoundsMon_1776 & 1776 & Data from Earl Core Monongalia Story \\
\hline CountyBoundsMon_1779 & 1779 & Data from Earl Core Monongalia Story \\
\hline CountyBoundsMon_1800 & 1800 & Data from NHGIS \\
\hline
\end{tabular}

Table 5.1: Boundary files created for the Historical GIS 
A major obstacle to capturing administrative boundary information was the availability of data.

Official state boundaries originate from the 1790 census, some fourteen years after the formation of Monongalia County and decades after the establishment of forts and settlement in the area. Thereafter, boundary information is only available at ten-year intervals in line with the national population census. County boundary details were similarly constrained but were available at smaller time intervals and archived thanks to the sketches of Earl Core and early surveyors. However, these maps are approximate at best and when georeferencing according to modern cartesian systems this factor must be borne in mind.

In addition to boundary information, infrastructure and natural features were also included because they were central to the frontier movement and especially the waterways. Political, cultural and economic relationships, and even race played an important part in the development of road networks and other developing infrastructure, particularly after the turn of the $18^{\text {th }}$ century for some with the appropriate political connections could influence where roads were built, how land was developed, and who lived in certain areas. As with other historical data ingested into the GIS, the spatial description of many features was obtained from contemporary textual descriptions, often made by early surveyors and travelers, and period maps which were invariably hand drawn. Thus, even when georeferencing maps based on geographic feature control points, the exact locations might still be questionable. Even the routes of roadways and trails can change over time such that the exact route of even a major historical route such as Braddock's Road that follows modern Route 40 may only now still be approximate. Some information, however, such as rivers or major geological features such as Sky Rock in Morgantown, can generally be considered as more accurate. 
The first forts in the region began to appear in the early to mid- $18^{\text {th }}$ century and are critical frontier markers since they were rapidly followed by westward settlement. The location of these were often in areas seen to be desirable in terms of defense, settlement, trade, or survival on the frontier. Forts were the first symbol of a 'conquered' land, and a semi-permanent indication that European settlers were indeed moving westward. Subsequently the creation of forts helped establish stability albeit to a continually moving frontier. Defensive structures consisted of one or more categories as a fort, stockade, or blockhouse (Cook, 1940: 1-2). Stockades generally consisted of a log structure surrounded by a palisade or wooden stake fence that could accommodate several families. A blockhouse was a single structure with rifle embrasures, while forts were generally garrisoned and often commissioned by the General Council. Forts and stockades provided a haven from assault on the frontier and often became the location of subsequent settlement that huddled around it. According to Veech $(1892,21-22)$, forts “...consisted of a greater or less space of land, enclosed on all sides by high log parapets, or stockades and cabins adapted to the abode of families. The only external openings were a large puncheon gate and small port-holes among the logs, through which the unerring rifle of the settler could be pointed against the assailants...these erections were of rough logs, covered with clap-boards and weight poles, the roofs sloping inwards...." 


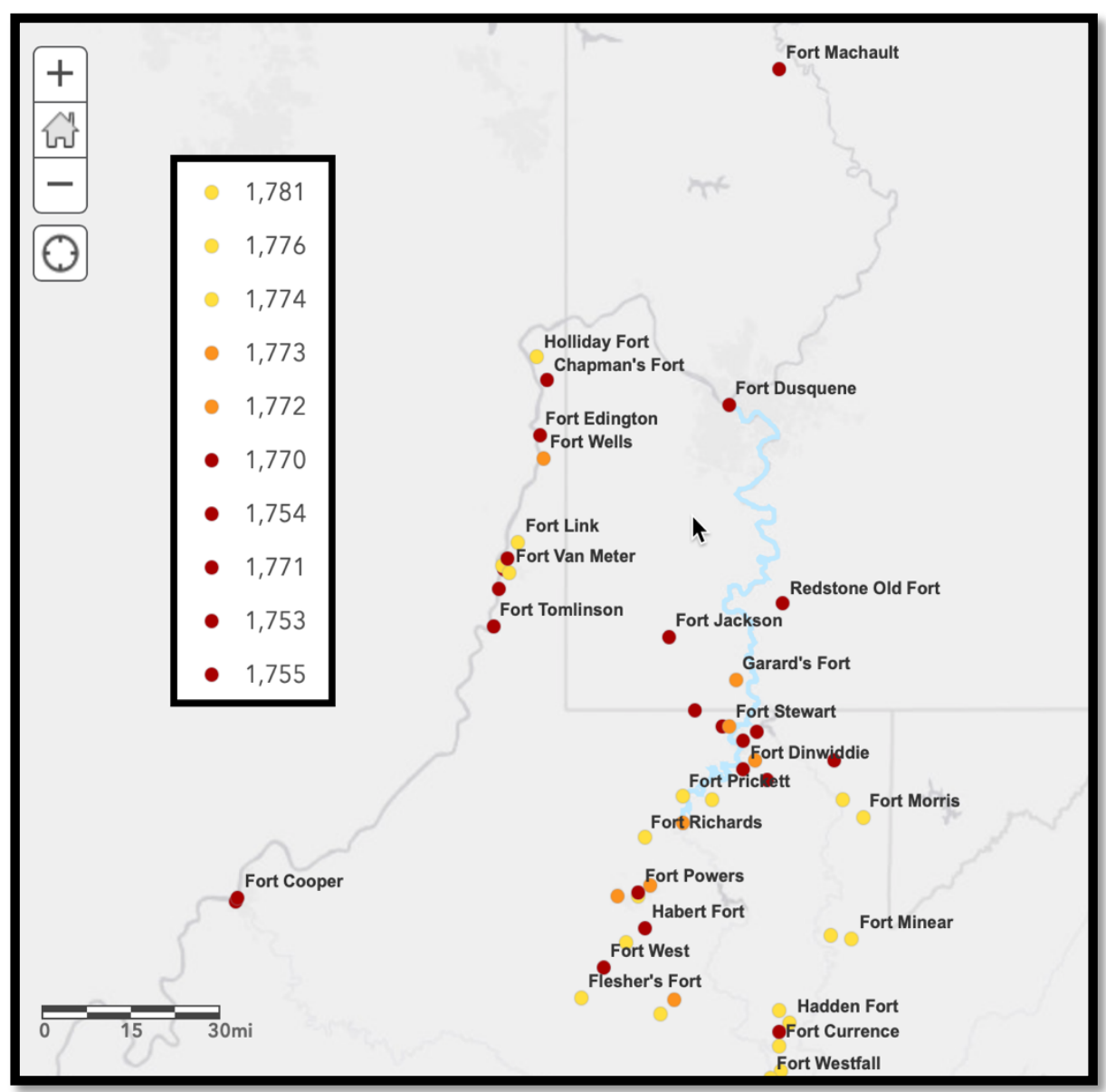

Figure 5.1: Forts constructed within the study area. The earliest local fort was Fort Pierpont in 1769. Source: Core (1974)
The earliest fort

erected in Monongalia

County was Fort

Pierpont in 1769 and a

series of forts

followed soon after

(Figure 5.1). The

locations of many of

these defensive

structures have been

determined based on

archaeological

evidence and

some remain approximate to within a mile or so. Many forts were demolished long before accurate mapping existed and therefore much of the data is sourced from hand drawn maps and descriptive texts and georeferenced according to proximity to prominent features such as the Mason-Dixon line and the Ohio River. While forts are representative of first contact, European settlements initially could thrive or failed depending on their proximity to these forts. An area well defended with a favorable topography would provide not only protection but would also attract infrastructure such as roads because access to neighboring settlements had the best chance of survival and could support trade and supplies routes. Early settlements in what was then northwestern Virginia, southwestern Pennsylvania and the Ohio Valley thrived because of 


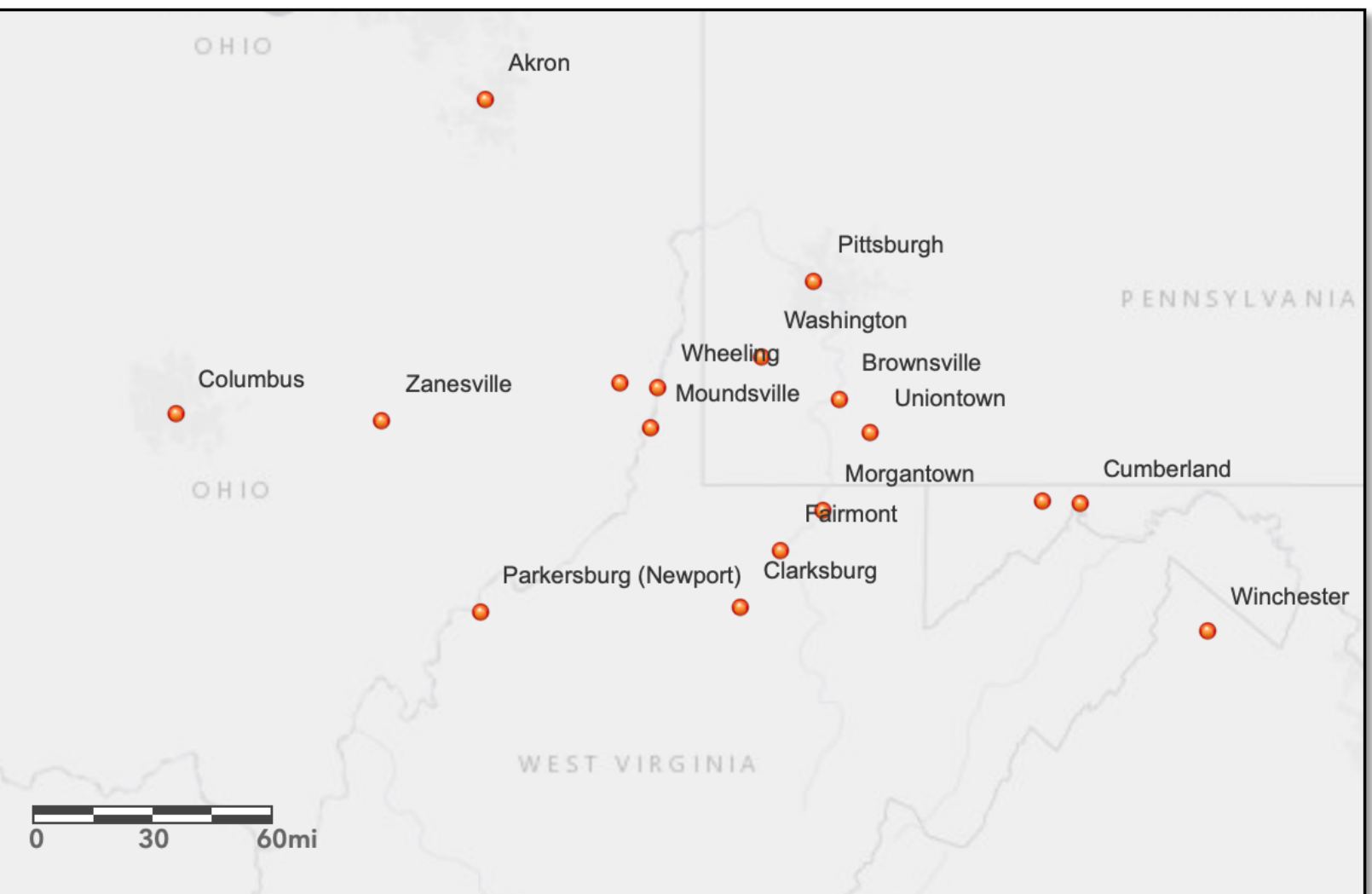

Figure 5.2: Settlements in the study area

natural advantages in the landscape that could be exploited for roads or water transportation or because of relationships built between European settlers and Native Americans. Thus, early settlements were established in Wheeling (1769) and Aliquippa or Logstown (1770) because of their proximity to the Ohio River or to Fort Pitt (Figure 5.2).

Where appropriate GIS can handle spatial historical data within Euclidean space such that forts or towns and the physical materiality of society can be mapped; other information must be handled by fixed attributes and static fields. The Historical GIS is a series of static maps telling a spatial story. Much of the information and spatial stories that might explain the 'why' as well as the 'where' remains largely exogenous to the system in the archived qualitative materials. The degree of interaction between user and the system is limited, especially if a non-expert. 
While interactive advances in GIS software are enabling some interaction such as brushing and linking this is still limited and the data is essentially presented and displayed as the author categorized and envisioned it. The GIS is essential to the deep map in this dissertation, but it seeks to push and extend the GIS capability to provide an interactive and holistic exploratory system.

It is challenging to weave primary and secondary source data into a spatio-temporal narrative that represents the symbiotic relationship between space, place and time. The way in which the data is organized in the database is critical to understanding how places and people relate to each other both temporally and spatially. In addition, analyzing contemporaneous events at multiple scales intensifies the complexity of the narrative for details and nuances not seen at one scale might be revealed at another. To contextualize some of the themes, memes, events, people, and places in readiness for constructing the APIs and the deep map a Mind Map was constructed 


\section{Organizing source materials through mind mapping}

Given the myriad sources, data, themes, events and ideas it is necessary to use some form of organizing framework with which to address these and in order to help structure the deep map. Merely throwing all the data together may provide one approach but such 'fishing expeditions' go only so far in getting at the structure of the questions under study. The idea of Mind Mapping is generally attributed to Tony Buzan, an English author, and proponent of a visualization technique based on psychology and neuroscience that organizes thoughts in a similar way that the human brain does. According to Brandner (2015), a blogger with the Creativity and Productivity Blog for Mindmeister, a leading mind mapping software company, mind maps are "graphical representations of information" (https://www.mindmeister.com/blog/why-mindmapping/) (Accessed 7/15/2021). A mind map begins as a blank canvas where thoughts,

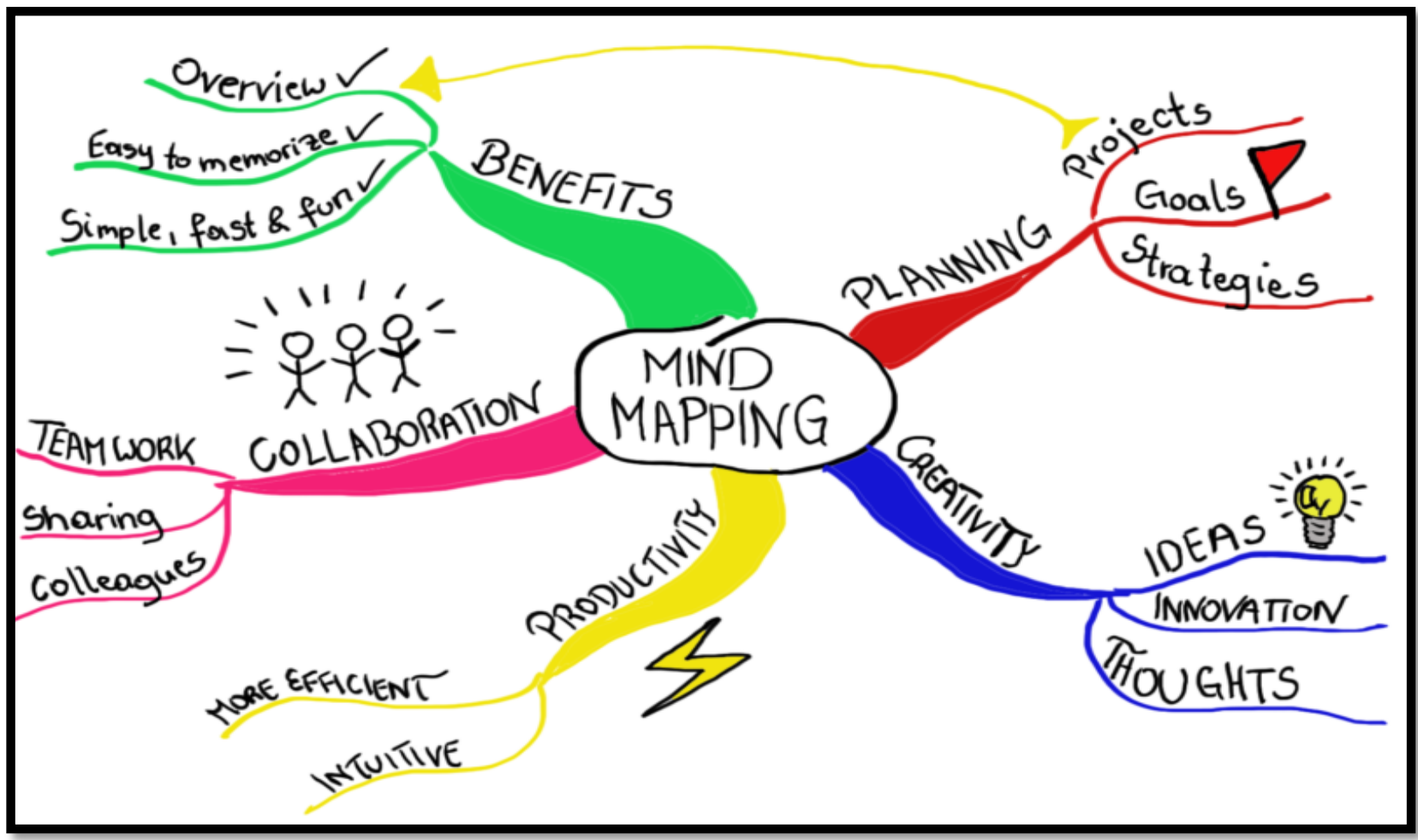

Figure 5.3: Example of Mind Map (Brandner, 2015). (https://www.mindmeister.com/blog/whymind-mapping/) 
keywords or relevant ideas are added and connected. Once the main tenets are recorded, the researcher can 'branch' each component with related ideas so as to create connections and reveal primary themes and relationships that can be visualized. Mind maps, according to Brandner (2015) have five components: a central image to stimulate memory, associations and thought processes; curvilinear branches that emanate from the central image and depict the basic ordering ideas (BOI); networks of smaller branches that depict ideas stemming from the BOI at different levels of detail; the conscious use of color to separate ideas by topic; and a single keyword for each branch (Figure 5.3).

Mind maps can be created through a stream of consciousness with paper and pen and/or within mind mapping software. Utilizing software tends to be cleaner but more rigid and structured. Figure 5.4 depicts a mind map sketched to explore how the life of a slave named Littleton in this study was connected to his community and how themes of race, culture, familial and social connections emerge as a part of his story. Mind mapping became a valuable tool in this study as

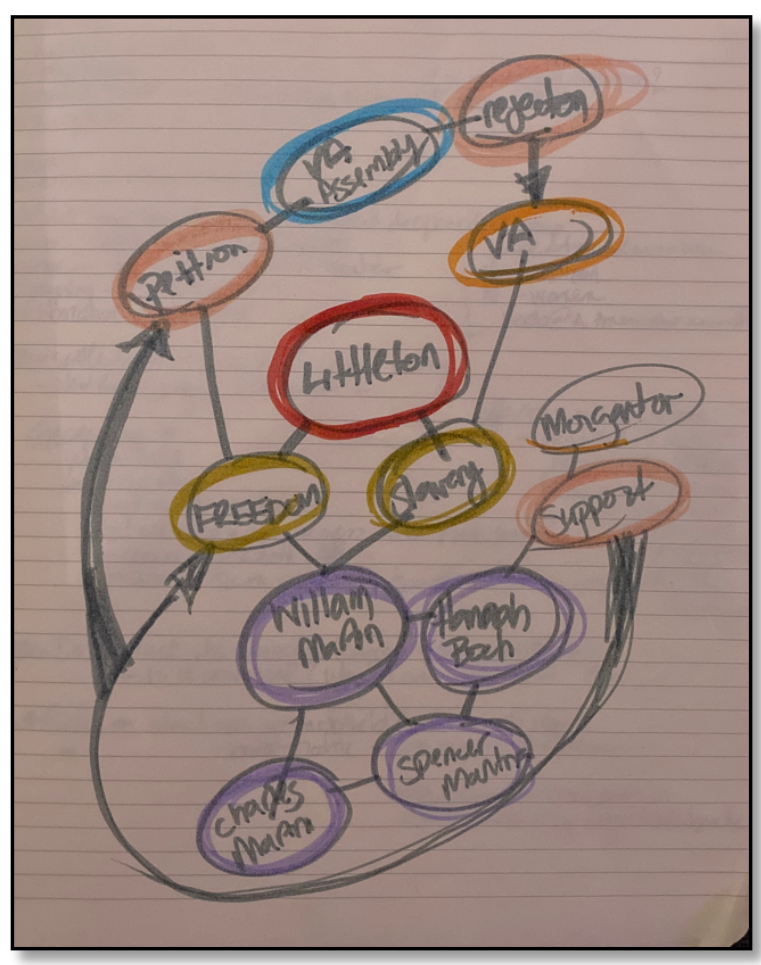

Figure 5.4: Mind Map sketch of the slave Littleton

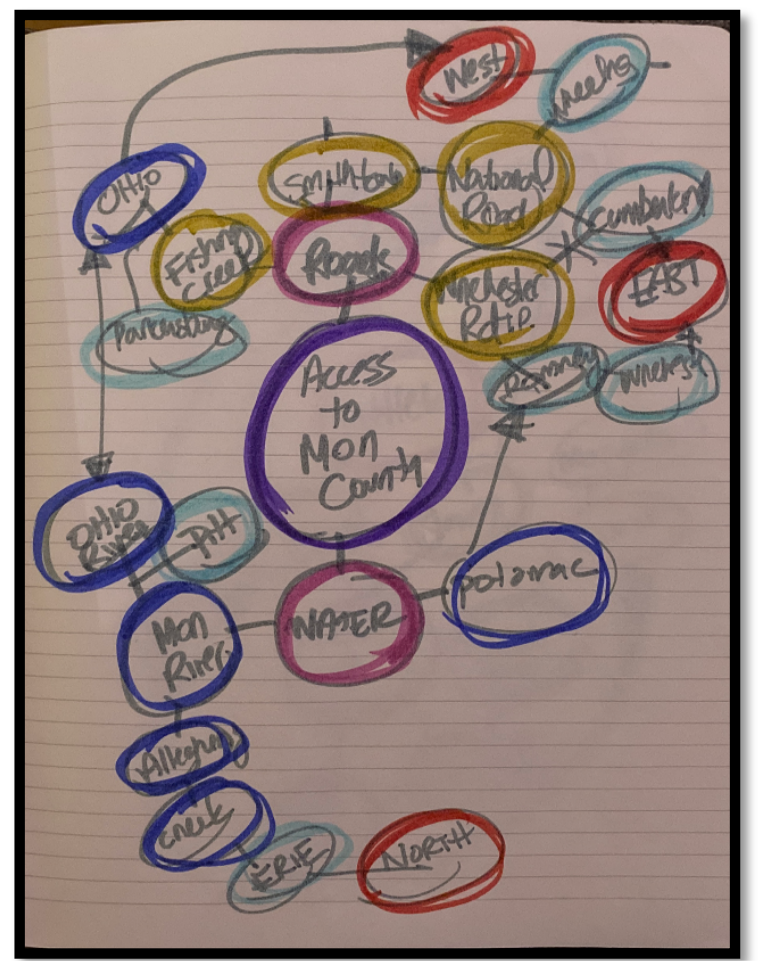

Figure 5.5: Mind Map sketch of the major openings to the interior of North America. 
a means of visually organizing ideas and themes, data, which then informed the framework and content of the deep map. For example, a mind map was created in order to organizes ideas and information about the role of waterways and road networks based on the petitions originating from early Monongalia County and how the surrounding regions connected to the study area (Figure 5.5). In particular this process helped differentiate how the frontier in this area showed more of a north to south trend rather than the expected east to west movement. In this way mind mapping not only helped to visually organize information but to also reveal relationships worthy of further investigation.

\section{Ghost mapping}

A further step in the process of moving from a historical GIS via mind mapping to a deep map was to develop what Ethington (2007) calls ghost maps. A ghost map consists of a layered collage of moments garnered from the GIS and related multi-media that depict significant elements, events, or themes associated with the study and which begins the process of depicting spatial stories. A ghost map conveys one or multiple stories using juxtaposed materials that are spatially grounded in a cartographic map which can be of varying accuracy. Thus, a ghost map is authored such that materials are used to reveal a story through varying levels of transparency and juxtaposition of the materials. Spatial concepts are used to construct the map such that materials that are geographically or temporally connected are adjacent to each other or linked in some manner. Mind maps were thus used in this study to help frame ideas and the connectivity necessary for the deep map and takes the project one step closer to that goal.

Ghost maps can thus stimulate differing perspectives to the data and study through a blending of materials and ideas in a visual form that extends beyond static mapping and incorporating qualitative information such as images, text, wills, land grants, travel diaries, sketch maps, and 


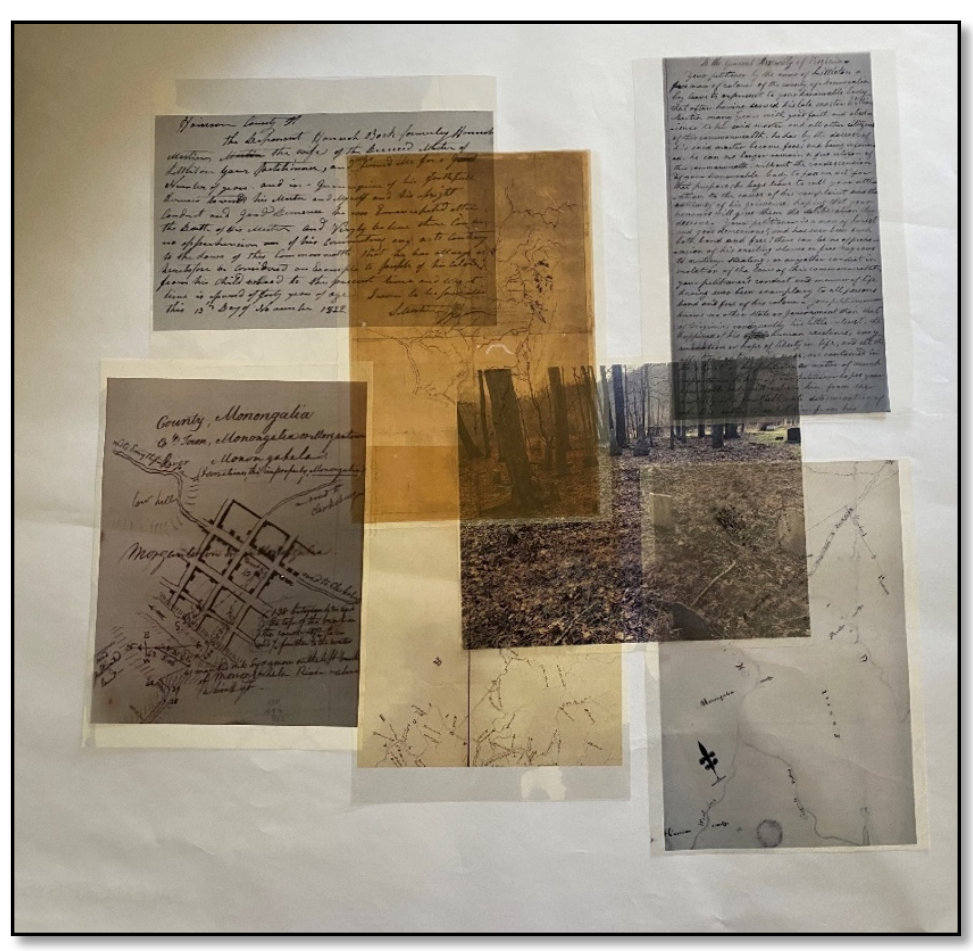

Figure 5.6: The first step in creating a ghost map was to access and review the materials through layering.

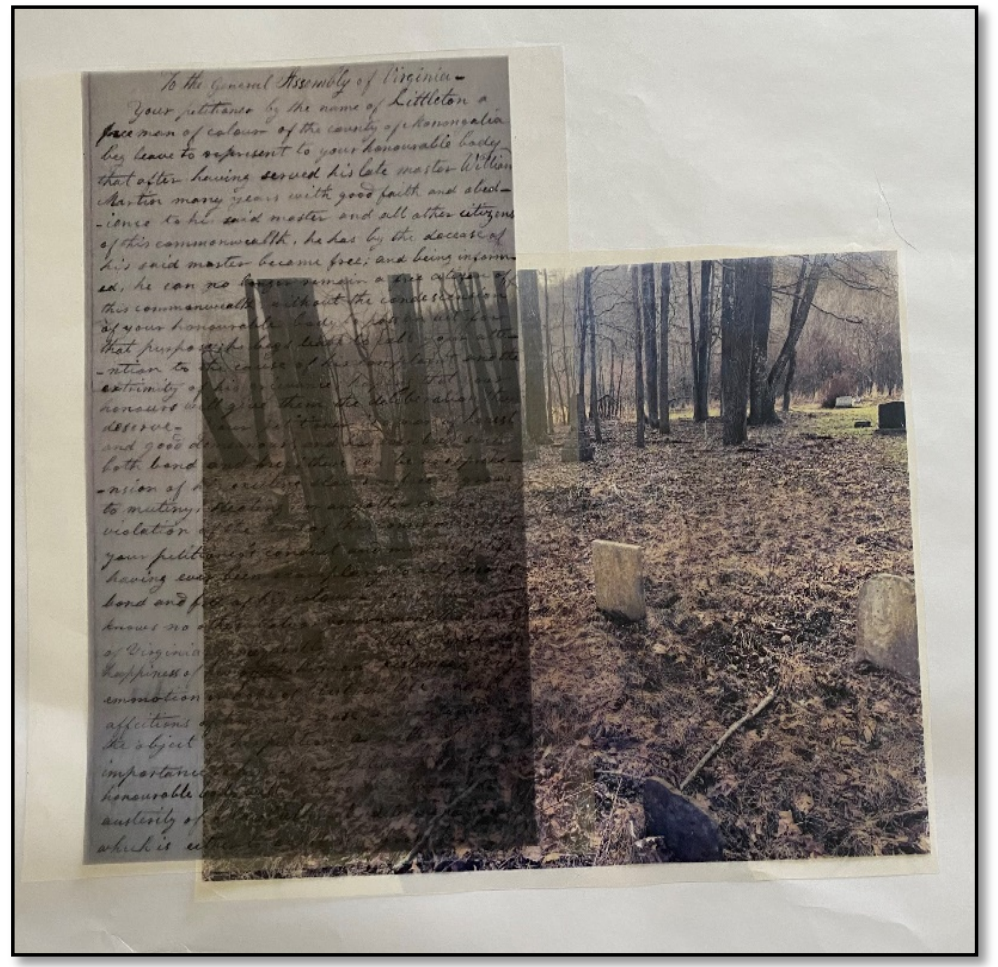

Figure 5.7: Ghost map design developed through arranging transparent images on workspace photos, into a graphical multi-medic

work that tells a spatial story and

contributes to understanding the

frontier history narrative.

The first step in creating a ghost map

is to examine the research texts to

formulate a preliminary understanding

and to then augment the map with

additional contributory data to create

spatial stories.

To facilitate the layering process and to develop a work that was both

visually appealing and most

importantly conveyed a spatial story,

images were selected and printed as

transparencies. The transparencies

were then arranged on a large

workstation surface in numerous

configurations in pursuit of spatial

stories (Figure $5.6 \& 5.7$ ). The images

were layered, juxtaposed with each

other and multiple assimilations

created to best convey how events 
transpired. Some images were given greater or lesser prominence through the use of layering and transparency process. One example of this ghost mapping exercise entailed organizing materials about the Martin Family and their slave Littleton. Living in $18^{\text {th }}$ Monongalia County (now including present day Marion and Harrison counties), the Martin family were deeply engrained in the community. In the popular meta narrative of the frontier movement even the existence of Littleton as a black slave as part of the frontier movement has been overlooked in preference of the European stereotype promulgated by the frontier movement story. The Martins themselves would even likely be ignored in the greater narrative because they did not lead lives in the national spotlight or play roles in major historical events. However, they were prominent property owners and members of the community. But as a freed slave, and as discussed in a later chapter, William Martin was an unacknowledged part of the frontier movement. Necessarily, the subjectivity associated with ghost mapping, as with mind mapping, may detract some from the valuable contributions these techniques bring to deep mapping but they were important components in formulating this deep map. 


\section{Chapter 6 | A deep map prototype of Turner's frontier thesis}

Methodologically, the deep map proposed here builds upon the historical GIS, the mind mapping exercise, and the ghost mapping previously discussed. Importantly, the deep map is built on a series of Application Programming Interfaces (APIs) that act to integrate the spatial data and multi-media outlined previously, guided by the mind mapping and ghost mapping. The system provides an interactive interface. To date no other deep map platform has been built on APIs so

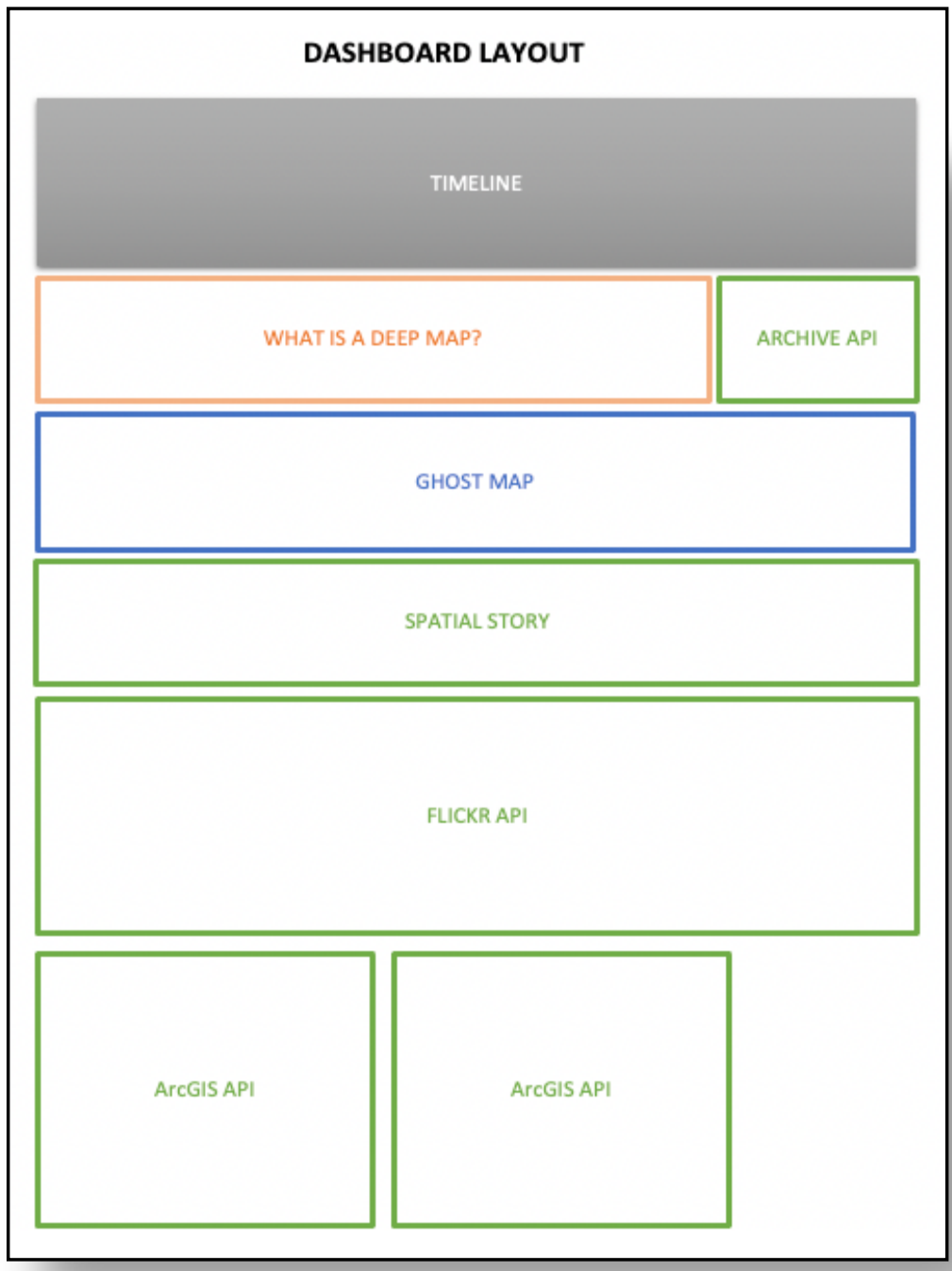

Figure 6.1: APIs utilized in deep map web application this is 'frontier' territory.

At the core of the deep mapping system is a quasispatial dashboard that allows for multiple elements to be called through the APIs, dependent on the request made by the user, and then displayed simultaneously in a dashboard (For more detailed information about how APIs function, see chapter 3) (Figure 6.1). In building this deep mapping system, four APIs were utilized and embedded in the dashboard. In particular four 
APIs were central to the system and include the Google Charts suite of APIs; Archive.org;

Flickr; and ArcGIS Online (Table 6.1)

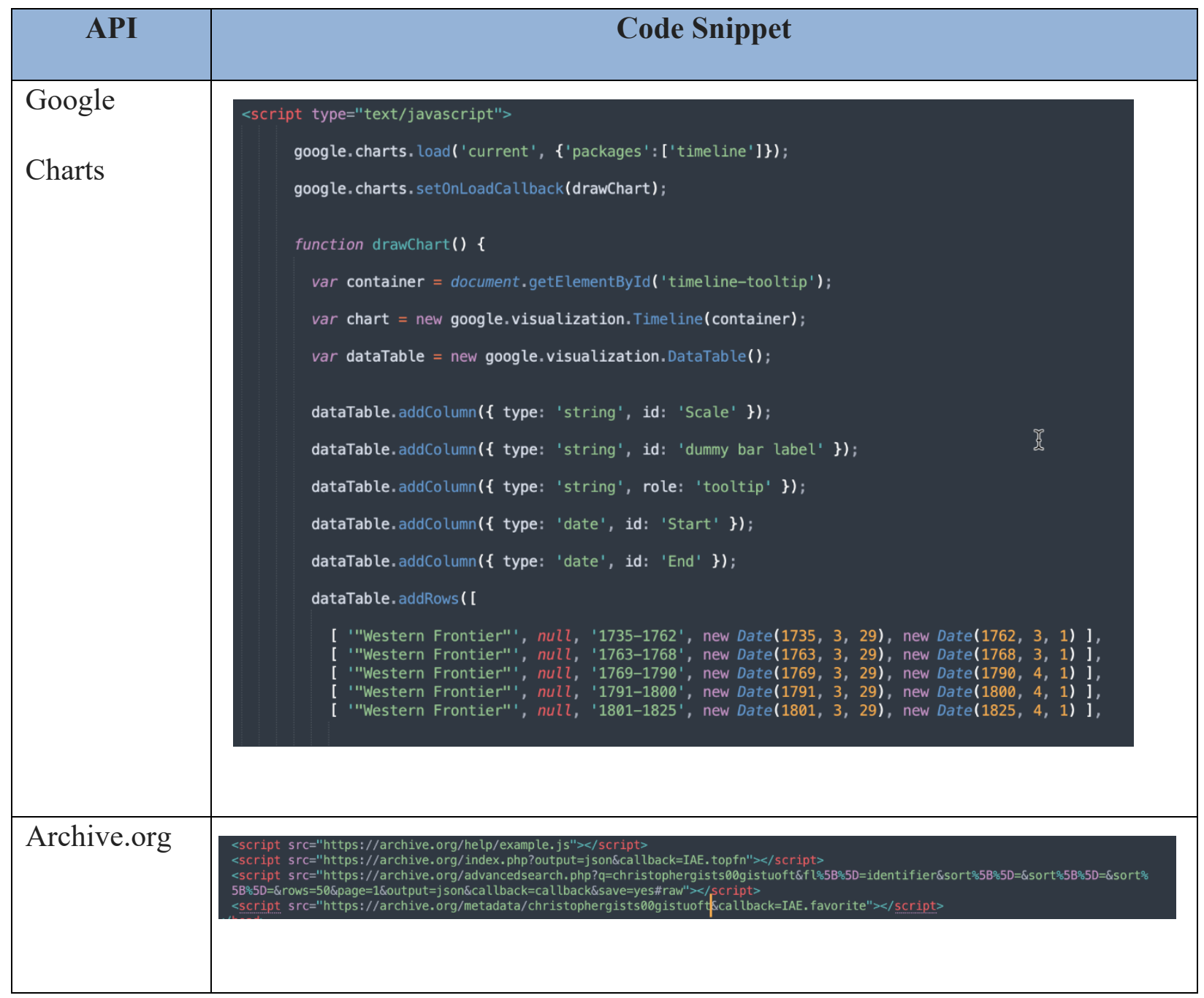




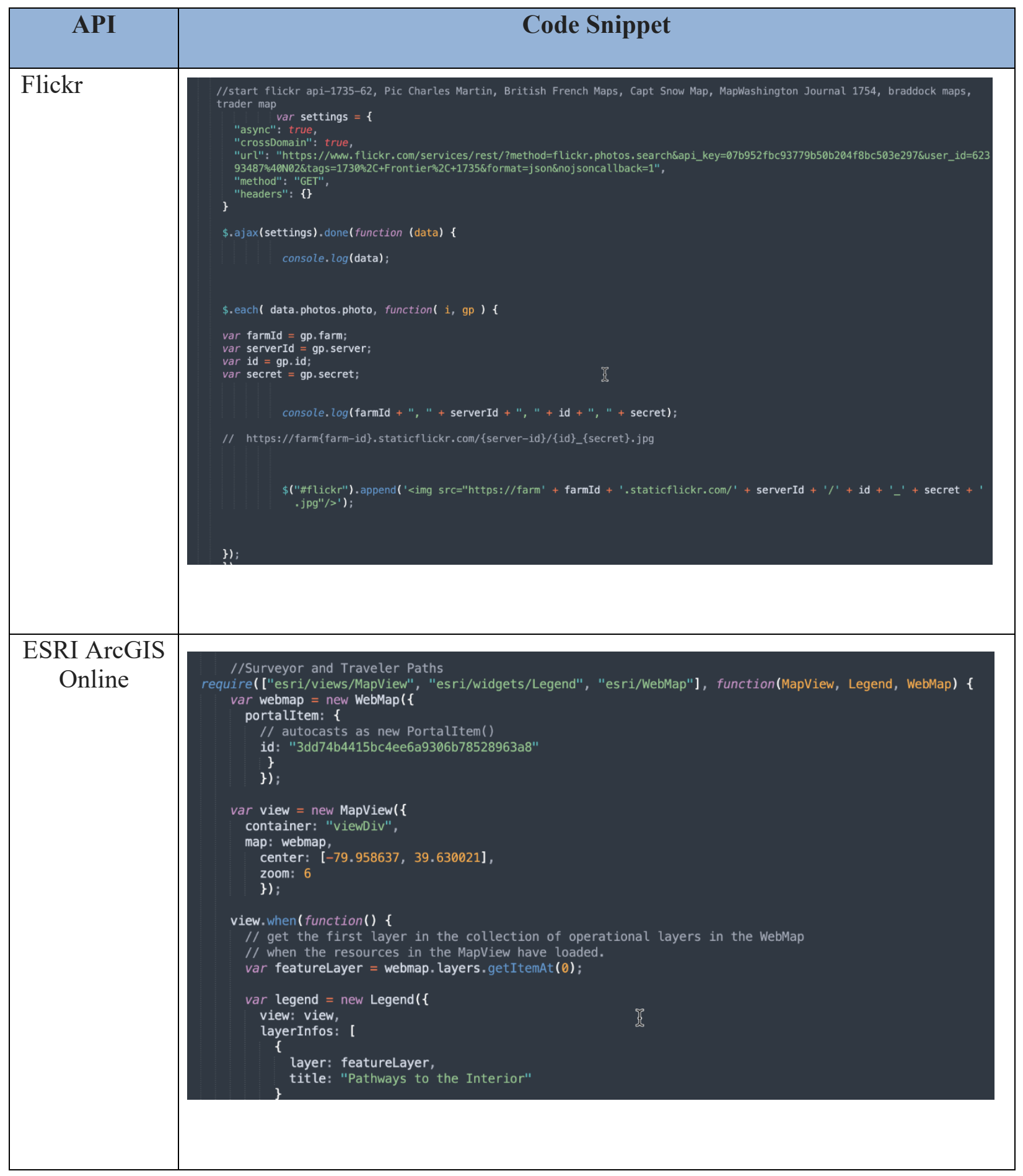

Table 6.1: APIs utilized in deep map web application 
Specifically, the dashboard controls and provides access to the APIs that in turn make function and data calls to their respective software platforms and databases. These API calls return data, or an image, or a map which is then displayed within the dashboard. The dashboard developed here is a web application that is divided into sections that use APIs that independently access the multiple software platforms and databases. These APIs are sets of computer code and procedures that initiate a command or 'call' to other web sites, databases, libraries, and operating systems to access information which is then transmitted to the dashboard and displayed. Figure 6.2 is a schematic of the preliminary APIs that were initially explored to populate the dashboard and deep map. The dashboard controls independent JavaScript calls to the multiple APIs that

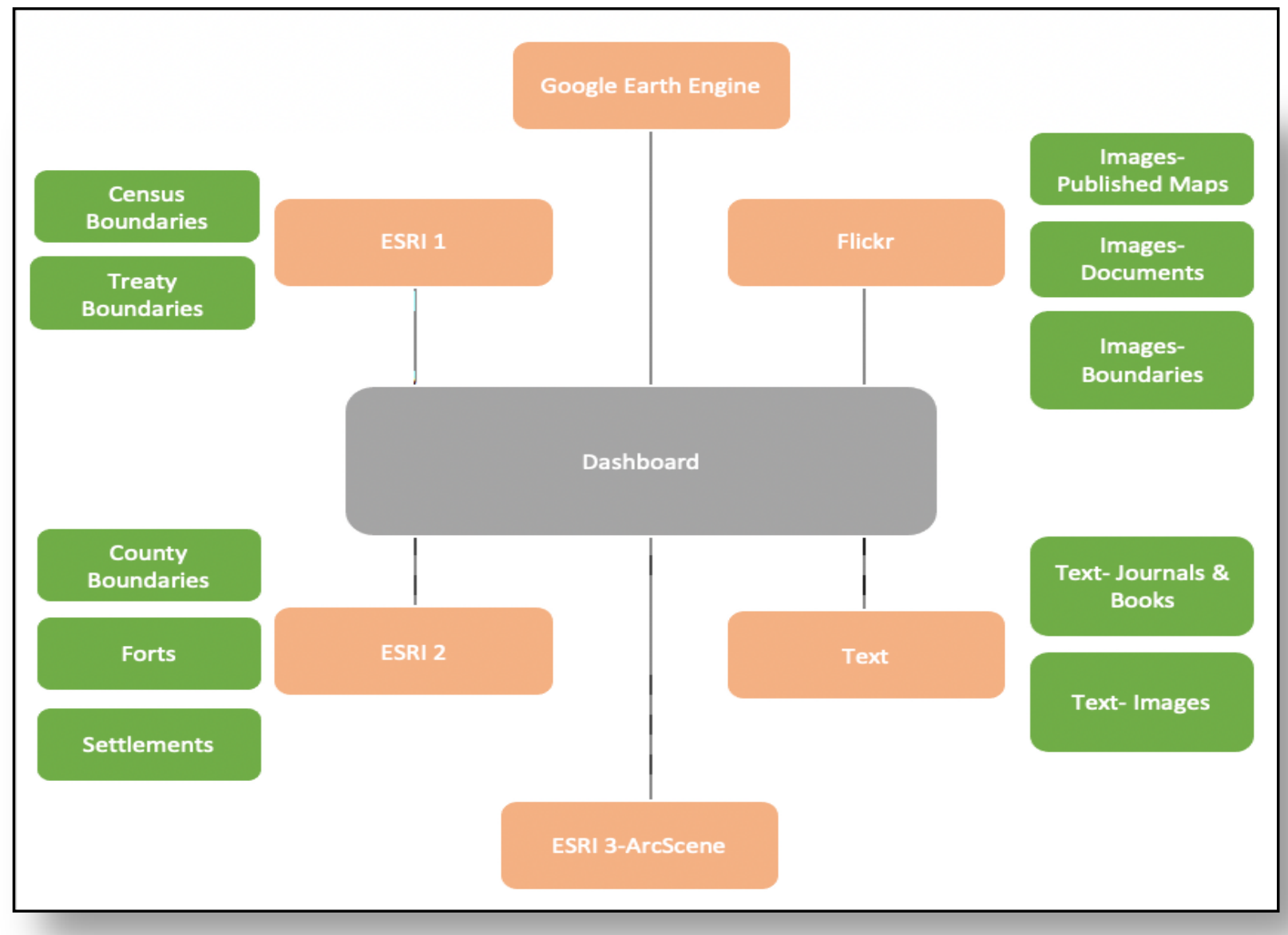

Figure 6.2: Chart of potential APIs to be utilized in deep map web application 
when a value or product is returned to the dashboard, it is then displayed and combined with the responses of other APIs. The returned APIs, which could be quantitative or qualitative in nature, are displayed together to support a spatial story which is integrated into the dashboard. For example, if the user selects a timeframe on the timeline respective to around 1800 , results will be returned that illustrates where westward settlement had reached overall at that time, what the county boundaries were at the same time, and some of the minute details of the Martin Family. In so doing the dashboard and APIs overcome a major roadblock encountered when using dedicated systems not designed for the purpose of blending qualitative, quantitative, and spatial data since these systems are tasked to a specific purpose. For example, GIS handles spatial data extremely well yet struggles with other formats and qualitative media. Similarly, for other dedicated systems. Using APIs, however, calls can be made through the dashboard to the GIS if need be but independent of other API calls made. For example, a call can be made to Flickr to access photographs, or to the Archive.org repository to retrieve textual narratives or some other document. In similar fashion, the dashboard can make API calls or searches to web pages such as Google Earth, ArcGIS Online, Google Maps, and local or regional or national online archives to collate any form of available source material deemed pertinent to the enquiry at hand. Such an approach is computationally challenging but provides a significant advance over previous 'stovepiped' applications and systems. In this way historical research and enquiry is not prescribed by a specific author as in a scholarly book, or by a system such as a GIS, but is truly open ended and exploratory. Given the sweeping capabilities enabled by such a platform it is valuable to have some thresholds and boundaries that help prevent the system from becoming anarchic. Thus, the mind mapping exercises help organize and manage the possible parameters of the search and study and indicate the connectivity in the system. 
The dashboard and API concept has gone through several iterations and confronted numerous problems and challenges that have arisen as a result of the rapidly changing field of APIs that are continuously released by major software vendors. Selecting a display and presentation core presented several issues as to how to compose the storyboard and how to organize and access the data. An early version of the system had a Prezi presentation at the core of the display dashboard and storyboard. Subsequently this was changed to JavaScript calls that connected each API much like cogs in a wheel. Prezi (https://prezi.com) (Accessed 7/15/2021) is a powerful video and virtual communication and presentation system that enables materials to be embedded within the system at multiple zoom levels that are connected to provide a compelling visual storytelling software alternative to the traditional slide-based presentation formats such as provided PowerPoint. The attractiveness of this capability for a deep mapping platform is obvious. However, the Prezi API is not well supported and it is better suited serving as an API call if needed rather than as the main interface. 


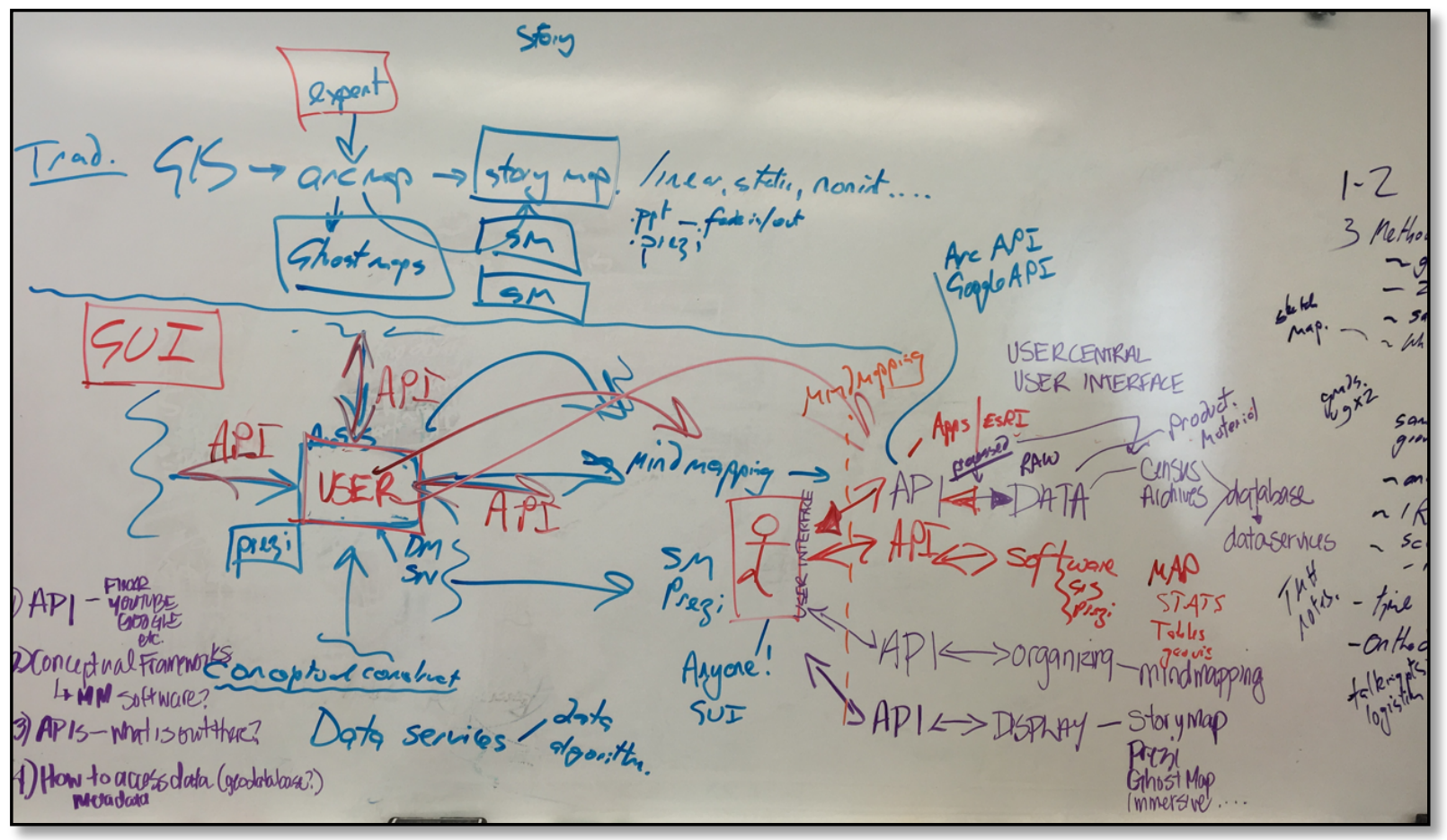

Figure 6.3: An early iteration of the deep map concept where the user and a GUI is at the center of the deep map.

So, although the Prezi API was tested as a possible component of the deep map it was insufficiently robust to handle the large quantities of data and multi-media involved. Eventually, it was determined that the core of the system should be built around JavaScript calls to multiple APIs. However, a Graphical User Interface (GUI) was needed to not only display the data, but to support user interaction with the system. The GUI is critical to interactively engaging the user. How to deal with data management and data organization was a major challenge, for as calls are made to the APIs and data is returned so that data needs to be organized and displayed in a manner that suits the users' needs and expectations. One option pursued was to create a backend database to the web page which would store the returned products. This approach was ultimately abandoned because of database update issues and problems arising from user interaction with the database (Figure 6.3). 


\section{Building the deep map framework}

The spatial data and maps in the Historical GIS were accessed from the dashboard using JavaScript calls to the ArcGIS Online API, which is a part of the ArcGIS Pro platform. Other media were similarly accessed through a number of APIs via JavaScript. APIs enable multiple calls to be made simultaneously to databases or software rather than having to access each system independently. Furthermore, the many types of data and media that can be retrieved is not limited by the need to format all materials according to a common form - the major challenge faced by Qualitative GIS. The system is thus dynamic, integrative, and exploratory and provides the user with considerable capacity to blend objects of interest to address specific questions or explore themes. Importantly, the framework is extensible such that with suitable resources, time, and especially access to a larger number of API experts to delve into why some APIs fail to function, any software platform with accessible APIs can be built into the system. In this instance four APIs were tested extensively and each API was linked multiple times to different data and media. ArcGIS Online API was selected in preference to other platform APIs such as Google Earth or Google Maps because of the focus of this study on space and place and the desire to embed spatial functionality that ArcGIS provides through its topological geometry that other online 'mapping' platforms do not possess. ArcGIS Online became the workhorse of the system. 


\begin{tabular}{|c|c|c|}
\hline API & Description & Typical Information Displayed \\
\hline $\begin{array}{l}\text { ArcGIS } \\
\text { Online }\end{array}$ & $\begin{array}{l}\text { The ArcGIS Online API provides the } \\
\text { primary vehicle to access the Historical } \\
\text { GIS as well as perform analysis, change } \\
\text { base maps, and view desired spatial } \\
\text { layers. It also can be animated to show } \\
\text { specific views or layers. There are two } \\
\text { dashboard elements that call ArcGIS } \\
\text { Online APIs. ArcGIS Online provides } \\
\text { the user with multiple scales in a more } \\
\text { efficient manner than utilizing alternative } \\
\text { mapping APIs such as Google Earth } \\
\text { Engine or Google Maps. }\end{array}$ & $\begin{array}{l}\text { - Maps of western boundaries, } \\
\text { including Proclamation of } 1863 \text {, } \\
\text { Treaty of Fort Stanwix and } \\
\text { census from } 1790-1820 \\
\text { - } \text { Maps of the evolution of } \\
\text { Monongalia County from } 1776 \\
\text { to } 1820 \\
\text { - Map of French/English } \\
\text { occupation } \\
\text { - Map of forts } \\
\text { - Map of settlements } \\
\text { Map of trails }\end{array}$ \\
\hline Flickr & $\begin{array}{l}\text { The Flickr API contains images of court } \\
\text { documents, land deeds, photographs, } \\
\text { sketch maps, non-cartesian maps and } \\
\text { other relevant media stored in image } \\
\text { form images. }\end{array}$ & $\begin{array}{ll}\text { - } & \text { Ghost Map } \\
\text { - } & \text { Text Images } \\
\text { - } & \text { Map Images } \\
\text { - } & \text { Photographs } \\
\end{array}$ \\
\hline Timeline & $\begin{array}{l}\text { Google Charts API was utilized as the } \\
\text { basis for creating an interactive timeline } \\
\text { that could be customized to a specific } \\
\text { timeframe with targeted events at } \\
\text { varying scales that were connected to } \\
\text { API calls. Each API call displayed data } \\
\text { from that particular time period to } \\
\text { support a spatial story. }\end{array}$ & $\begin{array}{l}\text { - Interactive Timeline with a } \\
\text { targeted timeframe. }\end{array}$ \\
\hline Archive & $\begin{array}{l}\text { The Archive.org API enables the user to } \\
\text { have access to its repository based on id, } \\
\text { keyword, date or name }\end{array}$ & $\begin{array}{l}\text { - Archives like travel journals } \\
\text { and period documents }\end{array}$ \\
\hline
\end{tabular}

Table 6.2: Details of APIs used for the deep map web application

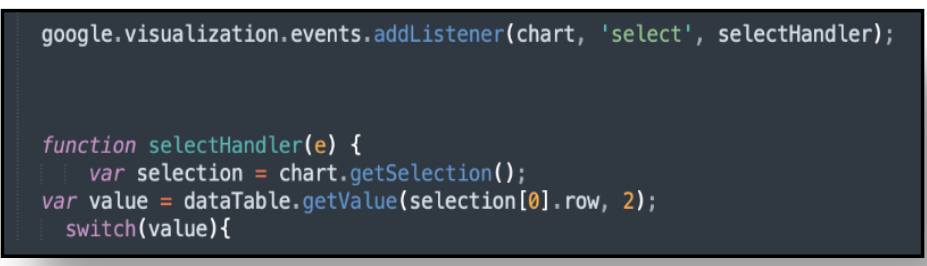

Figure 6.4: Code snippet of selectHandler function
The selection of particular APIs in

the deep map approach was

primarily based on the type of

primary or secondary source to be

accessed (maps, text, imagery, 


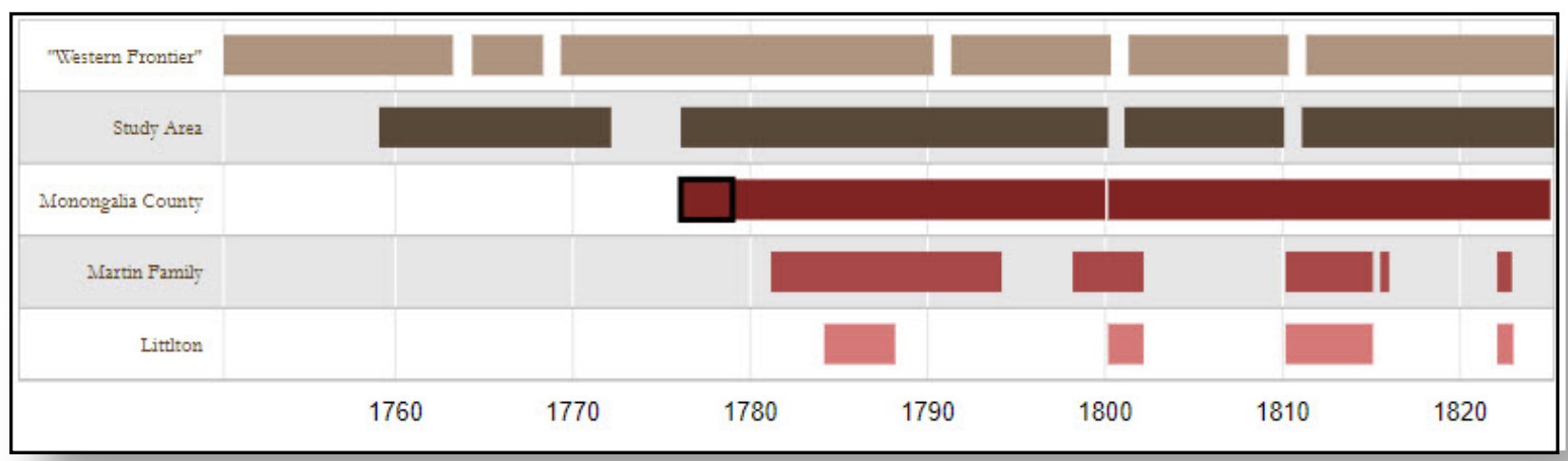

Figure 6.5: The user selects a timeframe on the timeline to populate a spatial story

documents, sketch maps), the ability to create a number of spatial stories, and the desire to demonstrate the capability of the system as a deep map. The selectHandler function (Figure 6.4) was utilized so that each API would be called based on a particular selection on the timeline (Figure 6.5). To call an API relative to a particular temporal timeline, for example, a switch statement ("case, break") was used whereby each timeline section was a different "case" (Figure 6.6). For example, the section of the timeline labeled ' $1763-1768$ ' was a 'case' and the system made function calls to the ArcGIS Online and Flickr JavaScript APIs. As another section on the timeline is selected, the case will break and a new 'case' is started using APIs relevant to

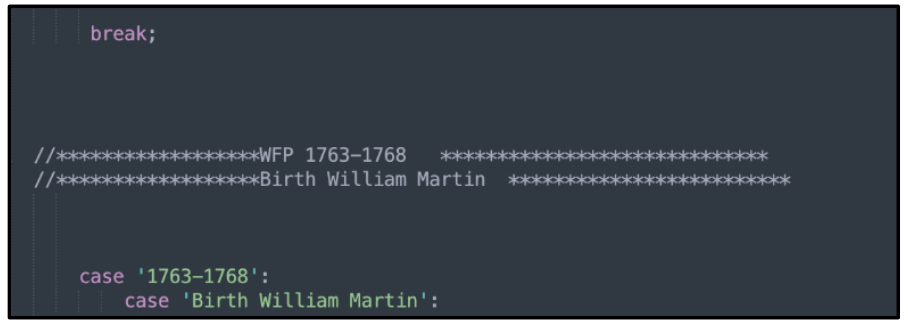

Figure 6.6: Code snippet of the switch statement used to call different APIs that particular section. Ultimately there were well over 1000 lines of code. Mind maps and word clouds were used as a preliminary means to mentally track and organize media and data. The temporal dimension was also tracked via the mind map to see the temporal overlaps of several of the themes contained in the deep map. The timeline (Figure 6.5) linked temporal events derived from the mind map and 
ultimately informed the content to be accessed by the APIs and displayed in the dashboard. A Ghost Map (Figure 6.7) is also displayed in the dashboard that explores the contingent links between local and large-scale events occurring at the same time in the western history narrative.

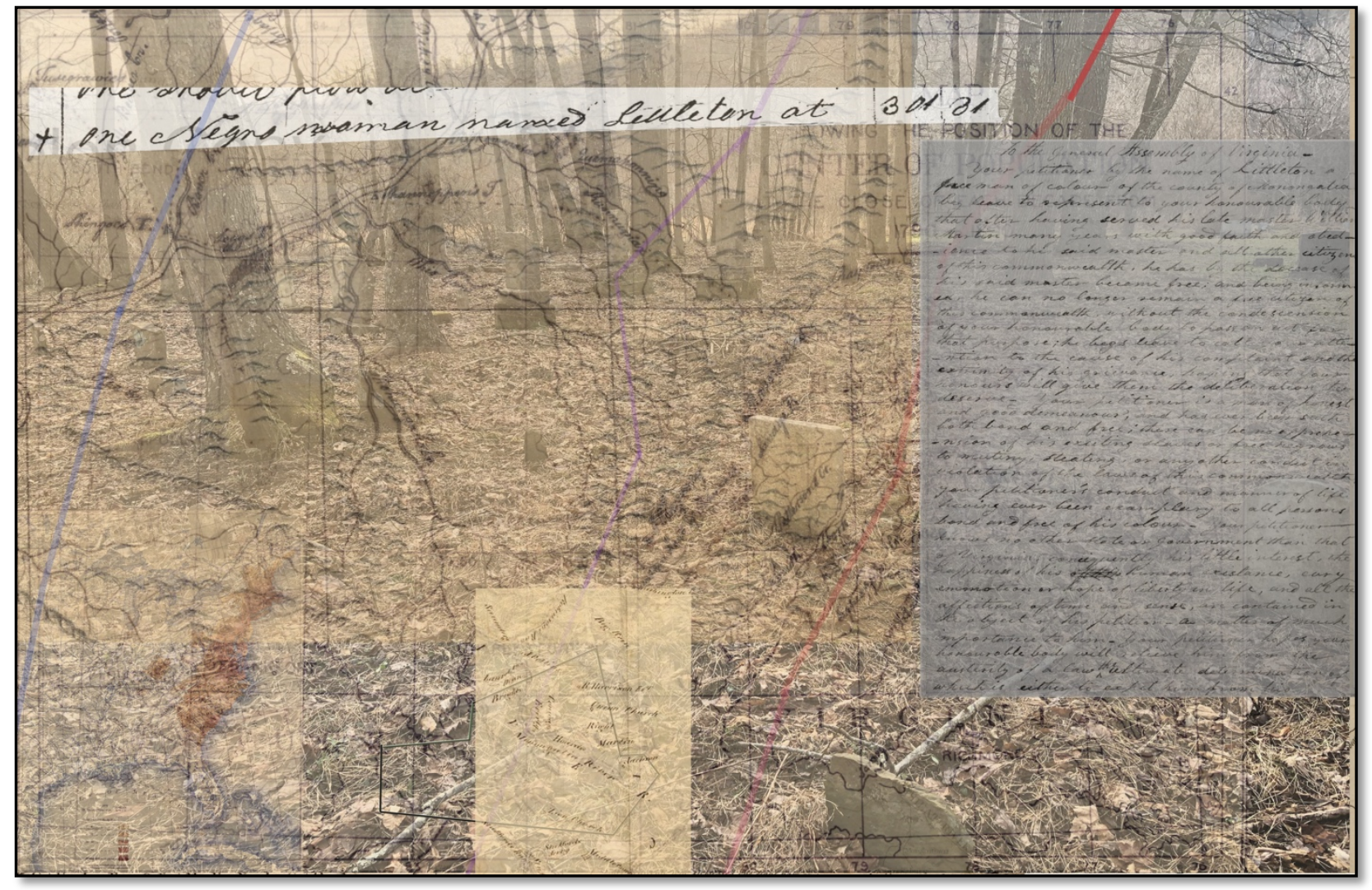

Figure 6.7: Ghost Map created from archival materials, maps and images

The deep map dashboard (Figure 6.8) displays each API in a particular window on the dashboard. The dashboard module provides a format where all the available materials can be displayed, juxtaposed, and examined no matter the scale, the time frame, or the media. Spatial stories can thus be generated and exported. Similarly, any of the media and data, if appropriate, can be exported via the API for subsequent analysis in one of the dedicated software platforms supporting the deep map. For example, the user can create and export a PDF document that contains all the API elements with a text based spatial story. 


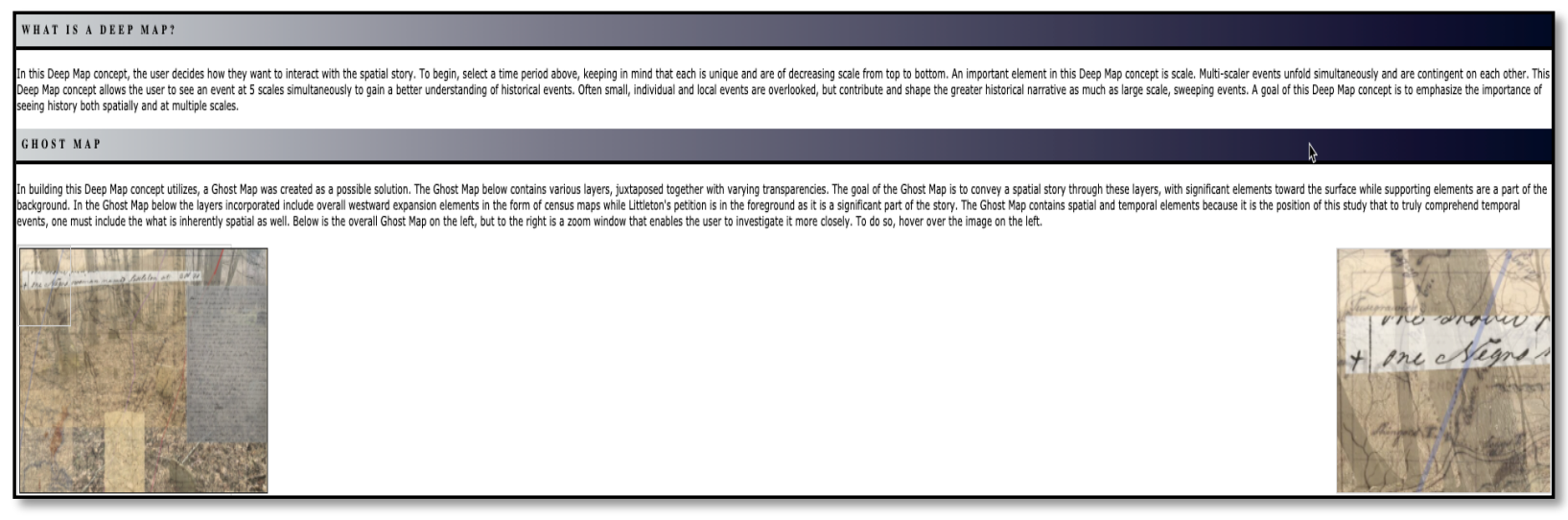

Figure 6.8: Deep Map web application dashboard before it is populated with the API responses

The dashboard was not without limitations for on a standard sized computer monitor only so many display windows can be viewed at any one time before it becomes overwhelming for the user. However, given that this is a prototype the operations of the deep map were prioritized over the wishes for larger format displays such as provided by the 30 feet by 10 feet CAVE which would not be available to any but a few people.

The deep map website is built on Hypertext Markup Language (HTML), the code commonly used to build websites and integrates Cascading Style Sheet (CSS) elements and uses jQuery and JavaScript to create a user interface and make calls to the APIs (Figure 6.9). The CSS elements, like fonts, colors and background image

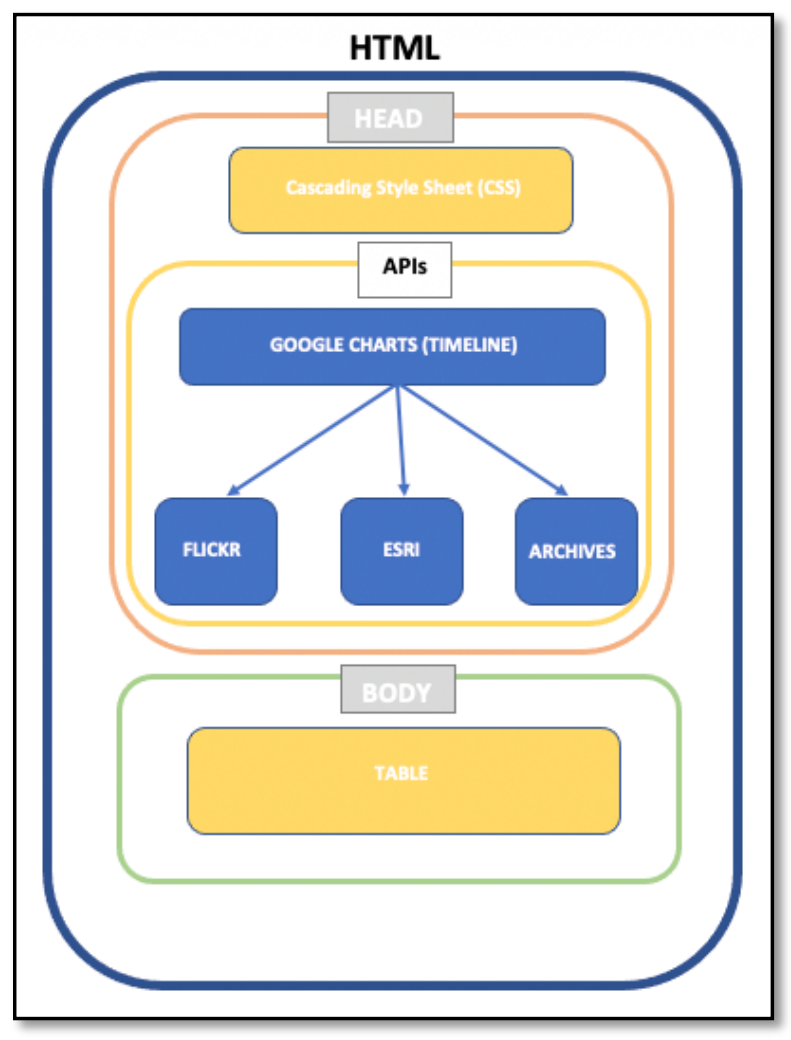

Figure 6.9: Chart illustrating the framework in which the code was structured 
sizes/layout were housed in their own document and linked to the HTML document. Each cell in the dashboard module was built using a table format and div elements, which correspond to a particular API call. The div elements essentially are 'containers' where the API results and other website components were display within the dashboard. Div elements can be stylized, sized and formatted for functional and aesthetic reasons. The timeline (Figure 6.10) utilizes a Google Charts JavaScript object that has been modified to encompass multiple themes and can handle a series of events within one interactive element. A number of timelines were tested, including

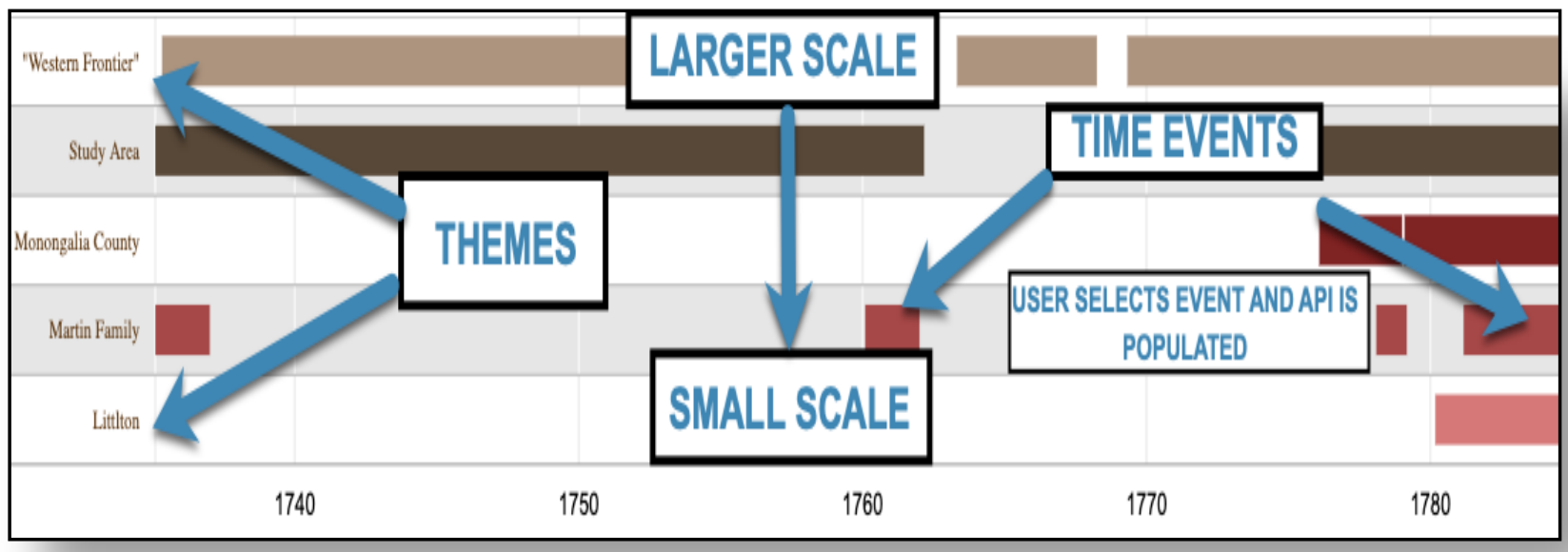

Figure 6.10: Timeline where five themes function as timelines, decreasing in scale from top to bottom. Each bar can be selected which then calls APIs respective to that time period and event.

Visme and Time Graphics, but Google Charts provided the greatest flexibility for integration into the website and for subsequent display. Furthermore, JavaScript objects are more easily manipulated within the code rather than accessing them via an intermediary piece of software. The Google Charts object was modified and adapted to not only represent events along a timeline, but to make individual API calls as an event is selected. Each tier of the timeline represents both a scale at which events can be analyzed and connects five themes labelled: Western Frontier, Study Area, Monongalia County, the Martin Family, and Littleton. These themes were selected for this demonstration because they are linked through commonalities in 
time and space. However, while each event in the timeline may occur at the same time and are tied to the same geographical region, they are doing so at a different scale. The timeline enables the user to see that time and space are intrinsically linked in that the API results that are ultimately displayed contribute to different aspects of the same spatial story. The events are this contingent on each other and exploring them simultaneously reveals a deeper story.

There are five timelines displayed in one element so that they can be connected through time and space and the user can explore the relationship between events within these themes. As a selection is made by the user in any interactive timeline, API calls are made that retrieve data and media relevant not only to the selection, but to events at other scales that share a contingent relationship. Each API was linked to a particular window on the dashboard. ArcGIS Online maps are displayed in divs while Flickr is displayed in a gallery format. Divs as part of the HTML code serve as placeholders or containers for web elements. The JavaScript that composed each API was written so that the response populates a particular div. Each of these populated divs, as well as the gallery section were formatted into a table such that each cell could maintain an uncluttered appearance on the dashboard. There are sections for a ghost map style collage of materials, archives, documents and images, a 'spatial story' (descriptive text that links 


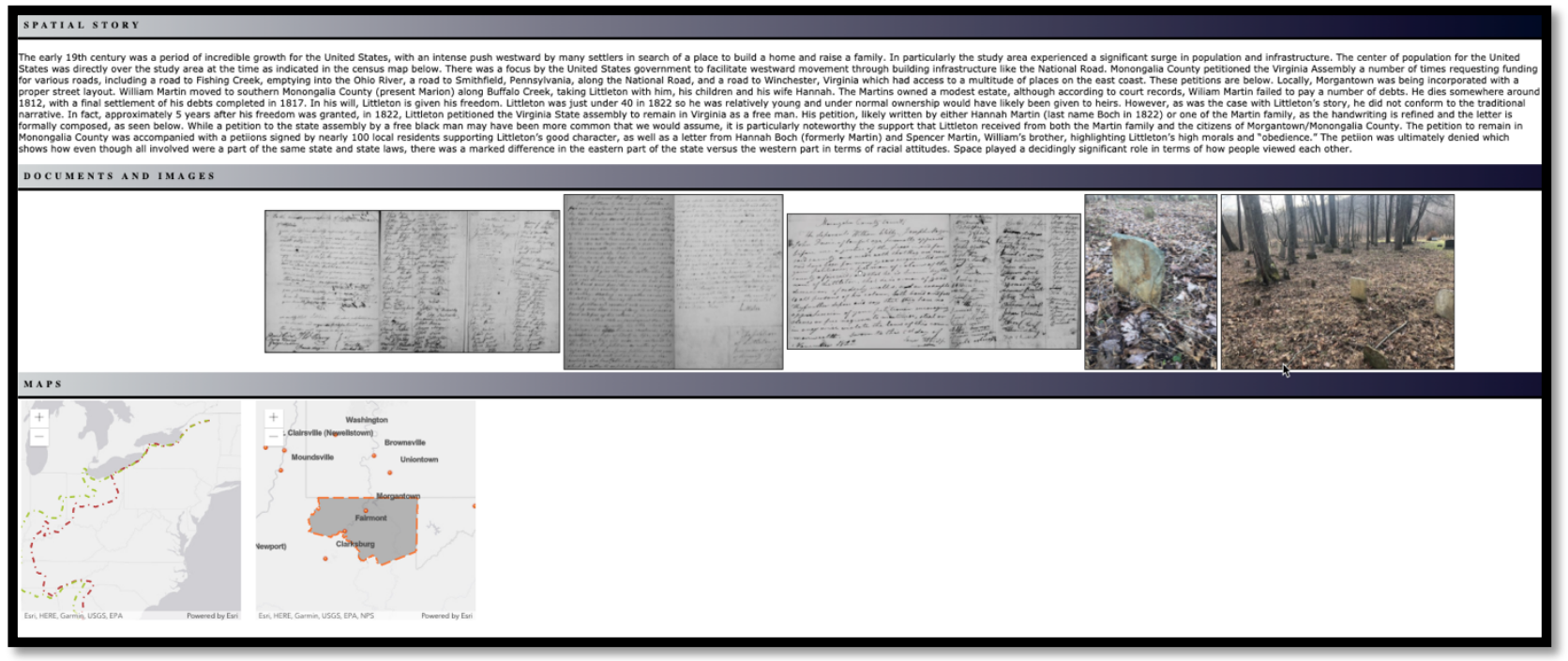

Figure 6.11: This example shows dynamic "spatial story" text at the top of the results that supports the images populated from the API call.

the APIs) and maps (Figure 6.11). Each work together to bring a piece of the story to the web application display. Ultimately, the user is able to choose multiple paths through the timeline and materials by selecting whichever time periods or events interest them in any order or sequence.

Although the rudimentary code for JavaScript API calls is derived from the software developer's tools stored on the respective software website, it required customization for it to seamlessly implemented in an application such as this. The ArcGIS Online API, for example, had to be tailored to include specific maps and data created by the author and accessed on the Esri server. Additionally, the timeline was adapted to include five scales instead of three. To enable a user to view a variety of materials, and experience a spatial story at multiple levels, the framework of the platform in this study required the calls of several JavaScript APIs simultaneously that then had to be displayed on a single dashboard. Making several calls not only required editing each JavaScript API to call the appropriate material, but these in turn had to be integrated into the HTML code in order to be displayed as an integrated website. Despite these difficulties, the 
platform as developed is easily extensible to include other APIs and capable of further development particularly as new technology and resources allow.

\section{Developing spatial stories of the frontier}

Ultimately, despite the technological challenges, the most important outcome of the study was how well the deep map operated and provided insight into frontier history. Two examples of how the deep map platform in operation are provided here. One involves examination of the frontier movement itself and the other is a micro-historical narrative of the Martin family that resonates with ongoing macro events that form the basis of Turner's frontier movement metanarrative.

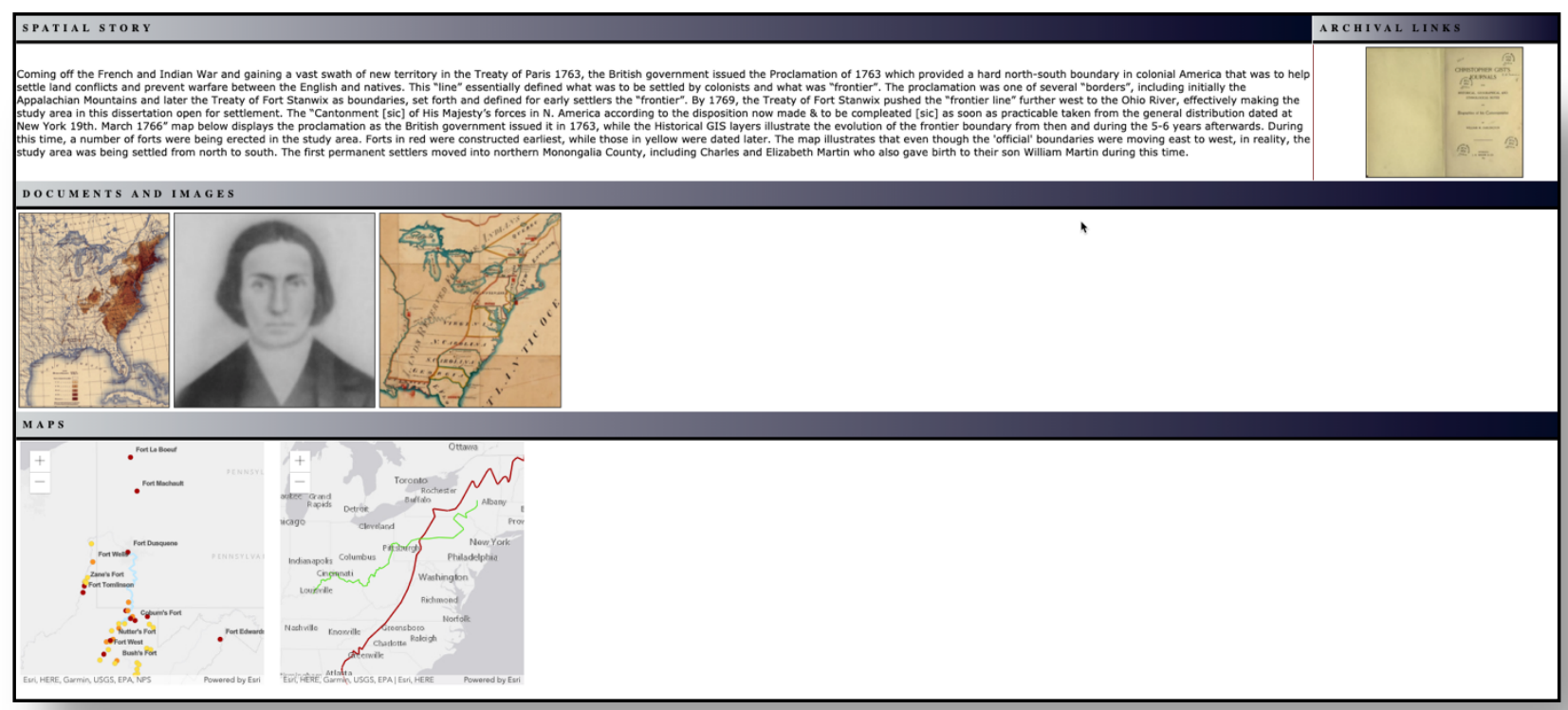

Figure 6.12: Spatial Story that results from selecting an event from the timeline related to westward development

The first example stems from a study of the settlement patterns and construction of forts and other dates of contact in the region and as displayed in the deep map. Due to official boundary lines such as the Proclamation of 1763 and historical national census maps most many narratives that explore westward expansion in North America assume that European settlement occurred 
from east to west. However, examining in greater detail the materials called up in the deep map, such as settlement patterns and the date that particular forts were built within the deep map, it is possible to see patterns that for this region suggested that a movement from north to south was perhaps more dominant (Figure 6.12). Mapping and analyzing the construction of forts in the study area, it is possible to hypothesize that early forts were built in the north of the region and that with time the fort construction progressed further south. While Europeans did move generally from the east, the study area was explored initially by the French who traveled from Lake Erie southward to the confluence of the Ohio and Monongahela Rivers. From that point, forts were built along two fronts, each essentially following the primary river routes. Thus, in the study region, it is possible that first contact was not typical of the many established narratives about the westward frontier.

A second example narrows to consider the case of the Martin family who were early settlers in the region. Constructing the Martin family spatial story is a weave of local history and place set against the backdrop of the frontier movement and ongoing macro historical events. The Martin family were among the first to erect a fort and obtained large swaths of land in then Monongalia County. Tracing the timeline of the Martin family over the course of just a generation provides an interesting insight into the early frontier town of Morgantown. Based on a culling of the materials, Colonel Charles Martin erected Fort Martin north of Morgantown, near the Pennsylvania/Virginia border, and he was part of the militia who protected the area from Native American attacks. Martin was married initially to Elizabeth Burrows and he remarried after her death. He was politically and socially well connected. He had four sons, one of whom named William. According to deed records, William Martin owned several hundred acres of land. William Martin's land, in contrast to his father's early holdings were located south of the original 
fort and settlement area. An 1817 inventory of his personal property included at least one slave, named Littleton. Littleton was originally owned as a boy by Charles Martin and was given to William on Charles' death around 1800. Littleton then served William's family, including his second wife, Hannah until William's death sometime between 1810 and 1822. Even though it was customary for the Martins, according to the wills of Charles and his other sons, to continue slave ownership through the next generation by leaving them to the widow or children, William broke from that tradition and set Littleton free upon his death. However, the Virginia State Assembly, located over 300 miles away and in the slavery entrenched south refused to allow him to remain in the state as a free man. Littleton, with the signatures of well over 100 Morgantown residents and leaders, and in particular the widow (and only female petitioner) Hannah Martin, appealed to the Virginia Assembly in 1821.

"Your petitioner hopes your honourable (sic) body will relieve him from the austerity of a law the ultimate determination of which is either to expel him from his native state and soil, or take from him the liberty he has attained by his good and obedient conduct when a slave; both of which circumstances he thinks to be incompatable (incompatible) with the natural rights of man or genius of liberty: first that he shall be driven from his native state and soil, as a fugitive or vagibond vagabond, after having worn out his juvenile days in the service of Virginia, to take refuge in an unknown State or country."

A final plea was made in December 1821 by Littleton which was again denied. The outcome of Littleton's case is unknown and was not resolved according to state archives. Littleton's account shows the strong racial and political differences already appearing between northern and southern Virginia and a precursor of West Virginia's secession in 1863 but contributes to the greater slave versus free debate that dominated $19^{\text {th }}$ century America. In addition, Hannah

\footnotetext{
${ }^{1}$ Legislative Petitions of the General Assembly, 1776-1865, Accession Number 36121, Box 165, Folder 69
} 
Martin (Boch) must have had a certain amount of influence in the community, even as a female, to initiate and develop a petition signed by so many prominent Morgantown residents in support of a man with very few rights in the early $19^{\text {th }}$ century, even as a free man.

Delving deeper into the story of one family and one slave, illustrates how the social and economic networks that underpin what was going on in terms of race and gender on the frontier at turn of the century, ultimately shaped the region. In some ways, Monongalia County and the Martin family were typical of the established narrative, holding large swaths of land and the slaves to support it and moving initially from the northern Virginia area westward to Monongalia County. However, in examining the family history more closely, William went against the tradition of passing slaves on to family members and he freed Littleton. Furthermore, although Morgantown was part of Virginia and the south, the widow Hannah with the support of a large cohort of local residents petitioned for Littleton to be freed and remain resident in the town. Such a story of women and slaves having some agency at this time and place is untypical of Turner's meta narrative and characterization of the westward frontier movement. 


\section{Chapter | 7 Conclusion}

The goal of the deep map application developed as a part of this dissertation was to advance the spatial turn in history by emphasizing that a greater balance between space and time needs to be struck in current scholarship. A web-based application was developed based on Application Programming Interfaces that supports the deep mapping and simultaneous exploration of space, place, and time. The web mapping application is informed by other methods such as Historical GIS, ghostmapping, and mind mapping. The deep mapping application is a prototype that can be modified and extended to include additional APIs and historical settings. While the deep map prototype in this dissertation enables the user to explore the American western frontier via a limited study area, it can be expanded to include a substantially larger knowledge base.

Significantly, the prototype deep map overcomes some of the constraints encountered when blending spatial data and qualitative media. The application is exploratory and reflexive and able to integrate many types of data. It is open to the user to determine and explore pathways through the data and to weave spatial stories as the research takes them.

The case study focusses on the historiography of the Turnerian western frontier thesis. Two small examples are provided using the deep map that question the east-west narrative and the role of gender and race at the frontier. In many ways Charles Martin was Turner's prototypical frontiersman in carving his path westward and contributing to conquering the frontier. Martin was a landholder, established a fort, had slaves, and raised a family. He was the quintessential American frontiersman. Martin had opportunity and was able to prosper greatly in early America. In the context of Turner's (1893) safety valve analogy, Martin benefited from the availability of great expanses of "new" land that contributed to stabilizing a growing economy as ever greater numbers of European immigrants entered North America. However, in deep 
mapping the Martin family beyond their patriarch and deconstructing the family dynamics and relationships within the community, the story reveals aspects that might otherwise be overlooked. Turner's warning in 1893 that the frontier, and hence the safety valve was closed, was only partly accurate insofar as thinking in terms of Euclidean space, or as physical boundaries on a map. While Turner's theory has some validity, one can envision "frontiers" that were not part of a physical topography that "closed". New social, economic, and cultural "frontiers" were continually being developed even though the frontier had passed by central Monongalia County. These new frontiers in race and gender, for example, were just as much a part of the making or remaking of the Martin family as they settled in the region. The frontier, as Turner saw it, may have moved on, but in reality, and as new western historians see it, the frontier had reinvented itself over and over again. Turner's concept of the frontier did not close so much as remade itself in differing socio-economic forms. The research in this study and deep mapping recognizes there is validity in both Turnerian and new western history perspectives. The Martin family story that emerges from the deep map suggests that gender and race on the frontier were not as rigid as may at first sight appear. The deep map experiment also emphasizes the critical role that space plays in human events. Ultimately, while many digital systems tend to present maps, texts, and media as fixed entities that limit the role of the reader, an API-enabled deep map enables multiple perspectives and spatial stories to be pursued such that the user is engaged in a conversation with the historical materials rather the recipient of a stated position. 


\section{Bibliography}

1760. "[Braddock's route, 1755, Fort Cumberland to Fort Pitt. ." Library of Congress Geography and Map Division Washington, D.C. . Accessed 07 15, 2021. https://lccn.loc.gov/gm71002325.

Abbot, J., et. al. 1998. "Participatory GIS: opportunity or oxymoron?" PLA Notes 33: 27-34.

Ashe, Thomas. 1808. Travels in America performed in $1806:$ for the purpose of exploring the rivers Alleghany, Monongahela, Ohio, and Mississippi, and ascertaining the produce and condition of their banks and vicinity. London.

- 1808. Travels in America performed in $1806:$ for the purpose of exploring the rivers Alleghany, Monongahela, Ohio, and Mississippi, and ascertaining the produce and condition of their banks and vicinity. London: John Abraham. https://www.loc.gov/resource/lhbtn.3028a.

Ayers, E. L., Thomas, W. G., Rubin, A. S. 2007. Valley of the Shadow Project: Virginia Center for Digital History. Accessed 2021.

Ayers, Edward L. 2003. In the Presence of Mine Enemies: The Civil War in the Heart of America, 18591864 (Valley of the Shadow Project). New York: W.W. Norton.

Baker, A. R. H. 2003. Geography and history: Bridging the divide. New York: Cambridge University Press.

Barrows, H. 1923. "Geography as Human Ecology." Annals of the Association of American Geographers 13 (1): $1-14$.

Bender, Thomas. 2007. "Theory, Experience, and the Motion of History." Rethinking History 11 (4): 495 500.

Berdan, Jennifer. 2013. "The Emerging Field of Digital Humanities: An Interview with Johanna Drucker." InterActions: UCLA Journal of Education and Information Studies 9 (2).

Berman, M.L., R. Mostern, and H. Southall. 2016. Placing Names: Enriching and Integrating Gazetteers. Indianapolis: Indiana University Press.

Berry, David M., and Anders Fagerjord. 2017. Digital Humanities Knowledge and Critique in a Digital Age. Wiley.

Billington, Ray Allen. 1984. American's Frontier Heritage. Albuquerque: University of New Mexico.

- 1981. Land of Savagery/Land of Promise: The European Image of the American Frontier in the Nineteenth Century. Norman: University of Oklahoma Press.

—. 1966. The Frontier Thesis: Valid Interpretation of American History? Malabar: Krieger Publishing Company.

Blache, Paul Vidal d La. 1950. Principles of Human Geography . Constable.

Bodenhamer, David, John Corrigon, and Trevor M. Harris. In Press. Deep Maps and Spatial Narratives. Bloomington: Indiana University Press.

- 2010. The Spatial Humanities: GIS and the Future of Humanities Scholarship. Bloomington: Indiana University Press.

Braudel, Fernand. 1949. La Méditerranée et le Monde Méditerranéen à l'Epoque de Philippe II (1949) (The Mediterranean and the Mediterranean World in the Age of Philip II) .

Bureau, U. S. Census. 1898. "Statistical Atlas of the United States based on the results of the eleventh census." Library of Congress Geography and Map Division Washington, D. C. . Accessed 07 15, 2021. https://lccn.loc.gov/07019233.

Butlin, R. A. 1993. Historical geography: Through the gates of space and time. London: E. Arnold.

n.d. CAVE Virtiual Reality: Mechdyne. https://www.mechdyne.com/av-vr-solutions/solutions/virtualaugmented-reality/cave/.

Clement, Tanya E. 2016. "Where Is Methodology in Digital Humanities?" In Debates in the Digital Humanities 2016, by Matthew K. Gold and Lauren F. Klein. Minneapolis: University of Minnesota Press.

Conzen, Michael P. 2010. Making of the American Landscape. New York: Routledge.

Cope, M., and J. Jung. 2009. "Qualitative geographic information systems." In International encyclopedia of human geography, by Rob Kitchin and Nigel, ed. Thrift, 7-11. Oxford: Elsevier.

Cope, M., Elwood, S. 2009. Qualitative GIS: A Mixed Methods Approach. Thousand Oaks: Sage. 
Core, Earl Lemley. 1977. The Monongalia Story: Volumes I-V. McClain Printing Company.

Cosgrove, Dennis E. 2008. Geography and vision: Seeing, imagining and representing the world. New York: I.B. Tauris.

Cosgrove, Dennis E., and S. Daniels. 1992. The iconography of landscape: Essays on the symbolic representation, design, and use of past environoments. New York: Cambridge University Press.

Cronon, William. 1992. Nature's Metropolis: Chicago and the Great West. W. W. Norton \& Company.

Cronon, William, et. al. 1980. Under an Open Sky: Rethinking America's Western Past. New York: W.W. Norton \& Company.

Cruz-Neira, Carolina, and et al. 1992. "The CAVE: audio visual experience automatic virtual environment." Communications of the ACM (Assocation for Computing Machinery) 35 (6).

Darby, H.C., et. al. 1953. "On relations of history and geography." Transactions and Papers of the Institute of British Geographers (Institute of British Geographers) 1-11.

Darlington, William M. 1893. Christopher Gist's Journals: With Historical, Geographical, and Ethonological Notes and Biographies of his Contemporaries. Pittsburgh: J. R. Weldon.

Dear, Michael et. al., ed. 2011. GeoHumanities: Art, History, Text at the Edge of Place. New York: Routledge.

DeBats, D., \& Gregory, I. 2011. "Introduction to Historical GIS and the Study of Urban History." Social Science History 35 (4).

DeBats, Donald A., and Ian N. Gregory. 2016. "Introduction to Historical GIS and the Study of Urban History." Social Science History 35 (4).

n.d. deep-mapping Michael Shanks. http://web.stanford.edu/ mshanks/MichaelShanks/51.html.

Denevan, William M., ed. 2009. Carl Sauer on Culture and Landscape: Readings and Commentaries. Baton Rouge: Geoscience Publications.

Descartes, Rene. 1644. Principles of Philosophy .

Domosh, Mona, Micahael Heffernan, and Charles W. J. Withers, . 2021. The SAGE Handbook of Historical Geography. 2 vols. SAGE Publication.

Edney, M. H. 1991. "Strategies for maintaining the democratic nature of Geographic Information Systems." Papers and Proceedings of the Applied Geography Conferences 14. 100-108.

Edward Wells, D. D. 1809. Historical Geography of the New Testament. Oxford: Clarendon Press.

Elwood, Sarah. 2006. "Critical issues in participatory GIS: Deconstructions, reconstructions, and new research directions." Transactions in GIS 10 (5): 693.

Elwood, Sarah. 2011. "Geographic information science: Visualization, visual methods, and geoweb." Progress in Human Geography 35 (3): 401-408.

Elwood, Sarah. 2006. "Negotiating knowledge production: The everyday inclusions, exclusions, and contradictions of participatory GIS research." Professional Geographer 58 (2): 197-208.

Elwood, Sarah. 2008. "Volunteered geographic information: Key questions, concepts and methods to guide emerging research and practice." GeoJournal 72 (3-4): 133-135.

Ethington, Philip J. 2007. "Placing the Past: 'Groundwork' for a Spatial Theory of History." Rethinking History 11 (4): 465-493.

Fallom, Batts and. 1761. A Journey from Virginia to beyond the Appalachian mountains .

Faragher, John Mack. 1998. Rereading Frederick Jackson Turner: 'The Significance of the Frontier in American History' and Other Essays. New Haven: Yale University Press.

Forsyth, Isla. 2011. "GeoHumanities: Art, History, Text at the Edge of Place." Scottish Geographical Journal 127 (3): 251-253.

Forsyth, Isla. 2011. "GeoHumanities: Art, History, Text at the Edge of Place." Scottish Geographical Journal 127 (3): 251-253.

Foucault, Michel. 1972. The Archaeology of Knowledge. New York: Pantheon.

n.d. French and Indian War: A Resource Guide. https:/www.loc.gov/rr/program/bib/frenchindian/.

n.d. G.W. Leibniz: Texts and Translations. http://philosophyfaculty.ucsd.edu/faculty/rutherford/Leibniz/.

Gardinar, Eileen. 2015. The Digital Humanities. Cambridge University Press.

George, H. B. 1901. The Relations of Geography and History. Oxford: Clarendon Press. 
Giordano, Alberto, and Tim Cole. 2018. "The limits of GIS: Towards a GIS of place." Transactions in GIS 22 (3): 664-676.

Gold, Matthew K., and Lauren F. Klein, . 2019. Debates in the Digital Humanities 2019. Minneapolis: University of Minnesota Press.

Goodchild, Michael F. 2007. "Citizens as Sensors: The world of volunteered geography." GeoJournal 69: 211-221.

Goodchild, Michael. 2009. "NeoGeography and the nature of geographic expertise." Journal of Location Based Services 3 (2): 82-96.

Gregory, Ian, Don DeBats, and Don Lafreniere, . 2018. The Routledge Companion to Spatial History. London: Routledge.

Harris, Trevor. 2015. Deep Mapping and Spatial Narratives. Bloomington: Indiana University Press.

Harris, Trevor M. n.d. "Deep Mapping and Sensual Immersive Geographies." In International Encyclopedia of Geography, by Audrey Lynn Kobayashi and Richardson Douglas. John Wiley \& Sons.

Harris, Trevor, and Daniel Weiner. 1998. "Empowerment, Marginalization, and "Community-integrated" GIS." Cartography and Geographic Information Systems 25 (2): 67-76.

Harris, Trevor, John Corrigon, and David Bodenhamer. 2010. Challenges for the Spatial Humanities: Toward a Research Agenda. Bloomington: Indiana University Press.

Harvey, F., et. al. 2005. "Introduction: Critical GIS." Cartographica 40 (4): 1-4.

Hawkins, Harriet. 2019. "Towards a GeoHumanities GIS." Transactions in Gis 23 (1): 161-163.

Haymond, Henry. 1909. History of Harrison County, West Virginia: From the Early Days of Northwestern VIrginia To The Present. Morgantown: Acme Publishing.

Heat-Moon, William Least. 1991. PrairyErth. New York: Houghton Mifflin Company.

Hine, Robert V., and et al. 2017. The American West: A New Interpretive History. Yale University Press.

Hine, Robert V., John Mack Faragher, and Jon T. Coleman. 2000. The American West: A New Interpretive History. New Haven: Yale University Press.

1880. History and Progress of the County of Marion, West Virginia, From its Earliest Settlement by the Whites, Down to the Present, Together With Bibliographical Sketches of its Most Prominent Citizens. Fairmont: Dunnington, George A.

Hoskins, W. G., and C. Taylor. 1955. The making of the English landscape. London: Hodder and Stoughton.

Hudson-Smith, Andrew, et. al. 2009. "NeoGeography and Web 2.0: Concepts, tools and applications." Journal of Location Based Services 3 (2): 118-145.

Huelman, Megan. 2011. Digital History Project Reviews. 02. Accessed 07 15, 2021. http://digitalhistory.unl.edu/p-reviews/shapinghuelman.php.

Humboldt, Alexander von. 1845-62. Cosmos: A Sketch of a Physical Description of the Universe. 5 vols. University of Berlin.

Hume, David. 1888. A treatise of human nature. Oxford: Clarendon Press.

Johnson, M. 2007. Ideas of landscape. Malden: Blackwell Publishing.

Johnson, Peter A., Nora Belblidia, and Stefan Campbell. 2011. "Neogeographic Tools to Create Openaccess Data: Mapping Vacant Land Parcels in Detroit." Journal of the Urban \& Regional Information Systems Association 23 (2): 33-37.

Jung, Jin-Kyu, and Sarah Elwood. 2010. "Extending the qualitative capabilities of GIS: Computer-aided qualitative GIS." Transactions in GIS 14 (1): 63-87.

Juricek, John T. 1966. "American Usage of the Word 'Frontier' from Colonial Times to Frederick Jackson Turner." Proceedings of the American Philosophical Society 10-34.

n.d. Kant's Views on Space and Time. https://plato.stanford.edu/entries/kant-spacetime/\#PrimSour.

Kirschenbaum, Matthew. 2012. "What Is Digital Humanities and What's It Doing in English Departments?" In Debates in the Digital Humanities, by Matthew K. Gold. Minneapolis: University of Minnesota Press. 
Knowles, Anne Kelly. 2016. "Historical Geographic Information Systems and Social Science History." Social Science History 40 (4).

Knowles, Anne Kelly, ed. 2008. Placing History: How Maps, Spatial Data, and GIS Are Changing Historical Scholarship. Redlands: ESRI Press.

Kwan, M., and L. Knigge. 2006. "Doing qualitative research using GIS: An oxymoronic endeavor?" Environment and Planning A 38 (11): 1999-2002.

Kwan, Mei-Po. 2009. "Three recent developments in critical GIS." Cartographica 44 (1): 11.

Kwan, Mei-Po, and G. Ding. 2008. "Geo-narrative: Extending geographic information systems for narrative analysis in qualitative and mixed-method research." Professional Geographer 60 (4): 443-465.

Lefebvre, Henri. 1992; 1974. The Production of Space (translated by Donald Nicholson-Smith). Oxford: Wiley-Blackwell.

—. 1992 (originally published 1974). The Production of Space. Oxford: Wiley-Blackwell.

n.d. "Legislative Petitions of the General Assembly, 1776-1865, Accession Number 36121, Box 335, Folder 19."

1825. "Legislative Petitions of the General Assembly, 1776-1865, Accession Number 36121, Box 335, Folder 19." Library of VIrginia Archives. Accessed 07 15, 2021. http://digitool1.lva.lib.va.us:1801/view/action/singleViewer.do?dvs=1626649190757 890\&local $\mathrm{e}=$ en_US\&show_metadata=true\&VIEWER_URL=/view/action/singleViewer.do?\&DELIVERY RULE_ID $=4 \&$ search_terms $=$ legpet $\% 20$ smithfield\&adjacency=N\&application=DIGITOOL$3 \&$ frameId $=1$.

Leszczynski, A. 2009. "Quantitative limits to qualitative engagements: GIS, its critics, and the philosophical divide." Professional Geographer 61 (3): 350-365.

Limerick, Patricia Nelson. 1987. The Legacy of Conquest: The Unbroken Past of the American West. New York: W.W. Norton.

Limerick, Patricia Nelson, Clyde A. Miler II, and Charles E. Rankin, . 1991. Trails: Toward a New Western History. Lawrence: University Press of Kansas.

Locke, John. 1689. An Essay Concerning Human Understanding. London.

Lodge, John. 175-. "A map of the British and French settlements in North America." Library of Congress Geography and Map Division Washington, D.C. Accessed 07 15, 2021. https://www.loc.gov/item/74693889/.

Magrane, Eric. 2019. "Applying the Geohumanities." International Journal of Applied Geospatial Research 10 (2): 27-38.

Massey, Doreen. 2005. For Space. London: Sage.

Mayhew, R. J. 2009. "Historical geography 2007-2008: Focault's avatars--still in (the) driver's seat." Progress in Human Geography 33 (3): 387.

Mayhew, R. J. 2010. "Historical geography 2008-2009: Mundus alter et idem." Progress in Human Geography 34 (2): 243.

Mayhew, R. J. 409. "Historical geography, 2009-2010: Geohistoriography, the forgotten braudel and the place of nominalism." Progress in Human Geography 35 (3).

McIlwraith, T. F. 2001. North America: The historical geography of a changing continent (2nd ed.). Rowman \& Littlefield Publishers.

Meinig, D. W. 1979. "The Beholding Eye." In The Interpretation of Ordinary Landscapes, 33-48. New York: Oxford University Press.

—. 1986. The Shaping of America: A Geographical Perspective on 500 Years of History, Vol 1-4. Binghamton: Vail-Ballou Press.

n.d. MeisterTask Focus Productivity \& Creativity Blog. https://www.meistertask.com/blog/.

Miles, Tiya. 2012. "The Long Arm of the South." The Western Historical Quarterly 43 (3): 274-281.

Milner, Clyde A., Anne M. Butler, and David Rich Lewis. 1997. Major Problems in the History of the American West. Boston: Wadsworth Cengage Learning.

Mitchell, W. J. T. 2002. Landscape and Power (2nd ed.). Chicago: University of Chicago Pres. 
Montoya, Maria E. 2012. "Onward to the Next Western History." The Western Historical Quarterly 271273.

Morissey, John, David Nally, Ulf Strohmayer, and Yvonne Whelan. 2014. Key Concepts in Historical Geography. Los Angeles: Sage.

Murrieta-Flores, Patricia, and et al. forthcoming. "Indigenous deep mapping: a conceptual and representational analysis of space in Mesoamerica and New Spain."

Naylor, S. 2008. "Historical geography: Geographies and historiographies." Progress in Human Geography 32 (2): 265.

Naylor, S. 2006. "Historical geography: Natures, landscapes, and environments." Progress in Human Geography 30 (6): 792.

Naylor, S. 2005. "History geography: Knowledge, in place and on the move." Progress in Human Geography 29 (5): 626.

Newton, Isaac. n.d. The Mathematical Principles of Natural Philosophy.

n.d. Oculus . https://www.oculus.com/rift-s/.

Offen, Ken. 2011. "Historical geography I: Vital traditions." Progress in Human Geography 1.

Openshaw, S. 1991. "Commentary: A view on the GIS crisis in geography, or, using GIS to put HumptyDumpty back together again." Environment and Planning A 23 (5): 621-28.

O'Sullivan, David. 2006. "Geographical Information Science: Critical GIS." Progress in Human Geography 30 (6): 783-91.

Paterson, Daniel. 1767. "Cantonment of His Majesty's forces in N. America according to the disposition now made $\&$ to be compleated as soon as practicable taken from the general distribution dated at New York 29th. March 1766." Library of Congress Geography and Map Division Washington, D.C. Accessed 07 15, 2021. https://lccn.loc.gov/gm72002042.

Pavlovskaya, Marianna. 2009. "Non-Qualitative GIS." In Qualitative GIS: A mixed methods approach, by M. Cope and S. Elwood. Thousand Oaks: Sage.

Pavlovskaya, Marianna. 2017. "Qualitative GIS." In The International Encyclopedia of Geography, by Douglas, et. al. ed. Richardson, 1-12. John Wiley \& Sons, Ltd.

Pickles, John. 1997. "Arguments, debates, and dialogues: the GIS-social theory debate and the concern for alternatives." In Geographic Information Systems, Vol 1.

- 1995. Ground truth: The social implications of geographic information systems. New York: Guilford Press.

Pickles, John. 1997. "Tool or science? GIS, technoscience, and the theoretical turn." Annals of the Association of American Geographers 87 (2): 363-372.

Presner, Todd, and et al. 2014. "Hypercities Thick Mapping in the Digital Humanities." UCLA Previously Published Works. https://escholarship.org/content/qt3mh5t455/qt3mh5t455.pdf.

Ritter, Carl. 1817; 1818; 1822. Erdkunde im Verhältnis zur Natur und zur Geschichte des Menschen oder allgemeine, vergleichende Geographie, als sichere Grundlage des Studiums und Unterricts in physicalischen und historischen Wissenschaften. 21 vols. G. Reimer.

Sauer, Carl O. 1925. "The Morphology of Landscape." University of California Publications in Geography (University of California Publications in Geography) 2 (2): 19-53.

Schlichting, Kurt. 2008. "Historical GIS: New Ways of Doing History." Historical Methods: A Journal of Quantitative and Interdisciplinary History 191-196.

Schuurman, Nadine. 2008. "Formalization Matters: Critical GIS and Ontology Research." Annals of Association of American Geographers 96 (4): 726-739.

Schuurman, Nadine, and Mei Po Kwan. 2004. "GIS and social science: New rules of engagement." Cartigraphica 39 (1).

Science Buddies. n.d. Mind Mapping. Accessed April 29, 2015. http://www.sciencebuddies.org/engineering-design-process/mind-mapping.shtml.

Semple, Ellen Churchill. 1903. American History and Its Geographic Conditions. Boston: Houghton, Mifflin \& Co.

Sheppard, Eric. 1993. "GIS and Society: ideal and reality." Friday Harbor Conference. Washington. 
Sheppard, Eric. 2005. "Knowledge production through critical GIS: Genealogy and prospects." Cartographica 40 (4): 5-21.

Sieber, R. E. 2004. "Rewiring for a GIS/2." Cartographica 39 (1): 25-39.

Sieber, Renee. 2006. "Public Participation Geographic Information Systems: A Literature Review and Framework." Annals of the Association of American Geographers 96 (3): 491-507.

Slotkin, Richard. 2000. Regeneration Through Violence: The Mythology of the American Frontier, 16001860. Norman: University of Oklahoma Press.

Smith, George Adam. 1931. The Historical Geography of the Holy Land. London: Collins.

Soja, Edward. 2009. "Taking Space Personally." In The Spatial Turn: Interdisciplinary Perspectives, by Barney Warf and Santa Arias, 232. London: Routledge.

Soja, Edward W. 2000. Postmetropolis: Critical Studies of Cities and Regions. Malden: Blackwell Publishers.

Soja, Edward W. 193. "Postmodern geographies and the critique of historicism." In Postmodern Contentions: Epochs, Politics, Space, edited by John Paul Jones, Wolfgang Natter and Theodore, R. Scatzki, 210. New York: Guilford.

-. 2011. Postmodern Geographies: The Reassertion of Space in Critical Social Theory. London: Verso.

Taylor, Faith E., et. al. 2020. "Messy maps: Qualitative GIS representations of resilience." Landscape and Urban Planning 198 (103771): 1-11.

Taylor, P. J., and M. Overton. 1991. "Further Thoughts on Geography and GIS." Environment and Planning A 1087-94.

Taylor, Peter J. 1990. "Editoral comment GKS." Political Geography Quarterly 9 (3): 211-212.

Thomas III, William G. 2004. "Computing and the Historical Imagination." In A Companion to Digital Humanities, by Susan, et. al. Schreibman. Malden: Blackwell Publishing.

Travis, Charles, and Alexander von Lunen, . 2016. The Digital Arts and Humanites: Neogeography, Social Media and Big Data Integrations and Applications. Dordrecht: Springer.

Tuan, Yi-Fu. 1977. Space and Place: The Perspective of Experience. Minneapolis: University of Minnesota Press.

Tuan, Yi-fu. 1974. Topophilia: A study of environmental perception, attitudes, and values. Englewood Cliffs: Prentice-Hall.

Turner, Frederick Jackson. 1893. "The Signficance of the Frontier in American History."

Turner, Frederick Jackson. 1925. "The Signficance of the Section in American History." The Wisconsin Magazine of History VIII (3): 255-280.

Veech, James. 1858. The Monongahela of Old. Pittsburgh.

von Lunen, Alexander, and Charles Travis, . 2013. History and GIS: Epistemologies, Considerations and Reflections. Dordrecht: Springer.

Warf, Barney, and Santa Arias. 2009. The Spatial Turn: Interdisciplinary Perspectives. London: Routledge.

Washington, George. 1865. The journal of Major George Washington : sent by the Hon. Robert Dinwiddie to the commandant of the French forces in Ohio : with a map. New York: Joseph Sabin.

Wells, E. 1908. An Historical Geography of the New Testament. London.

Wells, Edward. 1710; 1711; 1712. An Historical Geography of the Old Testament. 3 vols. University of Lausanne.

White, Richard. 1991. "It's Your Misfortune and None of my Own": A History of the American West. Norman: University of Oklahoma Press.

—. 2010. What is Spatial History? Accessed 01 4, 2021. http://web.stanford.edu/group/spatialhistory/cgibin/site/pub.php?id=29.

Wiley, Samuel T. 1883. History of Monongalia County, West Virginia, from its first settlements to the present time. Kingwood: Preston Publishing. 
Wright, D. J., M. F. Goodchild, and J. D. Proctor. 1997. "GIS: Tool or science? demystifying the persistent ambiguity of GIS as 'tool' versus 'science'." Annals of the Association of American Geographers 87 (2): 346-362.

Zinn, Melba Pender, ed. 2007. Monongalia County (West) Virginia Records of the District Superior and County Courts: Volume 4: 1800-1802. Westminster: Heritage Books.

Zinn, Melba Pender, ed. 1992. Monongalia County (West) VIrginia: Records of the District, Superior, and County Courts-Vols 1-10. 10 vols. Westminster, MD: Heritage Books. 